\title{
Highlights
}

- Recent progress on magnetic iron oxides in photocatalytic water purification.

- Integration between non-magnetic and magnetic photocatalysts (MIOIPs).

- MIOP's synthesis and use for photocatalytic water purification.

- Quick magnetic separation and recyclability of MIOIPs.

- Scope and challenges associated with MIOIPs in water treatment. 


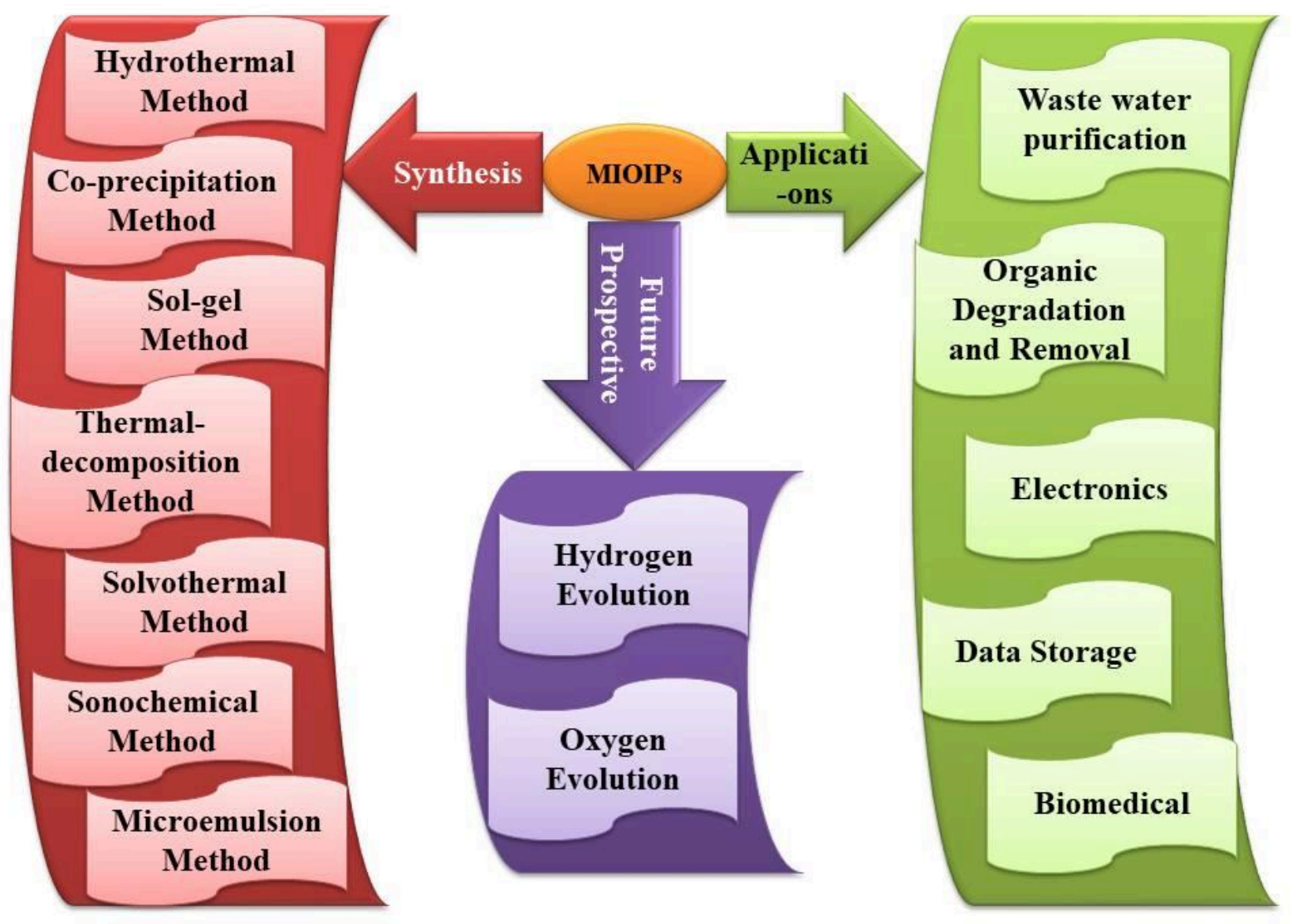




\section{Systematic review on applicability of magnetic iron-oxides integrated photocatalysts for degradation of organic pollutants in water}

Pardeep Singh ${ }^{a^{*}, b}$, Kirti Sharma ${ }^{a}$, Vasudha Hasija ${ }^{a}$, Vishal Sharma ${ }^{a}$, Sheetal Sharma ${ }^{a}$ Pankaj

Raizada $^{a, b}$, Mahavir Singh ${ }^{c}$, Adesh K. Saini ${ }^{a, b}$, Ahmad Hosseini-Bandegharaeid, e, Vijay Kumar

Thakurf $^{f}$

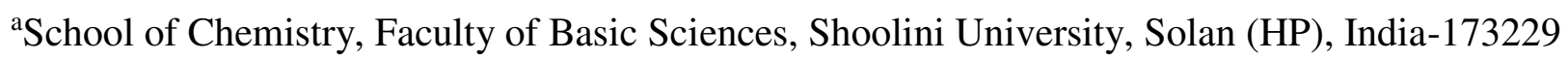

${ }^{\mathrm{b}}$ Himalayan Centre for Excellence in Nanotechnology, Shoolini University. Solan (HP) India173229

${ }^{\mathrm{c}}$ Materials Science Research Laboratory, Department of Physics, Himachal Pradesh University, Shimla 171005, India

${ }^{\mathrm{d} D e p a r t m e n t ~ o f ~ E n v i r o n m e n t a l ~ H e a l t h ~ E n g i n e e r i n g, ~ F a c u l t y ~ o f ~ H e a l t h, ~ S a b z e v a r ~ U n i v e r s i t y ~ o f ~}$ Medical Sciences, Sabzevar, Iran

eDepartment of Engineering, Kashmar Branch, Islamic Azad University, PO Box 161, Kashmar, Iran

${ }^{f}$ Enhanced Composites and Structures Center, School of Aerospace, Transport and Manufacturing, Cranfield University, Bedfordshire MK43 OAL, UK 
*Corresponding Author

Email:*pardeepchem@gmail.com

\begin{abstract}
Owing to bio-compatibility, abundance, and low cost, magnetic iron oxides are well suited for the design of efficient and magnetically separable photocatalysts for water treatment. This review presents a detailed survey of magnetic iron oxides integrated photocatalysts, in which we have discussed essential conditions needed for designing of efficient Magnetic Iron Oxide Integrated Photocatalysts (MIOIPs) for water purification. The synthesis methods and detailed experimental set-ups for fabrication of MIOIPs were discussed, and the integration manners of iron oxides $\left(\mathrm{Fe}_{2} \mathrm{O}_{3}, \mathrm{Fe}_{3} \mathrm{O}_{4}, \mathrm{FeO}\right.$, and ferrites) with binary, ternary and quaternary non-magnetic photocatalysts have been categorized. The mechanistic view of enhanced photocatalytic activity caused by different MIOIPs under various light sources was also elaborately argued. The role of various reactive species in photocatalytic oxidative degrading of organic pollutants was investigated. Altogether, this review paper has compressively considered and discussed various signs of advancements made towards MIOIPs synthesis and their stability, recyclability and catalytic efficacy for wastewater treatment.
\end{abstract}

Keywords: Magnetic iron oxides; Integrated photocatalysts; Quick recovery of photocatalysts; Enhanced photocatalytic activity; Wastewater remediation; Reusability. 


\section{Contents:}

Title page $\ldots \ldots \ldots \ldots \ldots \ldots \ldots \ldots \ldots \ldots \ldots \ldots \ldots \ldots \ldots \ldots \ldots \ldots \ldots$

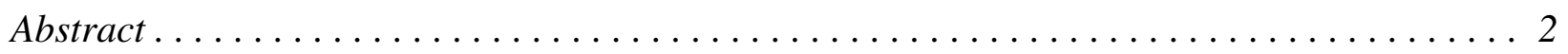

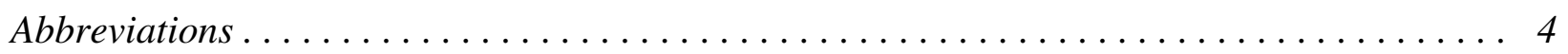

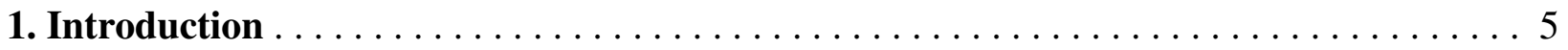

2. Iron oxides: Potential material with great future $\ldots \ldots \ldots \ldots \ldots \ldots \ldots \ldots$

2.1. Magnetic behavior, magnetic separation and toxicity of iron oxide photocatalyst ..... 10

2.2. Designing of iron oxides semiconductor photocatalysts $\ldots \ldots \ldots \ldots \ldots \ldots \ldots \ldots \ldots$

3. Synthesis of Iron oxides based photocatalyst $\ldots \ldots \ldots \ldots \ldots \ldots \ldots \ldots \ldots \ldots$

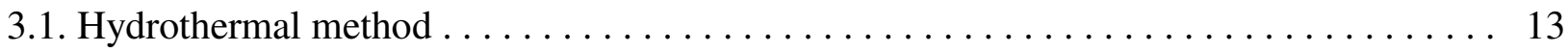

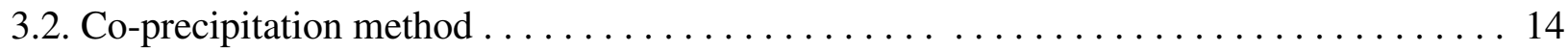

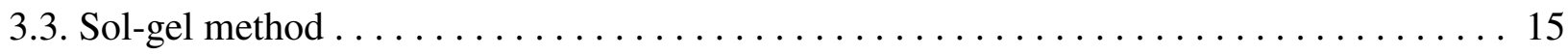

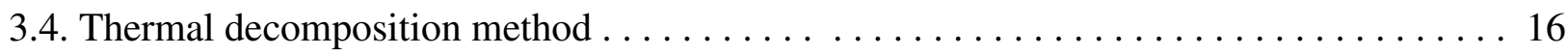

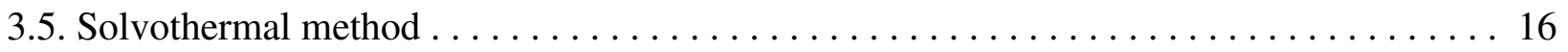

3.6. Sonochemical method ................................. 17

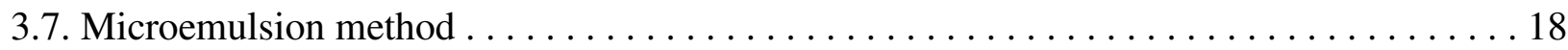

4. Iron oxides modified binary photocatalyst $\ldots \ldots \ldots \ldots \ldots \ldots \ldots \ldots \ldots \ldots \ldots$

4.1. Iron oxides modified binary metal oxide photocatalyst $\ldots \ldots \ldots \ldots \ldots \ldots \ldots \ldots$

5. Iron oxides modified ternary photocatalyst $\ldots \ldots \ldots \ldots \ldots \ldots \ldots \ldots \ldots \ldots \ldots \ldots \ldots \ldots$

5.1. Iron oxide modified ternary metal oxide photocatalyst $\ldots \ldots \ldots \ldots \ldots \ldots \ldots \ldots 27$

5.2. Iron oxide modified ternary carbon based photocatalyst $\ldots \ldots \ldots \ldots \ldots \ldots \ldots \ldots 28$

5.3. Iron oxide modified ternary graphene based photocatalyst $\ldots \ldots \ldots \ldots \ldots \ldots \ldots 29$

6. Iron oxide modified quaternary photocatalyst $\ldots \ldots \ldots \ldots \ldots \ldots \ldots \ldots \ldots \ldots \ldots \ldots \ldots \ldots$ 
6.1. Iron oxide modified quaternary metal oxide photocatalyst $\ldots \ldots \ldots \ldots \ldots \ldots \ldots$

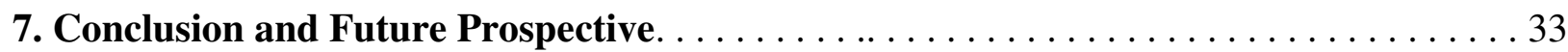

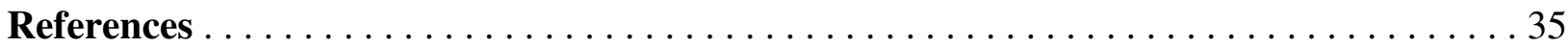

Abbreviations: AMX, Amoxicillin; BiOCl, Bismuth oxychloride; BET, Brunauer-EmmettTeller; BPA, Bisphenol A; BBF, Brilliant Blue FCF; BT, Bentonite; CO, carbon monoxide; $\mathrm{CO}_{2}$, Carbon dioxide; CB, Conduction band; CdSe, Cadmium selenite; CdS, Cadmium sulphide; Co, Cobalt; COD, Chemical oxygen demand; CR, Congo red; CV, crystal violet; DEA, Diethanolamine; DEG, Diethylene glycol; Eg, Energy band gap; Ev, Electron volt; EHP, Electronhole pair; E.coli, Escherichia coli; EDS, Energy-dispersive X-ray spectroscopy; FeO, Wustite; FC, Field cooled; FESEM, Field Emission Scanning Electron Microscope; FNPs, Ferrite nanosized photocatalysts; $\mathrm{FeCl}_{3} .6 \mathrm{H}_{2} \mathrm{O}$, Ferric chloride; FCC, Face cubic Centered; GSC, Graphene Sand Composite; $\mathrm{H}_{2}$, Hydrogen; HRTEM, High resolution transmission electron microscopy; Hc, Coercivity; $\alpha-\mathrm{Fe}_{2} \mathrm{O}_{3}$, Haematite; IONPs, Iron oxide nanoparticles; LA, Lignin Acid; LED, Light Emitting Diode; Ms, Saturation magnetization; Mr, Remanence magnetization; MSNPs, Magnetic separable nanosized photocatlyst; $\mathrm{MFe}_{2} \mathrm{O}_{4}$, Spinel ferrite; MNPs, Magnetic Nanosized Photocatalyst; MIOPs, Magnetic Iron Oxide Photocatlyst; MIOIPs, Magnetic Iron Oxide Integrated Photocatalysts; $\mathrm{MoS}_{2}$, Molybdenum disulphide; MB, Methylene Blue; MRI, magnetic resonance imaging; $\mathrm{MO}$, methyl orange; MWCNT, multiwalled carbon nanotubes; $\mathrm{NO}_{\mathrm{X}}$, Nitric oxide; NHE, Normal hydrogen electrode; $\mathrm{NH}_{3}$, Ammonia, 4-NP, 4-nitrophenol; NF, Norfloxacin; NO, Nitrate; $\mathrm{O}_{2}$, Oxygen; pH, Potential of hydrogen; PS, Persulfate; PMS, Peroxymonosulfate; PEI, Polyethylenimine; PCS, Photon correlation spectroscopy; rGO, Reduced Graphene Oxide; $\mathrm{RhB}$, Rhodamine B; SOx, Sulphur oxide; $\mathrm{SnO}_{2}$ Tin oxide; SEM, Scanning electron microscopy; SO, Sodium Oleate; SME, Sulfametoxazole; SHE, Standard Hydrogen Electrode; $\mathrm{TiO}_{2}$,Titatnium dioxide; TEM, Transmission electron spectroscopy; TOC, Total organic carbon; TBA, Tert-Butyl Alcohol; UV,Ultarvoilet; US, Ultrasound; VSM, Vibrating Sample Magnetometer; VB, Valence band; $\mathrm{WO}_{3}$, Tungsten trioxide; $\mathrm{WS}_{2}$, Tunstun disulphide; XRD, X-Ray Diffraction; ZnO, Zinc oxide; ZnS, Zinc Sulphide; ZFC, Zero field cooled; $\mathrm{ZrO}_{2}, \mathrm{Zrconium}$ dioxide; $\mathrm{SO}_{4}, \mathrm{Sulfate}$; ZF, $\mathrm{ZnO} @ \mathrm{Fe}_{3} \mathrm{O}_{4} ; \gamma-\mathrm{Fe}_{2} \mathrm{O}_{3}$, Magnetite; $\mathrm{HAuCl}_{4}$, Chloroauric acid.

\section{Introduction}


The chaotic growth of civilization and industrialization is mainly responsible for depletion of water resources which is indispensable for sustaining salubrious livelihoods. Influenced by the hastening anthropogenic activities and socio-economic development inadequate access to safe drinking water and sanitation are two utmost pervasive outcomes, even in regions currently deemed as water-rich [1-3]. According to United Nations World Water Development 2019 report, over 2 billion people are surviving in countries facing acute water stress and 1.2 billion people in world lack equitable access to clean and affordable drinking water. Recent, World health organization (WHO) statistics stipulates paramount outbreaks of water-borne diseases instigating around 485000 diarrheal deaths every year [4-6]. The arbitrary release of varied range of pollutants into water bodies by commercialized and human practices has posed serious threats to aquatic and public life. The most common emerging water pollutants are toxic organic aliphatic and aromatic molecules, surfactants, chlorinated organic dyes, detergents, pesticides, herbicides, insecticides, disinfection by-products, volatile organic compounds, plastics, heavy metals, oxides of nitrogen and sulphur and pathogens (viruses, bacteria, and fungi) [7-11]. Therefore, strategies to accentuate exclusion of aqueous phase pollutants are of great inevitability for researchers for overall water management.

Various water treatment processes have been developed over the years but have limited large scale application. The conventional methods include; adsorption on activated carbon and air stripping, incineration at high temperature, chlorination, filtration, sedimentation, biological treatment and coagulation etc. [12-13]. However, they are associated with potholes of heavy sludge and toxic by-products formation, time-consuming and cost-ineffective nature. Currently, the underlying drivers to eradicate the limitations of traditional methods are advanced oxidation processes (AOPs) for complete abatement of high levels of pollutants. Amongst the various AOPs, heterogeneous photocatalysis as a fundamental component of green chemistry has stimulated extensive research on designing environmentally benign and efficient photocatalysts [14]. Photocatalysis process utilizes UV-visible light or solar energy for oxidative or reductive degradation of organic pollutants into inorganic ions, $\mathrm{CO}_{2}$ and $\mathrm{H}_{2} \mathrm{O}$ with no further harmful byproducts [15-21]. The first report by Fujishima and Honda embarked the generation of photocatalysis by experimentation on photo-electrochemical water splitting via aid of titanium dioxide $\left(\mathrm{TiO}_{2}\right)$ driven by ultraviolet light. Since then, a variety of metallic semiconductor photocatalytic materials like metal oxide $\left(\mathrm{ZnO}, \mathrm{CaO}, \mathrm{ZnWO}_{4}, \mathrm{WO}_{3}, \mathrm{ZrO}_{2}, \mathrm{BiTiO}_{3}, \mathrm{SrTiO}_{3}, \mathrm{Fe}_{2} \mathrm{O}_{3}\right.$, 
$\mathrm{Ag}_{2} \mathrm{CO}_{3}, \mathrm{BiOBr}, \mathrm{BiOCl}, \mathrm{CaFe}_{2} \mathrm{O}_{4}, \mathrm{BiOCl}$, and $\mathrm{ZnFe}_{2} \mathrm{O}_{4}$ etc.), metal sulphide ( $\mathrm{ZnS}, \mathrm{CdS}, \mathrm{AgIn}_{5} \mathrm{~S}_{8}$, $\mathrm{CuInS}_{2}$ etc.) and noble metals have been ruggedly employed for water purification. The basic principle of heterogeneous photocatalysis has well been established in the literature which is primarily influenced by the electronic structure of semiconductor [20-24]. The photocatalyst absorbs light when the energy of incident radiations is equal or larger than band gap $\left(E_{g}\right)$ of the semiconductor. After absorption of light energy, an electron is excited from filled valance band (VB) of photocatalyst into its empty conduction band (CB) to create electron-hole pairs (EHP) [25]. When the photogenerated charge carriers are not utilized in photocatalytic reactions, they recombine within a few nanoseconds via either luminescence or heat generation. In the presence of adequate scavenger or surface defect to capture photogenerated EHP, recombination is forbidden, and subsequent redox reactions may happen [26-30].

The band gap positioning of various photocatalysts with respect to redox potential scale (vs. SHE; $\mathrm{pH} 7)$ is shown in Fig.1. The valence band holes are strong oxidants (+1.0 to $+3.5 \mathrm{~V}$ vs. SHE), while the conduction band electrons are good reductants (+0.5 to $-1.5 \mathrm{~V}$ vs. SHE) [22-28]. For example, redox potential of $\mathrm{VB}$ of $\mathrm{TiO}_{2}$ is more positive than $\mathrm{E}_{\mathrm{SHE}}\left(\mathrm{E}^{\bullet} \mathrm{OH} / \mathrm{H}_{2} \mathrm{O}=+2.27 \mathrm{~V}\right)$, whereas redox potential of $\mathrm{CB}$ of $\mathrm{TiO}_{2}$ is less negative than $\mathrm{E}_{\mathrm{SHE}}\left(\mathrm{E} \mathrm{O}_{2} / \mathrm{O}_{2}{ }^{--}=-0.28\right)$ [29]. Thus, ${ }^{\circ} \mathrm{OH}$ radicals are generated on reaction of $\mathrm{VB}$ holes with water molecule, whilst $\mathrm{CB}$ electrons react with $\mathrm{O}_{2}$ to create $\mathrm{O}_{2}{ }^{\cdot-}$ radicals. In the next step, reactive species $\left({ }^{\circ} \mathrm{OH}\right.$ and $\mathrm{O}_{2}{ }^{\bullet-}$ ) react with pollutant molecules to form intermediates followed by final degraded products. The following features of photocatalytic process permits its applicability in water purification $[30-33,1]$.

- Applicability at ambient temperature and pressure.

- Causing complete degradation of pollutants into innocuous products.

- Acquiring the required oxygen directly from the aqueous medium.

\section{$<$ Please insert Fig.1 here $>$}

The heterogeneous photocatalysts have several advantages over conventional homogenous catalytic system (Fig. 2). Chemical stability, low cost and non-selective catalytic activity are some of the main properties of heterogeneous photocatalysis over homogenous photocatalysis. However, pilot scale applications of heterogeneous semiconductor oxide photocatalysts are hindered by poor 
absorption of visible light and high recombination rate of EHPs [34, 35]. For instance, the wide band gap of anatase $\mathrm{TiO}_{2}(3.2 \mathrm{eV})$ corresponds to absorption of $387.5 \mathrm{~nm}$ wavelength in the UV region [36-40].

The poor selective adsorption and high concentration of organic pollutants in industrial waste deactivates photocatalyst and leads to catalytic poisoning which limits their applicability in water treatment process [41-43]. Moreover, isolation and recovery of non-magnetic photocatalysts from the reaction mixture is not very easy. This limitation hampers economics and sustainability of heterogeneous photocatalysts for water purification process [44-47]. Furthermore, immobilization of photocatalyst on different support systems reduces their effective surface area for photocatalytic reaction and, hence, the overall efficiency of photocatalytic system is lessened. Since, the solar spectrum comprises of only 5-7\% of UV light, whilst $47 \%$ and $46 \%$ of the spectrum consists of infrared and visible radiation, respectively[48-51].Thereby, it is essential to design a photocatalyst which responds to the entire solar spectrum region in-order to promote its photodegradation efficiency. An ideal and green heterogeneous photocatalyst must possess some unambiguous features like stability in aqueous phase, high activity, chemical inertness, low-cost, photo-stability, non-toxicity, efficient recovery, and reasonable recyclability for efficient water purification process [49-53].

\section{$<$ Please insert Fig.2 here $>$}

To overcome these issues, coupling of iron oxides nanoparticles (IONPs) with non-magnetic semiconductor photocatalysts seems to be the most rational solution. The separation of nonmagnetic photocatalysts can be achieved using magnetically separable IONPs in the production of hybrid photocatalytic systems [53-58]. Among all magnetic nanoparticles, iron oxides, i.e. $\mathrm{Fe}_{3} \mathrm{O}_{4}$ (magnetite), $\alpha-\mathrm{Fe}_{2} \mathrm{O}_{3}$ (hematite), $\beta-\mathrm{Fe}_{2} \mathrm{O}_{3}$ (beta phase), $\gamma-\mathrm{Fe}_{2} \mathrm{O}_{3}$ (magnetite), $\mathrm{FeO}$ (wustite), and spinel ferrites $\left(\mathrm{MFe}_{2} \mathrm{O}_{4}\right)$, have got much attention in the field of photocatalysis due to paramagnetism/ferrimagnetism, environmentally-friendly nature, and stability [54-56, 48, 32] (Fig.3 (a)). The magnetic nature of IONP enables easy and effective separation of photocatalyst from reaction mixture using an external magnetic field [54-56, 59]. Iron oxides with saturation magnetization of more than $1 \mathrm{emu} \mathrm{g}^{-1}$ can be easily separated using an external magnetic field [48]. Utilization of IONPs eliminates the use of tedious filtration and centrifugation methods to recover 
photocatalyst from the reaction solution. On the other hand, the used iron oxide should possess a relatively narrow band gap for higher visible light activity [46-48]. MIOIP nanocomposites must show enhanced photocatalytic activity in comparison to both bare iron oxide and pure semiconductor photocatalysts [43]. Photocatalytic applications of Magnetic iron oxide integrated photocatalyst (MIOIPs) are summarized in Table 1.

A literature survey on the Scopus database (keywords; Magnetic photocatalyst + Water purification) shows nearly 3000 papers from 2008 to 2018. Most of the articles are published in Chemical Engineering Journal, Journal of Cleaner Production, Advances in Colloid and Interface Science, Journal of Photochemistry and Photobiology C: Photochemistry Reviews, Nano today, and Applied Catalysis A: General. In the past ten years, research in this field has been shifted towards the applications of iron oxides in the photocatalytic water purification [49-51, 48, 32, 60] (Fig.3 (a)). Though it is not feasible to include every article correctly, still an increasing trend in MIOIPs for water purification can be observed. Interestingly, ferrites and FeO share respective 49 $\%$ and $33.6 \%$ of total number of published papers involving designing and applicability of magnetic photocatalysts for advanced oxidation water purification process (Fig. 3(b)).

\section{$<$ Please insert Fig.3 here $>$}

In the present review, our purpose is to present a broad overview on magnetic iron oxides supported photocatalysts for organic pollutants degradation from water. Most of the previously published reviews have been focused on the usage of iron oxide in water treatment through adsorption processes, reductive pathways, and catalytic degradations. Our review mainly involves recent developments in the photocatalytic activity of magnetically separable iron oxides integrated photocatalysts for wastewater treatment. We begin with an introductory discussion of heterogeneous photocatalysis, major drawbacks of non-magnetic photocatalyst, and the need for magnetically separable photocatalyst for water purification. In the first section, basic structure and magnetic properties of iron oxides were discussed. The second section contains various synthesis methods and different reaction conditions for MIOIPs preparation. The magnetic photocatalysts are classified and discussed in four subsections: (i) $\alpha-\mathrm{Fe}_{2} \mathrm{O}_{3}$ integrated photocatalysts, (ii) $\mathrm{Fe}_{3} \mathrm{O}_{4}$ supported catalysts, (iii) FeO supported photocatalysts and (iv) Ferrites based photocatalysts. Also, lastly, limitations and future perspectives of MIOIPs are also discussed. 


\section{Iron oxides: Potential material with great future}

Iron oxides are the most abundant metal oxides and can be synthesized at large scale under ambient reaction conditions. Recently, magnetic iron oxides are of great interest to researchers and environmentalists owing to their wide-range application in various fields including catalysis, pigments, targeted drug delivery, biosensors, magnetic resonance image, data storage, photocatalysis, environmental applications, etc. In this view, for example, many magnetic iron oxides with different size and morphology have been fabricated due to their importance in environmental research [57-59]. Out of eight known phases of iron oxides, $\alpha-\mathrm{Fe}_{2} \mathrm{O}_{3}$ (hematite), $\gamma$ $\mathrm{Fe}_{2} \mathrm{O}_{3}$ (maghemite), $\mathrm{Fe}_{3} \mathrm{O}_{4}$ (magnetite), and $\mathrm{FeO}$ (wustite) are the most popular and potential magnetic materials for water treatment. The hematite iron (III) oxide exists as $\alpha-\mathrm{Fe}_{2} \mathrm{O}_{3}, \beta-\mathrm{Fe}_{2} \mathrm{O}_{3}$, $\gamma-\mathrm{Fe}_{2} \mathrm{O}_{3}$, and $\varepsilon-\mathrm{Fe}_{2} \mathrm{O}_{3}$ phase, among which $\alpha-\mathrm{Fe}_{2} \mathrm{O}_{3}$ and $\gamma-\mathrm{Fe}_{2} \mathrm{O}_{3}$ are stable iron (III) oxides [6266]. Hematite exists as corundum structure with six Fe and $\mathrm{O}$ atoms per unit cell having space group R-3c and lattice parameters of $\mathrm{a}=5.0356 \mathrm{~nm}, \mathrm{c}=13.7489 \mathrm{~nm}$ (Fig. 4(a)) [62, 64]. Hematite has strong absorption of yellow light in the UV region [63]. It transmits orange colour in the visible region and red colour in the infrared region $[59,60,63]$. The cationic arrangement has $\mathrm{FeO}_{6}$ octahedrons pairs involving sharing of edges by three neighbouring octahedrons in the same plane and one face with an octahedron in an adjacent plane in (001) direction. The hematite shows $\mathrm{C}_{3 \mathrm{v}}$ symmetry [60] with two different $\mathrm{Fe}-\mathrm{O}$ bond lengths $[61,65]$. The most primitive magnet, $\mathrm{Fe}_{3} \mathrm{O}_{4}$ (magnetite) was discovered around 1500 B.C possessing cubic inverse spinel structure with $\mathrm{Fe}_{3} \mathrm{~m}$ space group (Fig.4 (b)). The unit cell contains both $\mathrm{Fe}^{2+}$ and $\mathrm{Fe}^{3+}$ ions which bring about unique magnetic behavior, $32 \mathrm{O}^{2-}$ ions in regular cubic closed pack with vacancies in Fe sites leading to crystal symmetry loss [63-65]. Both $\mathrm{Fe}_{3} \mathrm{O}_{4}$ and $\gamma-\mathrm{Fe}_{2} \mathrm{O}_{3}$ have a similar crystalline structure and chemical composition.

$\mathrm{FeO}$ (Wustite) has cubic a rock-like structure with the octahedral arrangement of iron and oxygen atoms in a unit cell (Fig.4(c)) [66]. The most important MNPs are transition metal oxides with spinel structural arrangements termed as ferrites. On the basis of their magnetic characteristics and crystal structures, ferrites are classified into three categories: (a) spinel ( $\mathrm{MFe}_{2} \mathrm{O}_{4} ; \mathrm{M}=\mathrm{Mn}, \mathrm{Fe}, \mathrm{Ni}$, $\mathrm{Co}, \mathrm{Zn}$, etc.), (b) garnet $\left(\mathrm{M}_{3} \mathrm{Fe}_{5} \mathrm{O}_{12} ; \mathrm{M}=\right.$ rare earth cations), (c) hexaferrite $\left(\mathrm{SrFe}_{12} \mathrm{O}_{19}\right.$ and $\left.\mathrm{BaFe}_{12} \mathrm{O}_{19}\right)$, (d) orthoferrite $\left(\mathrm{MFeO}_{3}, \mathrm{M}=\right.$ rare earth cations). Spinel ferrite nanoparticles, $\mathrm{AB}_{2} \mathrm{O}_{4}$ (general chemical formula) are most explored amongst these groups. Their homogeneous structure is composed of metallic cations $\mathrm{A}$ and $\mathrm{B}$ positioned at two discrete crystallographic sites 
tetrahedral and octahedral with Fe (III) as vital element. The spinel ferrites, with a general formula of $\mathrm{MFe}_{2} \mathrm{O}_{4}$ are thermally and chemically stable magnetic substances with potential photocatalytic applications for removal of toxic gases and heavy metal removal from aqueous phase [67-69]. Depending on the anchoring position of $\mathrm{M}$ (II) and Fe (III), there are three possible spinel arrangements, termed as normal, inverse, and mixed structures. In normal spinel ferrite, Fe (III) and $\mathrm{M}$ (II) are found at octahedral and tetrahedral sites, respectively whereas, in inverse spinel structure of ferrites, M (II) only occupies octahedral positions while Fe (III) is equally distributed on both sides $[70,71]$. In a mixed type of ferrite, both ions Fe(III) and M (II) lies on octahedral sites as well as tetrahedral sites (Fig.4 (d)) [32]. The afore-mentioned description on structure stability and abundantly available nature of iron oxides contributes to significantly enhanced photodegradation activity.

\section{$<$ Please insert Fig.4 here >}

\subsection{Magnetic behaviour, magnetic separation and toxicity of iron oxide photocatalyst}

The magnetic behavior of iron oxides can be categorized by their response to the applied external magnetic field. On the basis of orientations of magnetic moment, five basic types of magnetism can be leveled: diamagnetic, paramagnetic, ferromagnetic, antiferromagnetic, and ferrimagnetic $[72-74,44]$. The magnetization type can be determined from universal $(\mathrm{M}-\mathrm{H})$ hysteresis loops from which the values of $\mathrm{M}_{\mathrm{S}}$ (saturation magnetization), $\mathrm{M}_{\mathrm{r}}$ (remanence magnetization), and $\mathrm{H}_{\mathrm{C}}$ (coercivity) can be obtained [75-78, 44]. Superparamagnetic INOPs involves complete overlap of forward and backward magnetization curves $[75,77]$. $\mathrm{Fe}_{3} \mathrm{O}_{4}$ and $\gamma$ $\mathrm{Fe}_{2} \mathrm{O}_{3}$ exhibit saturation magnetization up to $92 \mathrm{emu} \mathrm{g}{ }^{-1}$ at room temperature [73]. However, $\alpha$ $\mathrm{Fe}_{2} \mathrm{O}_{3}$ exhibits weak ferromagnetism and saturation magnetization is usually less than one emu at room temperature [78]. Choi et al., prepared hollow nanospheres, solid nanospheres, hollow nanoellipsoids, and solid nanoellipsoids of $\mathrm{Fe}_{3} \mathrm{O}_{4}$ nanoparticles. $\mathrm{Fe}_{3} \mathrm{O}_{4}$ nanoparticles exhibit ferromagnetic behaviour, and their saturation magnetization $\left(\mathrm{M}_{\mathrm{s}}\right)$ and coercivity $\left(\mathrm{H}_{\mathrm{c}}\right)$ depends on shapes of nanoparticles. The $\mathrm{M}_{\mathrm{s}}$ value decreases in the following order: $\mathrm{Fe}_{3} \mathrm{O}_{4}$ nanospheres $(84.2$ emu g $\left.{ }^{-1}\right)>\mathrm{Fe}_{3} \mathrm{O}_{4}$ nanoellipsoids $\left(65.6 \mathrm{emu} \mathrm{g}^{-1}\right.$ ) > hollow $\mathrm{Fe}_{3} \mathrm{O}_{4}$ nanoellipsoids (53.0 emu g ${ }^{-1}$ ) [75]. Wu et al., interpreted shape dependent structural and magnetic properties of single and tubular clustered magnetite nanoparticles prepared by low-temperature co-precipitation and high- 
temperature hydrothermal reactions. The saturation magnetization $\left(\mathrm{M}_{\mathrm{S}}\right)$ of single and clustered nano- $\mathrm{Fe}_{3} \mathrm{O}_{4}$ was found to be 64.5 and $63.8 \mathrm{emu} \mathrm{g}^{-1}$, respectively, [76]. The permanent magnetization $\left(M_{r}\right)$ and coercivity $\left(H_{C}\right)$ were found to be, $15 \mathrm{emu} \mathrm{g}^{-1}$ and $205 \mathrm{Oe}$, respectively [78]. The shape and size of iron oxides greatly influence magnetic properties of nanoparticles due to the role of anisotropy in magnetism [77-81]. For example, Billas et al., reported magnetic moment of $2.7 \mathrm{mB}$ per atoms for Fe cluster of 300 atoms whereas, the value of the bulk was of 2.2 $\mathrm{mB}$ per atoms $[78,79]$.

\section{$<$ Please insert Fig. 5 here >}

Gautam et al., synthesized superparamagnetic photocatalysts by immobilizing $\mathrm{MnFe}_{2} \mathrm{O}_{4}$ onto the surface of graphene sand composite (GSC) and bentonite (BT) for photodegradation of ampicillin and oxytetracycline antibiotics. The hysteresis curve for $\mathrm{MnFe}_{2} \mathrm{O}_{4} / \mathrm{BT}$ and $\mathrm{MnFe}_{2} \mathrm{O}_{4} / \mathrm{GSC}$ is given in Fig. 6(a). The permanent magnetization of $\mathrm{MnFe}_{2} \mathrm{O}_{4} / \mathrm{GSC}$ and $\mathrm{MnFe}_{2} \mathrm{O}_{4} / \mathrm{BT}$ was determined to be 12.36 and 12.86 emu g ${ }^{-1}$, respectively. Both $\mathrm{MnFe}_{2} \mathrm{O}_{4} / \mathrm{BT}$ and $\mathrm{MnFe}_{2} \mathrm{O}_{4} / \mathrm{GSC}$ photocatalysts were separated in $10 \mathrm{~s}$ using an external magnet [81].

\section{$<$ Please insert Fig.6 here >}

Owing to superparamagnetic behaviour, IONPs are potential candidates for water purification. Accordingly, non-governmental agencies and many scientists have expressed their concern for toxic effect of IONPs on human and environment. They are being utilized in diverse biomedical applications like in cancer treatment by induced hyperthermia, in drug delivery, and in MRI (magnetic resonance imaging). The scientific reports on the potential toxicity of IONPs are very rare. Evaluation of toxicity of IONPs of size 30-40 nm in BRL 3A cell line derived from rat liver clearly showed no measurable effect on various parameters like morphology, redox imbalance and membrane integrity of cells [82]. Using in vitro methods in different cell lines, it was found that the treatment with PEI, citrate or polyacrylic acid coated iron oxide nanoparticles has less adverse effects on mammalian cells including astrocytes and human T lymphocytes and thus, it can be used for neural cell replacement therapies. These IONPs also showed a rapid labeling and transfection properties which is required for efficient bimodal MR-fluorescence imaging [83]. But in vivo studies by Valdiglesias et al., suggested that toxicity of iron-based nanoparticles depends on many factors like the size of nanoparticles and their dose without causing any acute toxic effect on mammalian cells [84]. 


\subsection{Designing of iron oxide-semiconductor photocatalysts}

Since the last three decades, semiconductor oxides, nitrides, and sulfides have shown noteworthy photocatalytic activity for water treatment. However, most oxides are UV active which restricts their applicability under solar light whereas; metal sulfides and nitrides have poor stability in the aqueous environment [11]. Recently, iron oxides are emerging as a strong candidate for visible light harvesting due to the band gap of 1.9-2.5 eV. Further, $\alpha-\mathrm{Fe}_{2} \mathrm{O}_{3}$ absorbs light up to 600 $\mathrm{nm}$ and collects up to $40 \%$ of solar spectrum energy $[84,85,59]$. However, recombination of photo-generated EHP lessens applicability of bare iron oxides for water purification. Secondly, difficult separation of non-magnetic photocatalyst remains a bottleneck for recyclability of photocatalyst due to consuming recovery of photocatalyst [86, 87, 59, 41, 44]. Therefore, combination of iron oxides with a semiconductor photocatalyst is essential to design efficient and a stable photocatalytic system. An efficient iron oxide-semiconductor nanocomposite should possess the following features [88-91, 41, 44, 62]:

(i) The method of preparation should be simple, facile and high yielding.

(ii) The nanocomposite should be magnetically separable via an external magnetic field.

(iii) The nanocomposite must exhibit enhanced photocatalytic activity than pure iron oxide and semiconductor photocatalyst.

(iv) The nanocomposite must be stable in the aqueous phase and have recyclability.

Till now several semiconductor photocatalysts have been employed for removing of organic contaminants from the aqueous phase. As per thermodynamic consideration, the redox potential of VB holes must be sufficiently positive to produce hydroxyl radical. On the other hand, CB electrons must be sufficiently negative to produce superoxide radical [92-94, 22, 23, 55]. The band edge positions and band gap energy of some semiconductors along with selected redox potentials are shown in Fig. 1. Clearly, the band edge position and band gap energy of $\mathrm{TiO}_{2}, \mathrm{ZnO}, \mathrm{Fe}_{2} \mathrm{O}_{3}$, $\mathrm{WO}_{3}, \mathrm{SnO}_{2}$, and $\mathrm{ZrO}_{2}$ are reasonably good for photocatalytic water remediation. The semiconducting solids absorb photons when $h v \geq E_{g}$, thereafter, an $\mathrm{e}^{-}$is excited from $\mathrm{VB}$ to $\mathrm{CB}$ leaving a hole in VB leading to generation of EHP. The construction of a heterostructure between more than one semiconductor via transference of holes and electron facilitates elimination of pollutants present in the aqueous phase [95-98]. On the basis of chemical composition, 
semiconductor photocatalysts can be classified as binary, ternary, and quaternary metal oxide/sulphide photocatalyst [99, 100]. This review highlights recent developments on iron oxides supported semiconductor photocatalysts with enhanced photocatalytic activity, easy separation, and high recyclability.

\section{Synthesis of iron-oxide based photocatalysts}

A plethora of techniques are used for synthesis of iron oxide-semiconductor photocatalysts. The practicability and cost-effectiveness are two factors governing the applicability of synthesis method [101-103]. The inherent colloidal property of magnetic iron oxide photocatalysts results in time-consuming synthesis process [104]. Advanced chemical based synthetic approaches has been followed for preparation of magnetic iron oxide photocatalysts including; flow injection synthesis [105], aerosol/vapour method, sonochemical reactions [106], coprecipitation, hydrothermal reactions [107], electrospray synthesis [108], sol-gel method [109], and microemulsion technique [110] as described in (Table 2).

\subsection{Hydrothermal method}

Hydrothermal method is a common technique for production of magnetic nano iron oxides, which involves mixing of soluble salts of divalent (ferrous) and trivalent (ferric) of iron metal [111-114]. A synergistic role of hydrolysis and oxidation of mixed metal hydroxides leads to formation of magnetic ferric oxide [115-121]. The particles sizes of IONPs are equally governed by rate of nucleation and crystal growth effect [122]. At higher temperature, size of IONPs decreases because of the fast nucleation rate than the crystal growth rate. Kefeni et al., [123] reported a hydrothermal procedure in which dissolvable salts of divalent and trivalent magnetic ferric oxides were mixed with mole ratios of $1: 2\left(\mathrm{Fe}^{2+} / \mathrm{Fe}^{3+}\right)$ to obtain IONPs $[124,125-132]$. It is observed that the influencing factors; reaction temperature and time depend on type of magnetic ferric oxide to be synthesized $[133,134]$. Taniguchi et al., prepared $\mathrm{Fe}_{3} \mathrm{O}_{4}$ nanoparticles by dissolving ferrous and ferric salts in sodium oleate [SO] using various molar ratios of [SO]/ [Fe] in the saline mixture at $230{ }^{\circ} \mathrm{C}$. The particles of different size and shape were formed by 0.05 of $[\mathrm{SO}] /[\mathrm{Fe}]$ at the lowest sodium oleate concentration. The resultant average size particles and Ms values were found to decrease with increase in molar ratio of oleate concentration from 0-0.5 [135]. 


\subsection{Co-precipitation method}

The co-precipitation technique is the most facile method for synthesizing uniform IONPs. In this process, trivalent and divalent d-block metal salts are intermixed in mole ratios of 1:2, respectively [136]. The quality of IONPs is controlled by regulating $\mathrm{pH}$ of reaction mixture. The co-precipitation is mostly carried out in an alkaline medium using $\mathrm{NH}_{4} \mathrm{OH}$ and $\mathrm{NaOH}$ [136]. The crystallinity of IONPs prepared using co-precipitation method is quite low. Thus, heat treatment is highly needed to increase the crystallinity degree. Moreover, scaling of products is another drawback of the co-precipitation method [137]. Xing et al., [138] prepared $\mathrm{Fe}_{3} \mathrm{O}_{4} / \mathrm{Au}$ nanocomposites by co-precipitation procedure. Firstly, $\mathrm{Fe}^{2+}$ and $\mathrm{Fe}^{3+}$ were mixed in $\mathrm{NH}_{4} \mathrm{OH}$ to obtain $\mathrm{Fe}_{3} \mathrm{O}_{4}$. In the next step, sodium citrate and $\mathrm{HAuCl}_{4}$ were added to $\mathrm{Fe}_{3} \mathrm{O}_{4}$ to prepare $\mathrm{Fe}_{3} \mathrm{O}_{4} / \mathrm{Au}$. The size of $\mathrm{Fe}_{3} \mathrm{O}_{4} / \mathrm{Au}$ was controlled ( 25 to $300 \mathrm{~nm}$ ) by varying reactants concentration. Kefeni et al., [123] reported the synthesis of magnetic $\mathrm{CoFe}_{2} \mathrm{O}_{4}$ and $\mathrm{Fe}_{3} \mathrm{O}_{4}$ photocatalyst by coprecipitation process. The $\mathrm{pH}$ of reaction solution was adjusted by using sodium hydroxide and ammonium solution. The obtained nano-sized magnetic photocatalyst possessed a spherical shape with an average particle size in $25-15 \mathrm{~nm}$ range. Thakur et al., [139] prepared magnetic $\mathrm{NiFe}_{\mathrm{x}} \mathrm{O}_{4}$ nanocomposites $10-15 \mathrm{~nm}$ (where $\mathrm{x}=1.8,2.0,2.2$ ) using co-precipitation method. There was no modification in particle arrangement with variation in $\mathrm{x}$ value, while spinel cubic arrangement of $\mathrm{NiFe}_{\mathrm{x}} \mathrm{O}_{4}$ was observed at room temperature. The saturated magnetization of $\mathrm{NiFe}_{1.8} \mathrm{O}_{4}$ and $\mathrm{NiFe}_{2.2} \mathrm{O}_{4}$ was lower than $\mathrm{NiFe}_{2.0} \mathrm{O}_{4}\left(\mathrm{Ms}=47.5 \mathrm{Am}^{2} \mathrm{~kg}^{-1}\right)$ as shown in Fig.7.

Previously, Zabotto et al., found saturation magnetization of $\mathrm{NiFe}_{2} \mathrm{O}_{4}$ sample was $46.5 \mathrm{Am}^{2} \mathrm{~kg}^{-1}$ [140]. This result claimed attainment of a higher value of saturation magnetization in coprecipitation procedure.

\section{$<$ Please insert Fig.7 here $>$}

Romimoghadam et al., [141] described the formation of IONPs using coprecipitation method. Briefly, a liquefied solution of $\mathrm{Fe}$ (III) and Fe (II) salts were continuously stirred with a base with appropriate ageing time. The precipitation of $\mathrm{Fe}_{3} \mathrm{O}_{4}$ is shown in the following chemical reaction (Eq. 1):

$$
\mathrm{Fe}^{2+}+2 \mathrm{Fe}^{3+}+8 \mathrm{OH}^{-} \rightarrow \mathrm{Fe}_{3} \mathrm{O}_{4}+4 \mathrm{H}_{2} \mathrm{O}
$$


Eq. (1) was generally controlled by regulating the solution $\mathrm{pH}$. It is significant to indicate that magnetite can be obtained in the $\mathrm{pH}$ range $8-14$ with $\mathrm{Fe}^{3+}(2): \mathrm{Fe}^{2+}$ (1) respective ratios in the presence of non-oxidizing conditions.

\subsection{Sol-gel Method}

Sol-gel procedure is a suitable chemical technique which proceeds via hydroxylation and condensation of precursors in a typical solvent resulting in "sol" formation. The inorganic polymerization and condensation helps in the formation of a 3D ferric oxides wet gel network [141]. Since reactions are operational at room conditions therefore, mild heat treatment is essential to remove volatile impurities in order to achieve a crystalline state of IONPs. The characteristics of gel totally depend on the structure formed during sol preparation and factors like temperature, reactant concentration, $\mathrm{pH}$, nature of salt, solvent, and stirring also influence chemical and physical properties of gel $[141,142]$. Among all methods, sol-gel synthesis is very advantageous due to its operational simplicity. It does not require any tedious reaction and sophisticated instruments also chemical reaction occurs at a low temperature. However, post-synthesis treatment for obtaining a high concentration of magnetically iron oxide photocatalyst is a major drawback of the sol-gel method. Ramesh et al., prepared Co/Mn substituted Ni-Zn ferrite nanocomposite by using the solgel method. Ni-Zn-Co and Ni-Zn-Mn ferrites were examined for their structural and magnetic characteristics [143]. Maron et al., synthesized $\mathrm{CoFe}_{2} \mathrm{O}_{4}$ by sol-gel method with high coercivity than micro-sized photocatalyst [144]. In addition, these nano-sized photocatalysts were coated with hydrophobic surfactants to obtain magneto-optical properties. Fig. 8 (a) displays TEM images of synthesized $\mathrm{CoFe}_{2} \mathrm{O}_{4}$ nanoparticles exhibiting a monolayer of cobalt ferrite nanocomposites, as verified by Langmuir-Blodgett technique. Cobalt ferrite nanoparticles were spherical with a diameter of $9 \pm 1.5 \mathrm{~nm}$. The inset of Fig.8 (b) shows the diffraction pattern obtained from a high resolution TEM image of cobalt ferrite nanoparticles resembled with FCC [121]. Fig.8(c) shows the reduced hysteresis loop at $10 \mathrm{~K}$ for isolated cobalt ferrite particles which exposed a coercive field about $\sim 15 \mathrm{kOe}$. The estimated value of remanent to saturation magnetization ratio $\left(\mathrm{M}_{\mathrm{r}} / \mathrm{M}_{\mathrm{s}}\right)$ for $\mathrm{CoFe}_{2} \mathrm{O}_{4}$ was found to be 0.88 . The obtained value was close to $\mathrm{M}_{\mathrm{r}} / \mathrm{M}_{\mathrm{S}}$ of isolated particles with cubic anisotropy was 0.83 (Fig.8 (c)). Sun et al., reported coercivity of $20 \mathrm{kOe}$ for nickel ferrite obtained by chemical reaction of acetylacetonate metal precursors with hexadecanediol using high-temperature decomposition method [145]. 


\section{$<$ Please insert Fig.8 here $>$}

\subsection{Thermal decomposition method}

Thermal decomposition technique is a very modest process for preparation of magnetic iron oxide nanoparticles involving decomposition of organometallic precursors like carbonyls and metallic acetylacetonates of organic surfactants (oleic acid and hexadecyl amine) [146]. The heating rate governs shape, uniform morphology, concentration of precursors and fine particle distribution of magnetic iron oxide nanoparticles [147]. Using this method, monodispersed IONPs with uniform morphology can be prepared [148]. Drezereshki et al., [149] prepared magnetic $\alpha$ $\mathrm{Fe}_{2} \mathrm{O}_{3}$ photocatalyst through thermal decomposition technique. Magnetic $\alpha-\mathrm{Fe}_{2} \mathrm{O}_{3}$ nanosized photocatalyst was calcinated at $500{ }^{\circ} \mathrm{C}$ for $1 \mathrm{~h}$ and $2 \mathrm{~h}$ to obtain $18 \pm 2$ and $24 \pm 2 \mathrm{~nm} \alpha-\mathrm{Fe}_{2} \mathrm{O}_{3}$ particles, respectively. The magnetic measurements indicated weak ferromagnetic behaviour of magnetic $\alpha-\mathrm{Fe}_{2} \mathrm{O}_{3}$ nanosized photocatalyst at room temperature. Fig. 9 displays TEM images of $\alpha-$ $\mathrm{Fe}_{2} \mathrm{O}_{3}$ photocatalyst in which 200 and 180 nanoparticles were counted in $\alpha-\mathrm{Fe}_{2} \mathrm{O}_{3}$ cluster after heating at $500{ }^{\circ} \mathrm{C}$ for 1 and $2 \mathrm{~h}$, respectively. The average particle size of hematite photocatalyst was about $50 \pm 3 \mathrm{~nm}$ and $24 \pm 2 \mathrm{~nm}$ for $1 \mathrm{~h}$ and $2 \mathrm{~h}$ heating, respectively.

\section{$<$ Please insert Fig.9 here $>$}

\subsection{Solvothermal method}

In solvothermal technique, either aqueous or non-aqueous solvents have been utilized to fabricate IONPs with controlled size distribution with accurate crystalline phases [150]. These physical and chemical properties of IONPs can be modified by making change in reaction time, reaction temperature, solvent, surfactant, and reactants [150-152]. Moreover, due to easiness, in term of its reaction conditions, the solvothermal technique is appropriate for scalable production of magnetic iron oxide photocatalyst. Wu et al., [152] prepared MWCNT@ $\mathrm{CoFe}_{2} \mathrm{O}_{4}$ composites via the solvothermal technique using $\mathrm{CoCl}_{2} \cdot 6 \mathrm{H}_{2} \mathrm{O}$ and $\mathrm{FeCl}_{3} .6 \mathrm{H}_{2} \mathrm{O}$ precursors in DEA and DEG as complexing agents. The reaction temperature was changed from $180{ }^{\circ} \mathrm{C}$ to $240{ }^{\circ} \mathrm{C}$ for $8 \mathrm{~h}$. The obtained structure of MWCNT@ $\mathrm{CoFe}_{2} \mathrm{O}_{4}$ nanocomposites was affected by reaction temperature. The superparamagnetic MWCNT@ $\mathrm{CoFe}_{2} \mathrm{O}_{4}-180$ composites contained $\mathrm{CoFe}_{2} \mathrm{O}_{4}$ nanoparticles consistently coated on carbon nanotubes surface. MWCNT@ $\mathrm{CoFe}_{2} \mathrm{O}_{4}-180$ had low cytotoxicity, 
good MRI enhancement effect, and negligible hemolytic activity. Ameer et al., [153] synthesized nano-sized $\mathrm{CoFe}_{2} \mathrm{O}_{4}$ and it's composite with rGO using 1-hexagonal assisted in situ reduction using the solvothermal method. The average size of synthesized particles was between 15-27 nm. $\mathrm{CoFe}_{2} \mathrm{O}_{4} / \mathrm{rGO}$ had consistent dispersion and spherical shape as confirmed by TEM analysis.

\subsection{Sonochemical method}

The sonochemical technique is suitable for the preparation of nano-sized magnetic ferric oxide photocatalyst [154]. In this process, bubbles are produced in the solvent medium during ultrasonic radiation which can successfully collect diffused energy from ultrasound wave. After this, a short-lived localized hot spot is produced with a temperature of $5000 \mathrm{~K}$ and pressure of 1000 bars. The heating rate inside the bubble should be greater than $10^{10} \mathrm{Ks}^{-1}[155]$. The particles prepared by sonochemical technique have similar composition as of bubble, which can act as the main factor in controlling the purity of nano-sized magnetic ferric oxide photocatalyst [156]. Several inorganic compounds like IONPs, alloys, carbides, $\mathrm{Fe}_{3} \mathrm{O}_{4} @ \mathrm{SiO}_{2}$ [157], $\mathrm{CuFe}_{2} \mathrm{O}_{4}[158]$ and $\mathrm{Fe}_{3} \mathrm{O}_{4}$ [159] have been prepared using this method. This method leads to reduction in crystal growth and controlled particle size distribution of IONPs [160]. The size of IONPs varies with change in temperature and the intensity of ultrasonic wave. Roshan et al., prepared $\alpha-\mathrm{Fe}_{2} \mathrm{O}_{3}$ nanoparticles via mixing precursors $\mathrm{FeCl}_{3} \cdot 6 \mathrm{H}_{2} \mathrm{O}$ and $\mathrm{NaOH}$ solutions followed by ultrasonication for $1 \mathrm{~h}$. The morphology and size of photocatalysts were influenced by ultrasonication power, temperature condition and sonication time. Fig. 10 presents the variation in size of $\alpha-\mathrm{Fe}_{2} \mathrm{O}_{3}$ with respect to sonication temperature. It is observed that with increment in sonication temperature from 30 to $80{ }^{\circ} \mathrm{C}$, particle size proliferated from $12 \mathrm{~nm}$ to $19 \mathrm{~nm}$. However, an antagonistic effect is significantly observed on increasing ultrasonication intensity at $80{ }^{\circ} \mathrm{C}$, which causes reduction in $\alpha-\mathrm{Fe}_{2} \mathrm{O}_{3}$ particle size from $24 \mathrm{~nm}$ to $19 \mathrm{~nm}$ [161].

\section{$<$ Please insert Fig.10 here >}

\subsection{Microemulsion method}

A microemulsion is composed of three phases of water, oil, and surfactants i.e. a transparent solution of small drops of unmixable phase (polar/non-polar) in a continuous phase (oil). The surfactant causes a decrease in surface tension between immiscible and continuous phases. The surfactants can disperse the resultant IONPs due to micellisation process [145]. Microemulsion 
technique involves normal oil-in-water as well as reverses water-in-oil phases. The major advantage of this technique is size control of synthesized particles. Moreover, this technique can be applied for production of IONPs at the industrial level. The dispersed phase comprises of monodroplets, with a size range from 2-100 $\mathrm{nm}$ in both cases, and provides a restricted environment for the synthesis of IONPs. Production of stable IONPs is the most attractive feature of the microemulsion method. By this method, recovery and reuse of surfactants and oil also permit numerous IONPs synthesis cycles. So, the microemulsion technique is considered as a costeffective technique [127]. However, due to slow nucleation rate, IONPs are less crystalline and more poly-dispersed. Patel et al., prepared magnetic iron oxide photocatalyst through microemulsion technique by changing factors like [water]/[surfactant] mole ratio, reactant concentration, oil length, and surfactant. The size of resultant magnetic iron oxide particles was between 20 and $50 \mathrm{~nm}$. The fabricated magnetic iron oxide was used as an adsorbent for fluoride removal from a synthetic solution containing fluoride. At $\mathrm{pH} 7$, the maximum removal of fluoride was observed with an adsorbent dose of $0.4 \mathrm{~g} / \mathrm{L}$ in $40 \mathrm{~min}$. The removal process fitted well with pseudo second-order kinetics [162].

\section{Iron oxides modified binary photocatalysts}

\subsection{Iron oxide modified binary metal oxide photocatalysts}

During the last four decades, numerous metal oxide catalysts such as $\mathrm{TiO}_{2}, \mathrm{ZnO}, \mathrm{CuO}, \mathrm{CdS}$, and $\mathrm{V}_{2} \mathrm{O}_{5}$ have been used as photocatalyst to mitigate organic/inorganic pollutant present in water. Among these photocatalysts, $\mathrm{TiO}_{2}$ and $\mathrm{ZnO}$ have been extensively used due to their non-toxicity, abundance, and photocatalytic activity. The major drawbacks associated with these metal oxides are low visible light activity, poor adsorption activity for aqueous phase pollutants, and difficult separation from the reaction solution. Recently, iron oxides have been used to improve the photocatalytic efficiency of metal oxide catalysts by modification through the formation of heterojunction between iron oxide and any of the above-mentioned metal oxides. In many cases, the improvements in the band gap, effective separation of the EHP and, fast separation photocatalyst from solution were observed [163].

For an instant, Shi et al., synthesized $\mathrm{Fe}_{3} \mathrm{O}_{4} @ \mathrm{TiO}_{2}$ photocatalyst for superior photocatalytic activity and photo-thermal conversion. Under solar radiation, Rhodamine B (RhB) dye from 
aqueous solution was efficiently removed by $\mathrm{Fe}_{3} \mathrm{O}_{4} @ \mathrm{TiO}_{2}$ photocatalyst. Degradation of $\mathrm{RhB}$ dye also increased from $85 \%$ to $94 \%$ with an increase in solar light from 1 to 10 suns ( 1 sun= 1000 $\mathrm{W} / \mathrm{m}^{2}$ ). The saturation magnetization of $\mathrm{Fe}_{3} \mathrm{O}_{4} @ \mathrm{TiO}_{2}$ photocatalyst was 32.9 emu g $\mathrm{g}^{-1}$. The photocatalyst recovery and degradation rate increased with increment in magnetic field strength from 25 to $100 \mathrm{mT}$. The effective separation of photogenerated EHP and magnetic recovery from reaction solution was the main features of $\mathrm{Fe}_{3} \mathrm{O}_{4} @ \mathrm{TiO}_{2}$ photocatalyst in effective degradation of RhB dye after successive 6 cycles [164].

Li. et al., prepared $\mathrm{Fe}_{3} \mathrm{O}_{4} @ \mathrm{TiO}_{2}$ composite via hydrothermal method involving tetrabutyl titanate as a precursor for removal of sulphur dioxide and $\mathrm{NO}_{\mathrm{x}}$ from industrial coal-fired fuel gas. Desulfurization and denitrification were examined using 10\% $\mathrm{Fe}_{3} \mathrm{O}_{4} @ \mathrm{TiO}_{2}$ composite at different temperatures of 100,150 , and $200{ }^{\circ} \mathrm{C}$. The highest reaction performance, i.e. the highest decrease in sulfate and nitrate concentration, was observed by $10 \% \mathrm{Fe}_{3} \mathrm{O}_{4} @ \mathrm{TiO}_{2}$ at $100{ }^{\circ} \mathrm{C}$ after $60 \mathrm{~min}$. The studies showed that $\mathrm{SO}_{2}$ and $\mathrm{NO}_{\mathrm{x}}$ were adsorbed on the surface of $\mathrm{Fe}_{3} \mathrm{O}_{4} @ \mathrm{TiO}_{2}$ composite by means of physical and chemical adsorption processes [165].

Sun et al., used a one-step convenient calcining technique to fabricate $\mathrm{Fe}_{3} \mathrm{O}_{4}$ loaded $\mathrm{TiO}_{2}$ photocatalyst. The photocatalytic activity of $\mathrm{Fe}_{3} \mathrm{O}_{4} @ \mathrm{TiO}_{2}$ was studied for decomposition of acetate red organic dye $(\mathrm{X} 3 \mathrm{~B})$ in water. The negligible degradation of organic dye in the absence of $\mathrm{Fe}_{3} \mathrm{O}_{4} @ \mathrm{TiO}_{2}$ photocatalyst indicated the stability of X3B dye under xenon lamp radiation. Photocatalytic activity of $\mathrm{Fe}_{3} \mathrm{O}_{4} @ \mathrm{TiO}_{2}$ photocatalyst was quite stable for consecutive five cycles [166]. Fig.11 (a-d) demonstrates the magnetic characteristics of $\mathrm{Fe}_{3} \mathrm{O}_{4} @ \mathrm{TiO}_{2}$ photocatalyst. It was reused and suitably attracted to a magnet so that the magnetic force became faster due to presence of higher iron contents in sample. The highest efficacy in the photocatalytic treatment of manufacturing wastewater was attained by utilization of $\mathrm{Fe}-\mathrm{TiO}_{2}$ photocatalyst having the ratio of 1:200 (Fe: $\left.\mathrm{TiO}_{2}\right)$ Fig.11 (a). Fig 11 (e) shows the most plausible mechanism for photocatalytic reaction and degradation of organic dye X3B. The degradation of X3B dye was significantly enhanced by the synergetic effect of Fenton's reaction and photocatalytic oxidative reaction

\section{$<$ Please insert Fig.11 here $>$}

Guanghong et al., prepared a nanotube photocatalyst, using a co-deposition method and exploited for photocatalytic degradation of Methylene blue (MB) dye in aqueous solutions. Loading of small-sized $\lambda-\mathrm{Fe}_{2} \mathrm{O}_{3}$ particles onto $\mathrm{TiO}_{2}$ resulted in a modified binary photocatalyst $(\lambda$ - 
$\mathrm{Fe}_{2} \mathrm{O}_{3} @ \mathrm{TiO}_{2}$ ) with superparamagnetic behaviour. The saturation magnetization of $\lambda-\mathrm{Fe}_{3} \mathrm{O}_{4} @ \mathrm{TiO}_{2}$ was $1.32 \mathrm{~A} \mathrm{~m}^{2} \mathrm{~kg}^{-1}$ possessing higher photocatalytic activity as compared to pure $\mathrm{TiO}_{2}$. The improvement in photogenerated EHP separation and enhanced visible light activity was due to heterojunction formation interaction between $\mathrm{TiO}_{2}$ and $\lambda-\mathrm{Fe}_{2} \mathrm{O}_{3}$ [167].

Cheng et al., synthesized $\mathrm{Fe}_{3} \mathrm{O}_{4} @ \mathrm{TiO}_{2}$ photocatalyst by sol-gel method to study membrane disintegration of marine fish pathogens. Under blue LEDs light, $\mathrm{Fe}^{3+}$ and $\mathrm{FeTiO}_{3}$ together contributed in photocatalytic activity of $\mathrm{Fe}_{3} \mathrm{O}_{4} @ \mathrm{TiO}_{2}$ photocatalyst. Under seawater, the electrons and active sites were covered by inorganic ions present in seawater, and the consequence was a reduced photocatalytic activity for $\mathrm{Fe}_{3} \mathrm{O}_{4} @ \mathrm{TiO}_{2}$ photocatalyst in saline sea water. It was concluded that, underneath sea-water, the marine fish pathogens could be killed by $\mathrm{Fe}_{3} \mathrm{O}_{4} @ \mathrm{TiO}_{2}$ through activation by blue LEDs [168].

Zazouli et al., fabricated $\mathrm{Fe}_{3} \mathrm{O}_{4} @ \mathrm{TiO}_{2}$ photocatalyst by simple precipitation technique using ammonia. The catalytic activity of nano-sized ferric oxide photocatalyst was assessed by degradation of food dye in the vicinity of an electron acceptor; PMS (Peroxymonosulfate). Under UVA radiations, brilliant blue FCF (BBF) was totally decolorized in $60 \mathrm{~min}$, using reaction conditions of 0.8g-L FTNs, PMS-2.0 Mm, and pH -6.0. In the absence of UV light, PMS was activated by the catalytic activity of nanosized $\mathrm{Fe}_{3} \mathrm{O}_{4} @ \mathrm{TiO}_{2}$ photocatalyst. $\mathrm{Fe}_{3} \mathrm{O}_{4} @ \mathrm{TiO}_{2}$ photocatalyst was stable and reusable for four times during recycling test experiments. The saturation magnetization (Ms) of $52.6 \mathrm{emu} / \mathrm{g}$ demonstrated successful coating of $\mathrm{Fe}_{3} \mathrm{O}_{4}$ onto $\mathrm{TiO}_{2}$ surface. [169].

Jing et al., successfully developed $\mathrm{Fe}_{3} \mathrm{O}_{4} @ \mathrm{TiO}_{2}$ photocatalyst by the sol-gel method having superior quinoline degradation efficiency of $88.47 \%$ which was higher than $79.58 \%$ efficiency obtained by commercial $\mathrm{TiO}_{2}$ powder. Under UV-radiations, after three cycles of repetitive use, it displayed $84.60 \%$ of photodegradation efficacy which was still higher than the efficiency conferred by $\mathrm{TiO}_{2}$ powder (79.58\%). The saturation magnetization (Ms) of $\mathrm{Fe}_{3} \mathrm{O}_{4} @ \mathrm{TiO}_{2}$ (in molar

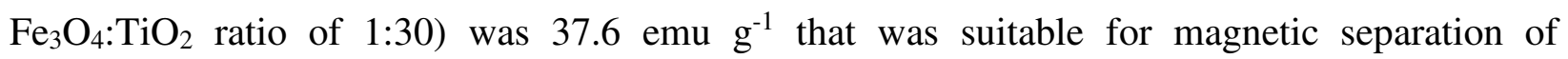
photocatalyst. The recycling experiments revealed that by using a permanent magnetic bar, $\mathrm{Fe}_{3} \mathrm{O}_{4} @ \mathrm{TiO}_{2}$ might be easily recovered from reaction solutions. Both magnetic property and photocatalytic activity of the fabricated photocatalyst were affected by the molar ratio of $\mathrm{Fe}_{3} \mathrm{O}_{4}$ to $\mathrm{TiO}_{2}$. The photodegradation of quinoline was improved by decreasing the molar ratio of $\mathrm{Fe}_{3} \mathrm{O}_{4}$ to 
$\mathrm{TiO}_{2}$ photocatalyst. However, magnetic separation was reduced with decrease in $\mathrm{Fe}_{3} \mathrm{O}_{4}$ content. Therefore, for improving both magnetic feature and the photocatalytic activity, it was essential to optimize the molar ratio of $\mathrm{Fe}_{3} \mathrm{O}_{4}$ to $\mathrm{TiO}_{2}[170]$.

Dehghan et al., prepared $\mathrm{ZnO} @ \mathrm{Fe}_{3} \mathrm{O}_{4}$ photocatalyst by supporting $\mathrm{ZnO}$ onto $\mathrm{Fe}_{3} \mathrm{O}_{4}$ surface for photodegradation of amoxicillin dye (AMX) under ultrasound (US) irradiation involving the formation of hydroxyl radical $(\bullet \mathrm{OH})$ as reactive species. The results exhibited that $90 \%$ of AMX dye was degraded in $120 \mathrm{~min}$. The photodegradation rate was significantly increased in the presence of $\mathrm{IO}_{4}^{-}$due to greater oxidation power. As prepared photocatalyst, exhibited significant recyclability for five catalytic cycles and even after fifth run the photocatalyst brought about an efficiency of more than $85 \%$. Under ultrasound irradiation, $\mathrm{Fe}_{3} \mathrm{O}_{4} @ \mathrm{ZnO}$ was cost-effective and acted as a promising sonocatalyst due to easier separation, reusability, high durability (even in acidic medium), and suitable photocatalytic performance for AMX dye removal from aqueous solution [171]. Fig.12 demonstrates the possible catalytic mechanism of $\mathrm{ZnO} @ \mathrm{Fe}_{3} \mathrm{O}_{4}$, in which both oxidation and desorption processes take place instantaneously. The reactive oxidizing species were found in the solution which indicated the degradation process took place in a homogenous solution, whereas heterogeneous catalysis occurred on $\mathrm{ZnO} @ \mathrm{Fe}_{3} \mathrm{O}_{4}$ surface. The ultrasound radiations caused the production of wide wavelength visible light due to the cavitation effect. In the next step, photogenerated EHP were produced (Eq. (2)) The generated $\mathrm{h}_{\mathrm{vb}}{ }^{+}$oxidized water molecules to produce hydroxyl free radical (Eq. (3) and (4)) and, at the same time, conduction band electrons $\left(\mathrm{e}_{\mathrm{CB}}{ }^{-1}\right)$ were reacting with dissolved oxygen and taking place of some series of reduction reactions led to production of the intermediates such as $\mathrm{H}_{2} \mathrm{O}_{2}, \mathrm{HO}_{2} \bullet, \bullet \mathrm{OH}$ and $\mathrm{O}_{2}^{-} \bullet$ in the conduction band.

$$
\begin{aligned}
& \left.\left.\left.\mathrm{ZnO} / \mathrm{Fe}_{3} \mathrm{O}_{4}\right)\right)\right) \rightarrow h_{V B^{+}}+e_{\mathrm{CB}^{-}} \\
& \mathrm{ZnO} / \mathrm{Fe}_{3} \mathrm{O}_{4}\left(h_{V B^{+}}\right)+\mathrm{H}_{2} \mathrm{O} \rightarrow \bullet \mathrm{OH}_{\text {ads }}+\mathrm{H}^{+} \\
& \mathrm{ZnO} / \mathrm{Fe}_{3} \mathrm{O}_{4}\left(e_{\mathrm{CB}^{-}}\right)+\mathrm{O}_{2} \rightarrow \mathrm{O}_{2}^{-\bullet} \\
& \mathrm{ZnO} / \mathrm{Fe}_{3} \mathrm{O}_{4}\left(e_{\mathrm{CB}^{-}}\right)+\mathrm{O}_{2}^{--}+2 \mathrm{H}^{+} \rightarrow \mathrm{H}_{2} \mathrm{O}_{2} \\
& \mathrm{O}_{2}^{\bullet-}+2 \mathrm{H}^{+} \rightarrow \mathrm{HO}_{2}^{\cdot} \\
& \bullet \mathrm{OH}+\mathrm{O}_{2}^{-\bullet}+\mathrm{H}_{2} \mathrm{O}_{2}+\mathrm{HO}_{2}^{-}+\mathrm{AMX} \rightarrow \text { Product } \rightarrow \mathrm{CO}_{2}+\mathrm{H}_{2} \mathrm{O}
\end{aligned}
$$


In the presence of US radiations, nanosized $\mathrm{Fe}_{3} \mathrm{O}_{4}$ particles were transformed into $\mathrm{Fe}^{2+}$ and $\mathrm{Fe}^{3+}$ ions, causing generation of more $\cdot \mathrm{OH}$ through Fenton reaction on catalyst surface between $\mathrm{H}_{2} \mathrm{O}_{2}$ molecules and $\mathrm{Fe}^{2+}$ and $\mathrm{Fe}^{3+}$ ions. Under parallel mechanisms, a number of reactive free radicals like ${ }^{\circ} \mathrm{OH}_{\text {(adsorbed) }}, \mathrm{HO}_{2}{ }^{\circ}$, and ${ }^{\circ} \mathrm{OH}_{\text {(free) }}$ were produced through: (a) thermal decomposition of water vapour under US radiations and (b) formation of $\cdot \mathrm{OH}$ free radicals on the surface of catalyst due to Fenton reaction between dissolved $\mathrm{Fe}^{2+}$ ions and $\mathrm{H}_{2} \mathrm{O}_{2}$ molecules. As a result, AMX dye was degraded by attack of ${ }^{\circ} \mathrm{OH}$ (ads) and ${ }^{\circ} \mathrm{OH}$ (free) radicals formed in liquid and solid phase to yield $\mathrm{CO}_{2}$ and $\mathrm{H}_{2} \mathrm{O}$ as the products (Eq. (7)) [171].

\section{<Please Insert Fig. 12 here>}

Goyal et al., synthesized $\mathrm{Fe}_{3} \mathrm{O}_{4} @ \mathrm{ZnO}$ photocatalyst by decorating $\mathrm{Fe}_{3} \mathrm{O}_{4}$ nanoparticles onto the surface of $\mathrm{ZnO}$ using the hydrothermal method to fabricate a catalyst with multifunctional photocatalytic activity for degradation of $\mathrm{MB}$ dye. The results claimed 50 ppm of $\mathrm{Fe}_{3} \mathrm{O}_{4} @ \mathrm{ZnO}$ was used to remove $82.9 \% \mathrm{MB}$ dye in $3 \mathrm{~h}$ reaction time. The saturation magnetization of $\mathrm{Fe}_{3} \mathrm{O}_{4}$ was $95 \mathrm{emu} \mathrm{g}^{-1}$ at $300 \mathrm{~K}$. Under UV radiations, removal efficiency of $12.9 \%$ was recorded for $\mathrm{Fe}_{3} \mathrm{O}_{4}$ particles after $3 \mathrm{~h}$. $\mathrm{Fe}_{3} \mathrm{O}_{4} @ \mathrm{ZnO}$ photocatalyst showed excellent photodegradation efficiency (90\%) after three successive photocatalytic cycles. After the treatment process, these nanocomposite particles were easily separated by an external magnetic field. The large surface area of $\mathrm{Fe}_{3} \mathrm{O}_{4} @ \mathrm{ZnO}$ showed large adsorption efficiency for $\mathrm{Cu}^{2+}$ and $\mathrm{Pb}^{2+}$ metal ions at $\mathrm{pH}$ 5.5. Antibacterial activity of $\mathrm{Fe}_{3} \mathrm{O}_{4} @ \mathrm{ZnO}$ was also studied against $S$. aureus and Escherichia coli (E.coli). It was established that the multifunctional $\mathrm{Fe}_{3} \mathrm{O}_{4} @ \mathrm{ZnO}$ photocatalyst was an adequate choice for potential application in degradation of organic dyes, exclusion of heavy metal ions, and bacteria removal [172].

$\mathrm{Xu}$ et al., developed $\mathrm{Fe}_{3} \mathrm{O}_{4} @ \mathrm{ZnO}$ microrods by an economic one-step synthesis route for photocatalytic tremendous degradation of $100 \% \mathrm{RhB}$ dye in a reaction time of $40 \mathrm{~min}$. The constructed photocatalyst showed excellent efficiency for the elimination of toxic metal ions $\left(\mathrm{Ni}^{2+}\right.$, $\mathrm{Hg}^{2+}, \mathrm{Co}^{2+}, \mathrm{Cd}^{2+}, \mathrm{Fe}^{3+}$ and $\left.\mathrm{Pb}^{2+}\right)$ than alone $\mathrm{Fe}_{3} \mathrm{O}_{4}$ and $\mathrm{ZnO}$ structures. Therefore, the researcher expected that this photocatalyst would find an industrial use for elimination of the unwanted pollutants from wastewater [173]. Fig.13 exhibits SEM images of ZF1, ZF2, ZF3, ZF4, ZF5 samples which, respectively, contain $0,0.125,0.167,0.25,0.5 \mathrm{mmol}$ of $\mathrm{FeCl}_{3} .6 \mathrm{H}_{2} \mathrm{O}$. $\mathrm{ZnO}$ had a rod-like morphology with one hexagonal trunk and two hexagonal tips (Fig.13 (a)). On addition 
of $\mathrm{FeCl}_{3} \cdot 6 \mathrm{H}_{2} \mathrm{O}$ to above sample, a flat end and regular hexagonal micro-sized $\mathrm{ZnO}$ rods were covered with $\mathrm{Fe}_{3} \mathrm{O}_{4}$ was detected (Fig.13 (b-d)). The diameter and length of $\mathrm{ZnO}$ micro-rods were in the range of 100-200 nm and 1-2 $\mu \mathrm{m}$, respectively. The nano-sized $\mathrm{Fe}_{3} \mathrm{O}_{4} @ \mathrm{ZnO}$ rods were obtained by addition of $0.25 \mathrm{mmol} \mathrm{FeCl}_{3} \cdot 6 \mathrm{H}_{2} \mathrm{O}$ to the sample as shown in Fig.13 (d). Fig.13 (e) depicts distortion in regular morphology of $\mathrm{ZnO}$ micro-rods with addition of $0.5 \mathrm{mmol} \mathrm{FeCl}_{3} \cdot 6 \mathrm{H}_{2} \mathrm{O}$ [173].

\section{<Please insert Fig.13 here>}

Xia et al., fabricated $\mathrm{Fe}_{3} \mathrm{O}_{4} @ \mathrm{ZnO}$ photocatalyst successfully via a superficial two-step scheme using different molar ratios of parent metal oxides. The outstanding photodegradation of methyl orange (MO) followed by first-order reaction kinetics model was explained on the basis of photocatalytic activity of $\mathrm{Fe}_{3} \mathrm{O}_{4} @ \mathrm{ZnO}$ photocatalyst. $0.51 \mathrm{gL}^{-1}$ catalyst was used to degrade $\mathrm{MO}$ dye with an initial concentration of $6.0 \times 10^{-5} \mathrm{~mol} \mathrm{~L}^{-1}$. Under UV light, $93.6 \%$ of MO was degraded at $\mathrm{pH} 7$ in $1 \mathrm{~h}$. The value of saturation magnetization (Ms) of $\mathrm{Fe}_{3} \mathrm{O}_{4} @ \mathrm{ZnO}$ was $67.72 \mathrm{emu} \mathrm{g}^{-1}$, whereas Ms value was $82.01 \mathrm{emu}^{-1}$ for $\mathrm{Fe}_{3} \mathrm{O}_{4}$. Studies conducted on five successive photocatalytic cycles revealed that as-prepared $\mathrm{Fe}_{3} \mathrm{O}_{4} @ \mathrm{ZnO}$ photocatalyst shows a tremendous photocatalytic activity in photodegradation of MO dye (above $70 \%$ degradation) in aqueous solution. It has been regarded as recyclable photocatalyst due to its catalytic activity that decreased slightly after five cycles of usage [174].

Sin et al., developed $\mathrm{Fe}_{3} \mathrm{O}_{4} @ \mathrm{ZnO}$ using a surfactant-free technique. $\mathrm{Fe}_{3} \mathrm{O}_{4} @ \mathrm{ZnO}$ had good optical properties, high purity, well crystallinity, and unique morphologies. Under visible light, $\mathrm{Fe}_{3} \mathrm{O}_{4} @ \mathrm{ZnO}$ photocatalyst displayed excellent photocatalytic ability for elimination of phenol and inactivation of E. coli. Efficient separation of the EHP resulted in enhanced photocatalytic activity of $\mathrm{Fe}_{3} \mathrm{O}_{4} @ \mathrm{ZnO}$ photocatalyst. The saturation magnetization value of photocatalyst was $2.81 \mathrm{emu}$ $\mathrm{g}^{-1}$ that facilitated the separation of $\mathrm{Fe}_{3} \mathrm{O}_{4} @ \mathrm{ZnO}$ from aqueous solution by applying an external magnetic field. Thus, magnetic separation of $\mathrm{Fe}_{3} \mathrm{O}_{4} @ \mathrm{ZnO}$ photocatalyst was helpful in wastewater treatment. $\mathrm{Fe}_{3} \mathrm{O}_{4} @ \mathrm{ZnO}$ maintained high photocatalytic activity after four catalytic cycles of usage [175].

Li et al., constructed $\mathrm{Fe}_{3} \mathrm{O}_{4} @ \mathrm{ZnO}$ photocatalyst with aid of hydrothermal atomic layer deposition method for photocatalytic removal of phosphate from wastewater. The improvement in electrostatic interaction and surface area of $\mathrm{Fe}_{3} \mathrm{O}_{4} @ \mathrm{ZnO}$ photocatalyst caused $94.8 \%$ removal of 
phosphate in 5 min under a weak magnetic field. In addition, multilayer adsorption due to innersphere complexation was responsible for removal of phosphorous by photocatalyst. The saturation magnetization value of $\mathrm{Fe}_{3} \mathrm{O}_{4}$ was $69.6 \mathrm{emu} \mathrm{g}^{-1}$, which slightly decreased after heterojunction formed between $\mathrm{Fe}_{3} \mathrm{O}_{4}$ and $\mathrm{ZnO}$, and consequently $\mathrm{Ms}$ value for $\mathrm{Fe}_{3} \mathrm{O}_{4} @ \mathrm{ZnO}$ was 60.7 emu g ${ }^{-1}$. Reusability of magnetic $\mathrm{Fe}_{3} \mathrm{O}_{4} @ \mathrm{ZnO}$ adsorbent examined by adsorption-desorption processes for successive catalytic cycles under weak magnetic field, and only $7.1 \%$ decrease was observed after five cycles. The magnetic separation of photocatalyst resulted in real time application of photocatalyst for pollutants remediation from water [176].

Karunakaran et al., prepared $\mathrm{Fe}_{3} \mathrm{O}_{4} @ \mathrm{SnO}_{2}$ photocatalyst using both sonochemical and hydrothermal method for photodegradation of an industrial pollutant (phenol) under visible light. It was concluded that the hydrothermally prepared $\mathrm{Fe}_{3} \mathrm{O}_{4} @ \mathrm{SnO}_{2}$ photocatalyst displayed better photocatalytic activity than the photocatalyst prepared by the sonochemical method. The decreased catalytic activity of sonochemically prepared photocatalyst was due to the low concentration of $\mathrm{SnO}_{2}$. The saturation magnetization of $\mathrm{Fe}_{3} \mathrm{O}_{4} @ \mathrm{SnO}_{2}$ prepared photocatalyst was 1.5 and 3.6 emu $\mathrm{g}^{-1}$ for sonochemical and hydrothermal methods, respectively. Furthermore, the bactericidal activity of $\mathrm{Fe}_{3} \mathrm{O}_{4} @ \mathrm{SnO}_{2}$ was reported for E.coli inactivation, and the bactericidal activity of hydrothermally prepared photocatalyst was higher than the sonochemically prepared one [177]. $100 \%$ of E.coli inactivation was achieved in 20 min using hydrothermally prepared $\mathrm{Fe}_{3} \mathrm{O}_{4} @ \mathrm{SnO}_{2}$, while using sonochemically prepared $\mathrm{Fe}_{3} \mathrm{O}_{4} @ \mathrm{SnO}_{2}$ resulted in $80 \%$ of E.coli inactivation in 20 $\min$.

Dong et al., used a two-step hydrothermal technique to prepare efficient $\mathrm{Fe}_{3} \mathrm{O}_{4} @ \alpha-\mathrm{MnO}_{2}$ photocatalyst nanoflower. The photocatalytic activity of $\mathrm{Fe}_{3} \mathrm{O}_{4} @ \alpha-\mathrm{MnO}_{2}$ was examined by activation of persulfate (PS) for degradation of $92 \%$ bisphenol A (BPA) in aqueous solution. Due to the synergetic effect of manganese, iron, and hydroxyl groups on $\mathrm{Fe}_{3} \mathrm{O}_{4} @ \alpha-\mathrm{MnO}_{2}$ surface, $\mathrm{Fe}_{3} \mathrm{O}_{4} @ \alpha-\mathrm{MnO}_{2}$ photocatalyst showed high TOC removal and degradation rates [178]. Fig.14 (a) demonstrates the photocatalytic mechanism of $\mathrm{Fe}_{3} \mathrm{O}_{4} @ \alpha-\mathrm{MnO}_{2} @ \mathrm{PS}$ system. $\mathrm{MnO}_{2}$ activated persulfate ions produced more free radicals as compared to $\mathrm{Fe}_{3} \mathrm{O}_{4}$. Briefly, $\mathrm{S}_{2} \mathrm{O}_{8}{ }^{2-}$ reacted with $\alpha$ $\mathrm{MnO}_{2}$ through $-\mathrm{OH}$ for reduction of $\mathrm{Mn}^{4+}$ to $\mathrm{Mn}^{3+}$ and generation $\mathrm{S}_{2} \mathrm{O}_{8}{ }^{-}$. In the next step, $\mathrm{Fe}^{2+}$ ions from $\mathrm{Fe}_{3} \mathrm{O}_{4}$ promoted the decomposition of $\mathrm{S}_{2} \mathrm{O}_{8}{ }^{*-}$ to form $\mathrm{SO}_{4}{ }^{--}$ions. $\mathrm{SO}_{4}{ }^{*-}$ ions reacted with water to generate hydroxyl radicals. The degradation of organic pollutant BPA was accomplished 
by hydroxyl radical due to synergistic contact among Mn, Fe, and surface-OH groups. Fig.14 (b) shows the magnetic hysteresis loop of photocatalyst indicating a remarkable super-paramagnetism and saturation magnetization value of $39.9 \mathrm{emu} \mathrm{g}^{-1}$. Due to its excellent stability and reusability characteristics, $\mathrm{Fe}_{3} \mathrm{O}_{4} @ \alpha-\mathrm{MnO}_{2} @ \mathrm{PS}$ system maintained a catalytic efficiency of 80\% after five successively catalytic cycles [178].

\section{$<$ Please insert Fig. 14 here $>$}

Zhang et al., prepared hollow spheres of $\mathrm{Fe}_{3} \mathrm{O}_{4} @ \mathrm{MnO}_{2}$ photocatalyst via the hydrothermal method for the extraction of uranium (VI) from aqueous solution. The saturation magnetization value of $\mathrm{Fe}_{3} \mathrm{O}_{4} @ \mathrm{MnO}_{2}$ was $~ 22.7 \mathrm{emu} \mathrm{g}^{-1}$. At $\mathrm{pH}>7$, absorption and desorption processes were independent on ionic strength, whereas at $\mathrm{pHs}$ below 7 both processes of adsorption and desorption were ionic strength dependent. The reaction temperature controlled both adsorption and desorption processes of uranium (VI) onto $\mathrm{Fe}_{3} \mathrm{O}_{4} @ \mathrm{MnO}_{2}$ hollow spheres. These adsorption and desorption reactions were endothermic, irreversible, and spontaneous. The hollow spheres of $\mathrm{Fe}_{3} \mathrm{O}_{4} @ \mathrm{MnO}_{2}$ photocatalyst were used in nuclear waste management for sorption of uranium (VI). By virtue of easy separation, high removal efficiency, and eco-friendly performance, $\mathrm{Fe}_{3} \mathrm{O}_{4} @ \mathrm{MnO}_{2}$ hollow spheres had a valuable potential for uranium (VI) removal in nuclear waste [179].

Zhao et al., reported $\mathrm{Fe}_{3} \mathrm{O}_{4} @ \mathrm{MnO}_{2}$ photocatalyst using mild hydrothermal process for removing heavy metals, like $\mathrm{Cu}^{2+}, \mathrm{Pb}^{2+}, \mathrm{Cd}^{2+} \mathrm{Ni}^{2+}$ and $\mathrm{Zn}^{2+}$, from the water media. The saturation magnetization value of 17.28 emu $\mathrm{g}^{-1}$ confirmed easier separation of $\mathrm{Fe}_{3} \mathrm{O}_{4} @ \mathrm{MnO}_{2}$ from the reaction solution. The negatively charged surface at $\mathrm{pHs}>2.6$ and high surface area of $\mathrm{Fe}_{3} \mathrm{O}_{4} @ \mathrm{MnO}_{2}$ was confirmed by some physical analyses. The adsorption behaviour of $\mathrm{Fe}_{3} \mathrm{O}_{4} @ \mathrm{MnO}_{2}$ was examined by Langmuir and Temkin and Redlich-Peterson adsorption models. The metal ions $\mathrm{Zn}^{2+}, \mathrm{Cd}^{2+}, \mathrm{Cu}^{2+}, \mathrm{Pb}^{2+}$, and $\mathrm{Ni}^{2+}$ showed, respectively, 100.24, 169.90, 111.90, 208.17, and $55.63 \mathrm{mg} / \mathrm{g}$ adsorption capacities. The removal process fitted well with the pseudosecond-order model $\left(\mathrm{R}^{2}>0.99\right)$. Reusability experiments were performed to examine the stability of $\mathrm{Fe}_{3} \mathrm{O}_{4} @ \mathrm{MnO}_{2}$ and $10 \%$ decrease was observed in removal efficiency after four catalytic cycles. Therefore, results revealed that $\mathrm{Fe}_{3} \mathrm{O}_{4} @ \mathrm{MnO}_{2}$ had high efficiency for adsorption of heavy metals from water owing to its good recyclability and environment-friendly behaviour [180].

Yang et al., synthesized flower-like core-shell $\mathrm{MnO}_{2}$-coated $\mathrm{Fe}_{3} \mathrm{O}_{4}$ magnetic composite $\left(\mathrm{Fe}_{3} \mathrm{O}_{4} @ \mathrm{MnO}_{2}\right)$ by simple hydrothermal method. $\mathrm{Fe}_{3} \mathrm{O}_{4} @ \mathrm{MnO}_{2}$ composite particles had a size in 
the range of 300-400 $\mathrm{nm}$ with an amorphous $\mathrm{MnO}_{2}$ shell having flower-like appearance. The composite had a specific surface area of $149.0 \mathrm{~m}^{2} \mathrm{~g}^{-1}$ and saturation magnetization of $32 \mathrm{emu} \mathrm{g}^{-1}$ at $300 \mathrm{~K} . \mathrm{Fe}_{3} \mathrm{O}_{4} @ \mathrm{MnO}_{2}$ composite selectively removed Congo red (CR) from aqueous media from a solution containing several dyes $\mathrm{CR}$, crystal violet $(\mathrm{CV}), \mathrm{RhB}, \mathrm{MB}$, and $\mathrm{MO}$ dyes. $\mathrm{CR}$ had the highest elimination rate of $95 \%$ compared with the other undertaken dyes which had removal rates lower than $15 \%$. The electrostatic interaction between dye molecules and photocatalyst was in charge for the higher absorption capacity of $\mathrm{Fe}_{3} \mathrm{O}_{4} @ \mathrm{MnO}_{2}$ for CR dye [181].

Fang et al., developed a heterogeneous Fenton system similar to $\mathrm{Fe}_{3} \mathrm{O}_{4} @ \mathrm{MnO}_{2}$ core-shell catalyst for removal of $96.8 \%$ azo dye acid orange 7 (AO7) in $120 \mathrm{~min}$ from wastewater. The catalytic activity of $\mathrm{Fe}_{3} \mathrm{O}_{4} @ \mathrm{MnO}_{2}$ core- shell catalyst was superior to that of bare $\mathrm{Fe}_{3} \mathrm{O}_{4}$ or $\mathrm{MnO}_{2}$. The removal of $\mathrm{AO} 7$ dye was affected by various reaction parameters like initial $\mathrm{pH}$, catalyst dosage, $\mathrm{H}_{2} \mathrm{O}_{2}$ dosage, and temperature. The saturation magnetization value of $\mathrm{Fe}_{3} \mathrm{O}_{4} @ \mathrm{MnO}_{2}$ was $45.32 \mathrm{emu} \mathrm{g}^{-1}$. After seven catalytic cycles, the efficiency of removal process of AO7 was reduced from 96.8 to $83.1 \%$ thus, displaying high degree of stability and reusability [182]. Fig. 15 displays the proposed mechanism for the degradation of $\mathrm{AO} 7$ in $\mathrm{Fe}_{3} \mathrm{O}_{4} @ \mathrm{MnO}_{2} / \mathrm{H}_{2} \mathrm{O}_{2}$ system. The radical quenching tests were performed for identification of free radical species in catalytic mechanism. The chloroform and TBA were exploited as a scavenger for $\mathrm{O}_{2} \bullet^{-}$and hydroxyl radical, respectively. In the first step, $\mathrm{H}_{2} \mathrm{O}_{2}$ was adsorbed on top of the surface of catalyst (Eq. (8)) and $\mathrm{HO}_{2} \bullet$ was formed, whereas $\mathrm{Mn}^{4+}$ was reduced to $\mathrm{Mn}^{2+}$ (Eq. (9)). On reacting with $\mathrm{H}_{2} \mathrm{O}_{2}, \mathrm{Fe}^{3+}$ in $\mathrm{Fe}_{3} \mathrm{O}_{4}$ was also reduced to $\mathrm{Fe}^{2+}$ (Eq. (10)). The generated $\mathrm{Fe}^{2+}$ got into reaction with $\mathrm{Mn}^{4+}$ to produce $\mathrm{Fe}^{3+}$ and $\mathrm{Mn}^{2+}$ (Eq. (11)). Moreover, $\mathrm{Mn}^{2+}$ species might react back with $\mathrm{H}_{2} \mathrm{O}_{2}$ to release the $\mathrm{HO} \cdot$ in the solution as shown in Eq. (12). $\mathrm{HO}_{2} \bullet$ radical decomposed into $\mathrm{H}^{+}$and $\mathrm{O}_{2} \bullet^{-}$as presented by Eq. (13). Finally, HO• oxidized AO7 dye to the final degraded product as shown in Eq. (14) [182].

$$
\begin{aligned}
& \mathrm{Mn}^{4+}+\mathrm{H}_{2} \mathrm{O}_{2} \rightarrow \mathrm{Mn}^{4+} \bullet \mathrm{H}_{2} \mathrm{O}_{2} \\
& \mathrm{Mn}^{4+} \bullet \mathrm{H}_{2} \mathrm{O}_{2} \rightarrow \mathrm{Mn}^{2+}+\mathrm{HO}_{2}^{\bullet} \\
& \mathrm{Fe}^{3+}+\mathrm{H}_{2} \mathrm{O}_{2} \rightarrow \mathrm{Fe}^{2+}+\mathrm{HO}_{2} \\
& \mathrm{Fe}^{2+}+\mathrm{Mn}^{4+} \rightarrow \mathrm{Mn}^{2+}+\mathrm{Fe}^{3+} \\
& \mathrm{Mn}^{2+}+\mathrm{H}_{2} \mathrm{O}_{2} \rightarrow \mathrm{Mn}^{4+}+\mathrm{HO} \bullet
\end{aligned}
$$




$$
\mathrm{HO}_{2}^{\bullet} \rightarrow \mathrm{H}^{+}+\mathrm{O}_{2}^{--}
$$

$\mathrm{HO} \bullet+\mathrm{AO} 7 \rightarrow$ degrdaed products

\section{$<$ Please insert Fig.15 here $>$}

\section{Iron Oxide modified ternary photocatalyst}

\subsection{Iron oxide modified ternary metal oxide photocatalyst}

Yingzhe et al., proposed a new aqueous solution ball milling technique for the synthesis of ternary nano-magnetic $\mathrm{Cu} @ \mathrm{Fe} @ \mathrm{Fe}_{3} \mathrm{O}_{4}$ photocatalyst at room temperature using electromagnetic field of high frequency with no residue or waste gas production. The non-thermal effect of microwave triggered the catalytic activity of $\mathrm{Cu} @ \mathrm{Fe} @ \mathrm{Fe}_{3} \mathrm{O}_{4}$ for $\mathrm{MB}$ dye with saturation magnetization to be $38.56 \mathrm{emu} \mathrm{g}^{-1}$. Further, some marvelous soft-magnetic characteristics were exhibited by nano-size photocatalysts and its particles were easily attracted by external magnetic field. The magnetic photocatalysts could be effortlessly re-dispersed in the solution after the removal of the external magnetic field. The aqueous solution ball milling technique aided by high frequency was found to be a potential method for preparation of nano-sized $\mathrm{Cu} @ \mathrm{Fe} @ \mathrm{Fe}_{3} \mathrm{O}_{4}$ photocatalyst [183].

Hou et al., described the preparation of $\mathrm{Fe}_{3} \mathrm{O}_{4} @ \mathrm{SiO}_{2} @ \mathrm{Bi}_{2} \mathrm{MoO}_{6}$ microspheres by using the hydrothermal technique for $\mathrm{RhB}$ dye degradation under visible light irradiation. $\mathrm{Fe}_{3} \mathrm{O}_{4} @ \mathrm{SiO}_{2}$ magnetic nanoparticles were fixed up with three-dimensional flower-like structure of $\mathrm{Bi}_{2} \mathrm{MoO}_{6}$ as observed in a scanning electron microscope (SEM). More absorption of light in the visible region was observed for photocatalyst as compared to pure $\mathrm{Bi}_{2} \mathrm{MoO}_{6}$ with saturation magnetization value to be $5 \mathrm{emu} \mathrm{g}^{-1}$ of obtained nanocomposite. Under an external magnetic field, the nanocomposite was easily separated with reproducibility of five cycles from the reaction mixture [184].

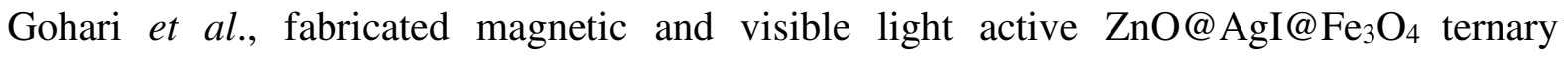
nanocomposites by ultrasonic wave assisted method for various dyes under the visible-light irradiation. The as-prepared nanocomposite possessed 5, 6 and 32 folds more powerful photocatalytic activity than $\mathrm{ZnO} @ \mathrm{Fe}_{3} \mathrm{O}_{4}$ for $\mathrm{MO}, \mathrm{MB}$, and $\mathrm{RhB}$ dye degradation, respectively. The photocatalyst was separated in the presence of an external magnetic field and was efficient for four catalytic cycles, with no loss in photocatalytic activity. More harvesting of visible light, 
magnetic separation and the effective separation of photo generated EHP resulted in an enhanced activity of this ternary photocatalyst [185].

\subsection{Iron oxides modified ternary carbon based photocatalyst}

Vartooni et al., used carbonization of waste red water of 2, 4, 6-trinitrotoluene to prepare porous carbon via co-precipitation procedure for synthesis of porous carbon and $\mathrm{Ag} @ \mathrm{Fe}_{3} \mathrm{O}_{4} @ \mathrm{C}$ nanocomposite. Using Caesalpinia gilliesii flower aqueous extract, the $\mathrm{Ag}^{+}$was reduced to $\mathrm{Ag}$ nanoparticles (Ag NPs) and stabilized on the surface of carbon support. A few minutes were sufficient for generation of Ag NPs at ambient temperature. Several characterizing techniques such as FTIR, Raman, BET, FESEM, TEM, EDS, XRD, elemental mapping, and VSM techniques were used the nanocomposites as well as the synthesized porous carbon. FESEM and TEM micrographs

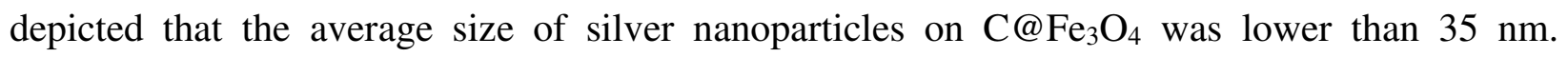
$\mathrm{Ag} @ \mathrm{Fe}_{3} \mathrm{O}_{4} @ \mathrm{C}$ had $\mathrm{M}_{\mathrm{s}}$ value of 17 emu g ${ }^{-1}$ and exhibited catalytic activity for the reduction of 4nitrophenol (4-NP) and MO dye. Moreover, the catalyst was re-used for 3 times without substantial loss in its activity [186].

Tian et al., synthesized $\mathrm{Fe}_{3} \mathrm{O}_{4} @ \mathrm{C} @ \mathrm{ZnO}$ ternary photocatalyst by a facile one-pot technique using lignin amide (LA) as a source of carbon and bridging ligand. This composite consisted of hexagonal wurtzite $\mathrm{ZnO}$, amorphous carbon, and cubic spinal $\mathrm{Fe}_{3} \mathrm{O}_{4}$. The particle size of $\mathrm{Fe}_{3} \mathrm{O}_{4} @ \mathrm{C} @ \mathrm{ZnO}(20 \mathrm{~nm})$ was larger than those of $\mathrm{Fe}_{3} \mathrm{O}_{4} @ \mathrm{ZnO}$ and $\mathrm{Fe}_{3} \mathrm{O}_{4}$, approximately. Under visible light and ultraviolet radiations, $\mathrm{Fe}_{3} \mathrm{O}_{4} @ \mathrm{C} @ \mathrm{ZnO}$ photocatalyst showed greater efficacy of degradation for organic pollutants. $94 \%$ of catalytic activity was maintained after 5 times of recycling for antibody norfloxacin (NF) [187]. After calcination of $\mathrm{Fe}_{3} \mathrm{O}_{4} @ \mathrm{LA}, \mathrm{Fe}_{3} \mathrm{O}_{4}$ was covered with a thin layer of carbon to form $\mathrm{Fe}_{3} \mathrm{O}_{4} @ \mathrm{C}$ (Fig.16 (a)). As exhibited in Fig. 16 (b) and (c), the size of $\mathrm{Fe}_{3} \mathrm{O}_{4} @ \mathrm{C} @ \mathrm{ZnO}$ was found to be the in range of 20-40 nm. The HR-TEM image of $\mathrm{Fe}_{3} \mathrm{O}_{4} @ \mathrm{C} @ \mathrm{ZnO}$ photocatalyst is displayed in Fig.16 (d) shows lattice d-spacing of approximately $0.16 \mathrm{~nm}$ and $0.25 \mathrm{~nm}$ which confirmed phase of $\mathrm{ZnO}$ (110) plane and the phase of $\mathrm{Fe}_{3} \mathrm{O}_{4}(311)$ plane respectively. Fig. 16(e) demonstrates pore size distribution plots and adsorption-desorption isothermal curves of $\mathrm{Fe}_{3} \mathrm{O}_{4} @ \mathrm{C} @ \mathrm{ZnO}$ photocatalyst and $\mathrm{Fe}_{3} \mathrm{O}_{4} @ \mathrm{ZnO}$. The average pore size and specific surface area of 0.5- $\mathrm{Fe}_{3} \mathrm{O}_{4} @ \mathrm{C} @ \mathrm{ZnO}$ was, respectively, $60 \mathrm{~nm}$ and $14.91 \mathrm{~m}^{2} \mathrm{~g}^{-1}$. On the other hand, $\mathrm{Fe}_{3} \mathrm{O}_{4} @ \mathrm{C} @ \mathrm{ZnO}-0.5$ mesoporous photocatalyst was prepared without LA with pore size of $15 \mathrm{~nm}$ and surface area of $97.01 \mathrm{~m}^{2} \mathrm{~g}^{-1}$, which was 6.5 times greater than the synthesized 
$\mathrm{Fe}_{3} \mathrm{O}_{4} @ \mathrm{ZnO}$. These results led to a conclusion that a large surface area of the ternary photocatalyst raised photocatalytic for NF antibody removal [187].

\section{<Please insert Fig.16 here>}

\subsection{Iron oxides modified ternary grapheme-based photocatalyst}

Recently, graphene has emerged as a star candidate for production of supported photocatalysts. Cheng et al., fabricated P25@graphene@ $\mathrm{Fe}_{3} \mathrm{O}_{4}$ ternary hybrid nanocomposite by immobilizing $\mathrm{Fe}_{3} \mathrm{O}_{4}$ and $\mathrm{TiO}_{2}(\mathrm{P} 25)$ nanoparticles on reduced graphene oxide using superficial technique. P25@graphene@ $\mathrm{Fe}_{3} \mathrm{O}_{4}$ nanocomposite showed a great activity for degradation of $\mathrm{RhB}$ dye in water, so that $100 \%$ of the dye was degraded in 25 min under UV light. In the presence of an external magnetic field, saturation magnetization value of P25@graphene@ $\mathrm{Fe}_{3} \mathrm{O}_{4}$ was 5.276 emu $\mathrm{g}^{-1}$ which ensured magnetic separation of photocatalyst particles from solution. The magnetically separated photocatalyst was used for five consecutive cycles with no activity loss [188]. Banerjee et al., also synthesized ternary nanocomposites via a facile sol-gel technique for degradation of $\mathrm{MB}$ dye using ferric oxide, $\mathrm{TiO}_{2}$ and reduced graphene oxide (GO) integrated rGO@ $\mathrm{Fe}_{3} \mathrm{O}_{4} @ \mathrm{TiO}_{2}$ photocatalyst. The rapid elimination of $\mathrm{MB}$ dye caused 99\% removal attainment in $6 \mathrm{~min}$, under UV light, while under visible light $94 \%$ of dye was removed in 9 min. The high photocatalytic dye removal ability of synthesized nanocomposite was ascribed to synergistic effect of three components present in photocatalysts. The highest removal of MB dye

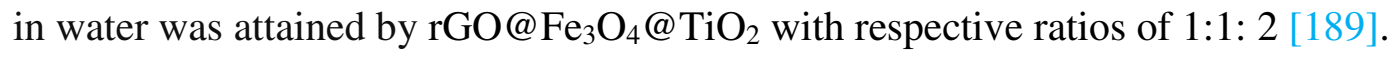

Mousavi et al., synthesized $\mathrm{g}-\mathrm{C}_{3} \mathrm{~N}_{4} @ \mathrm{Fe}_{3} \mathrm{O}_{4} @ \mathrm{MnWO}_{4}$ ternary photocatalyst using the refluxing-calcination technique for photocatalytic degradation of $\mathrm{MB}, \mathrm{RhB}, \mathrm{MO}$, and Fuchsin dyes under visible light. The photocatalytic elimination of RhB dye was influenced by different conditions involving the calcination temperature, $\mathrm{MnWO}_{4}$ content, and reflux time. The maximum photocatalytic activity was shown by $\mathrm{g}_{-} \mathrm{C}_{3} \mathrm{~N}_{4} @ \mathrm{Fe}_{3} \mathrm{O}_{4} @ \mathrm{MnWO}_{4}(10 \%)$ at the ideal $\mathrm{MnWO}_{4}$ content. The photocatalytic activity of g- $\mathrm{C}_{3} \mathrm{~N}_{4} @ \mathrm{Fe}_{3} \mathrm{O}_{4} @ \mathrm{MnWO}_{4}$ was 7 times higher for RhB dye degradation, 10 times higher for MB dye degradation, 25 times higher for MO degradation, and 31 times higher for Fuchsin dye degradation than pure $\mathrm{C}_{3} \mathrm{~N}_{4}$. The outstanding photocatalytic activity of ternary photocatalyst was due to large BET specific surface area and better separation of charge carriers [190]. The M-H magnetization curves of g- $\mathrm{C}_{3} \mathrm{~N}_{4} @ \mathrm{Fe}_{3} \mathrm{O}_{4} @ \mathrm{MnWO}_{4}(10 \%)$ and $\mathrm{Fe}_{3} \mathrm{O}_{4}$ were obtained to investigate magnetic properties. The obtained curves revealed the 
superparamagnetic nature of photocatalyst which is due to zero value of magnetic remanence. The saturation magnetization of 19.5 and 55.8 emu g ${ }^{-1}$ were recorded for $\mathrm{g}-\mathrm{C}_{3} \mathrm{~N}_{4} @ \mathrm{Fe}_{3} \mathrm{O}_{4} @ \mathrm{MnWO}_{4}$ $(10 \%)$ and $\mathrm{Fe}_{3} \mathrm{O}_{4}$, respectively. The lower magnetization value of $\mathrm{g}-\mathrm{C}_{3} \mathrm{~N}_{4} @ \mathrm{Fe}_{3} \mathrm{O}_{4} @ \mathrm{MnWO}_{4}$ (10\%) revealed the easy separation of photocatalyst by a magnet. Fig.17 (b) demonstrates photocatalytic degradation of $\mathrm{RhB}$ dye using $\mathrm{g}_{-} \mathrm{C}_{3} \mathrm{~N}_{4} @ \mathrm{Fe}_{3} \mathrm{O}_{4} @ \mathrm{MnWO}_{4}$ photocatalysts. The enhanced photoactivity of photocatalyst was due to transfer of photo-exciton at the exposed surface of photocatalyst components in $\mathrm{g}-\mathrm{C}_{3} \mathrm{~N}_{4} @ \mathrm{Fe}_{3} \mathrm{O}_{4} @ \mathrm{MnWO}_{4}$. Both $\mathrm{g}-\mathrm{C}_{3} \mathrm{~N}_{4}$ and $\mathrm{MnWO}_{4}$ produced EHP in their respective conduction band and valence band. The photoexcited electrons were transferred from $\mathrm{CB}$ of $\mathrm{g}-\mathrm{C}_{3} \mathrm{~N}_{4}$ to $\mathrm{CB}$ of $\mathrm{Fe}_{3} \mathrm{O}_{4}$ and $\mathrm{MnWO}_{4}$ due to more negative potential of $\mathrm{CB}$ of $\mathrm{g}_{-} \mathrm{C}_{3} \mathrm{~N}_{4}$ than those $\mathrm{Fe}_{3} \mathrm{O}_{4}$ and $\mathrm{MnWO}_{4}$. Alternatively, photogenerated holes of $\mathrm{MnWO}_{4}$ were transferred to less positive valence band potential of $\mathrm{g}-\mathrm{C}_{3} \mathrm{~N}_{4}$. Due to the appropriate band potential of $\mathrm{MnWO}_{4}$, reduction of $\mathrm{O}_{2}$ to $\mathrm{H}_{2} \mathrm{O}_{2}$ was completed. On the other hand, reduction of $\mathrm{O}_{2}$ to ${ }^{\cdot} \mathrm{O}_{2}{ }^{-}$ was not possible by electrons present in the $\mathrm{CB}$ of $\mathrm{Fe}_{3} \mathrm{O}_{4}$ and $\mathrm{MnWO}_{4}$. The holes occupying VB of $\mathrm{g}-\mathrm{C}_{3} \mathrm{~N}_{4}$ would directly oxidize targeted dye pollutants into $\mathrm{CO}_{2}, \mathrm{H}_{2} \mathrm{O}$, and inorganic ions (Fig.17 (b)) [190].

\section{$<$ Please Insert Fig.17 here $>$}

Yangieh et al., fabricated visible light-active magnetically separable g$\mathrm{C}_{3} \mathrm{~N}_{4} @ \mathrm{Fe}_{3} \mathrm{O}_{4} @ \mathrm{Ag}_{2} \mathrm{CrO}_{4}$ photocatalysts for effective removal of $\mathrm{RhB}$ dye. The highest photocatalytic activity obtained was 3 times greater than that of pure $g-\mathrm{C}_{3} \mathrm{~N}_{4}$ and 5 times more than that of the $g-\mathrm{C}_{3} \mathrm{~N}_{4} @ \mathrm{Fe}_{3} \mathrm{O}_{4}$, with $20 \%$ concentration of ternary nanocomposite, under same reaction conditions. The increased separation of charge carriers and appropriate positioning of bands in nanocomposite promoted performance of $g-\mathrm{C}_{3} \mathrm{~N}_{4} @ \mathrm{Fe}_{3} \mathrm{O}_{4} @ \mathrm{Ag}_{2} \mathrm{CrO}_{4}$ nanocomposites [191]. The saturation magnetization of $12.9 \mathrm{emu} \mathrm{g}^{-1}$ facilitated quick separation of photocatalysts from the reaction solution. The $\mathrm{RhB}$ dye was degraded in 360 min using $\mathrm{C}_{3} \mathrm{~N}_{4} @ \mathrm{Fe}_{3} \mathrm{O}_{4} @ \mathrm{Ag}_{2} \mathrm{CrO}_{4}$ (20\%) photocatalyst.

Mousavi et al., synthesized magnetically separable ternary g- $\mathrm{C}_{3} \mathrm{~N}_{4} @ \mathrm{Fe}_{3} \mathrm{O}_{4} @ \mathrm{BiOI}$ photocatalyst under ultrasonication radiations. The synthesized photocatalyst possessed photocatalytic degradation ability which was 10, 22 and 21 times higher than that of bare $g-\mathrm{C}_{3} \mathrm{~N}_{4}$ for $\mathrm{RhB}, \mathrm{MB}$ and MO dyes, respectively. The more effective separation of EHP and more utility 
of visible light irradiation resulted in an outstanding activity of the magnetic photocatalyst [192]. Fig. 18(a) describes the plausible mechanism for the photocatalytic ability of as-prepared photocatalyst. Compared to $\mathrm{g}-\mathrm{C}_{3} \mathrm{~N}_{4}$, BiOI had lower energy values for valence band as well as for conduction band. The potential of the conduction band of $\mathrm{g}-\mathrm{C}_{3} \mathrm{~N}_{4}$ was more negative than $\mathrm{O}_{2} / \bullet \mathrm{O}_{2}{ }^{-}$ , thus the produced electrons in the conduction band of $\mathrm{g}-\mathrm{C}_{3} \mathrm{~N}_{4}$ were transferred effortlessly to the conduction band of $\mathrm{BiOI}$ and a few of them reacted with $\mathrm{O}_{2}$ to produce $\cdot \mathrm{O}_{2}{ }^{-}$. On the other hand, electrons in the $\mathrm{CB}$ of $\mathrm{BiOI}$ could not reduce $\mathrm{O}_{2}$ to $\mathrm{O}_{2}^{-}$because of the more positive potential of BiOI than $\mathrm{O}_{2} / \cdot \mathrm{O}_{2}^{-}$. The electrons in $\mathrm{CB}$ of $\mathrm{BiOI}$ reacted $\mathrm{O}_{2}$ and $\mathrm{H}^{+}$ion to produce $\mathrm{H}_{2} \mathrm{O}_{2}$. After this, $\cdot \mathrm{OH}$ were produced by the decomposition of $\mathrm{H}_{2} \mathrm{O}_{2}$. Although the valence band potential of $\cdot \mathrm{OH} / \mathrm{H}_{2} \mathrm{O}$ and $\bullet \mathrm{OH} /{ }^{-} \mathrm{OH}$ were more positive than the $\mathrm{VB}$ potential of $\mathrm{g}-\mathrm{C}_{3} \mathrm{~N}_{4}$ and $\mathrm{BiOI}$, no reaction was taken place between the photo generated holes and adsorbed $\mathrm{H}_{2} \mathrm{O}$ an ${ }^{-} \mathrm{OH}$, to produce $\cdot \mathrm{OH}$ radical. The main reactive species involved in degradation of $\mathrm{RhB}$ dye were $\bullet \mathrm{OH}$ radicals and holes.

Fig. 18(b) illustrates the magnetization curve for $\mathrm{Fe}_{3} \mathrm{O}_{4}$ and $\mathrm{g}-\mathrm{C}_{3} \mathrm{~N}_{4} @ \mathrm{Fe}_{3} \mathrm{O}_{4} @ \mathrm{BiOI}$ photocatalyst. After heterojunction formation between $\mathrm{g}-\mathrm{C}_{3} \mathrm{~N}_{4} @ \mathrm{BiOI}$ and $\mathrm{Fe}_{3} \mathrm{O}_{4}$, the saturation magnetization of $\mathrm{Fe}_{3} \mathrm{O}_{4}$ decreased from 55.5 to $8.7 \mathrm{emu} \mathrm{g}^{-1}$. After water treatment, the photocatalyst was separated from the reaction solution by the aid of the external magnetic field and re-used for five catalytic cycles (Fig.18(b)) [192].

\section{<Please insert Fig.18 here>}

\section{Iron oxide modified quaternary photocatalyst}

\subsection{Iron oxide modified quaternary metal oxide photocatalyst}

Yangieh et al., synthesized visible-light active and magnetically separable photocatalyst $\mathrm{Fe}_{3} \mathrm{O}_{4} @ \mathrm{ZnO} @ \mathrm{Ag}_{3} \mathrm{VO}_{4} @ \mathrm{AgI}$ using superficial ultrasonication method for degradation of RhB dye under visible-light radiation. The $n-n$ heterojunction formation between two semiconductors with thin band gap and effective separation of charge carriers resulted in high photocatalytic activity. The studies revealed that ammonium oxalate and benzoquinone influenced degradation reaction 
significantly. The main active site for photocatalytic degradation of $\mathrm{RhB}$ dye were holes and $\bullet \mathrm{O}_{2}{ }^{-}$ - Additionally, it was shown that the photocatalytic activity of photocatalyst was affected by calcination temperature and ultrasonic-radiations. The photocatalyst exhibited significant recyclability for five catalytic cycles [193]. Fig. 19(a) displays M-H magnetization curve of as prepared quaternary photocatalyst at room temperature. At $8500 \mathrm{Oe}$, the saturation magnetization of quaternary photocatalyst and $\mathrm{Fe}_{3} \mathrm{O}_{4}$ nanoparticle was 6.26 and $55.5 \mathrm{emu} \mathrm{g}{ }^{-1}$, respectively. No remanence in M-H curves confirmed superparamagnetic behaviour of as-prepared photocatalyst with complete elimination from the suspension by applying the external magnetic field as demonstrated in inset of Fig. 19(a).

Fig.19 (b) demonstrates the plausible mechanism for the improved photocatalytic activity of $\mathrm{Fe}_{3} \mathrm{O} 4 @ \mathrm{ZnO} @ \mathrm{Ag}_{3} \mathrm{VO}_{4} @ \mathrm{AgI}$ photocatalyst involving effective separation of photogenerated EHP. The CB edge and Fermi level of $\mathrm{ZnO}$ and $\mathrm{AgI}$ were higher than $\mathrm{Ag}_{3} \mathrm{VO}_{4}$ (Fig. 19(b)) thus, $\mathrm{AgI}$ and $\mathrm{Ag}_{3} \mathrm{VO}_{4}$ produced photo-excitons due to appropriate level of band potentials. The photoexcited electrons were transferred from $\mathrm{CB}$ of $\mathrm{Ag}_{3} \mathrm{VO}_{4}$ to $\mathrm{CB}$ of $\mathrm{ZnO}$ and $\mathrm{AgI}$. At the same time, photo-excited holes were transferred from $\mathrm{VB}$ of $\mathrm{AgI}$ to $\mathrm{VB}$ of $\mathrm{Ag}_{3} \mathrm{VO}_{4}$. So, photo-excited electrons were accumulated in the $\mathrm{CB}$ of $\mathrm{ZnO}$ and $\mathrm{AgI}$, while photogenerated holes were accumulated on $\mathrm{VB}$ of $\mathrm{Ag}_{3} \mathrm{VO}_{4}$, due to $\mathrm{n}-\mathrm{n}$ heterojunction between $\mathrm{Ag}_{3} \mathrm{VO}_{4}, \mathrm{AgI}$, and $\mathrm{ZnO}$. The

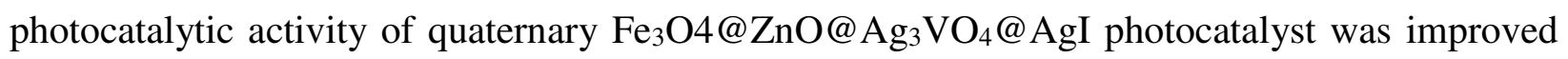
due to separation of photo-excited EHP [193].

\section{<Please insert Fig. 19 here>}

Kumar et al., fabricated magnetic quaternary nano-photocatalyst BiOCl@g$\mathrm{C}_{3} \mathrm{~N}_{4} @ \mathrm{Cu}_{2} \mathrm{O} @ \mathrm{Fe}_{3} \mathrm{O}_{4}$ (BGC-F) using facile co-precipitation method for 99.5\% of sulfamethoxazole (SME) dye was degraded in $60 \mathrm{~min}$. The outstanding optical activity of BGC-F was due to p-n-p junction formation, appropriate band gap, and improved UV-visible spectral response. The magnetic saturation value of $\mathrm{BGC}-\mathrm{F}$ was $26 \mathrm{emu} \mathrm{g}^{-1}$ which facilitated magnetic separation of photocatalyst from reaction solution. The quenching studies demonstrated that the main reactive species are $\cdot \mathrm{O}_{2}{ }^{-}$and $\bullet \mathrm{OH}$ radicals. LC-MS analysis explored various pathways of SME dye degradation process. The mineralization and degradation of SME dye were confirmed by bactericidal activity and TOC@COD. Moreover, little or negligible toxicity was shown by treated water on PBL cells of human [194]. 


\section{Conclusion and Future Prospective}

In conclusion, this review recapitulates recent developments in magnetic iron oxide integrated photocatalysts (MIOIPs) and their promising attention seeking ability for water remediation. The in-depth research delved into modifications with binary, ternary, and complex nanocomposites help us to circumvent problems associated with bare IONPs. Evidently, the key advantage strengthening the utility of MIOIPs is its facetious magnetic separability and facile synthesis methods. Within the scope of knowledge, it is clearly known that the fate of photoinduced electrons and holes are vital for photodegradation process and could be influenced by various factors, such as electronic structure and morphology of magnetic iron oxide nanosized photocatalyst. In view of many advantages of magnetic IONPs integrated photocatalysts, the following mentioned points should be taken into consideration for pilot-scale applications of MIOIPs:

i. While designing and synthesizing of MIOIPs, the researchers must try to keep a balance between two contradictory factors: (i) magnetic recovery of photocatalysts from the reaction solution and (ii) Agglomeration of MIOIPs in reaction solution due to magnetic interaction.

ii. The researchers should focus on green methods for synthesis of magnetic iron oxide photocatalysts.

iii. As corrosion in aqueous environment remains a major obstacle for long-term and largescale applicability of MIOIPs based photocatalytic systems, more attention should be paid to development of core-shell nanoparticles with MIOIPs as a core.

iv. The photocatalytic activity of MIOIPs based photocatalytic systems must be explored for degradation of gaseous pollutants and soil pollution.

v. Due to its eco-friendly and bio-compatible behaviour, the magnetic iron oxide nanosized photocatalysts have many applications in several areas, such as in health for the treatment of cancer, in electronics for communication by magnetism and in purification of water at bulk level, which is the most imperative applications.

The use of fabricated MIOIPs has numerous benefits for removal of heavy metals and dyes from contaminated water. IONPs, possessing low toxicity can be readily used in free or integrated forms to reach a standpoint of wide solar spectrum response. Later, real time effects of the presence of IONPs in water sources are still unidentified, thus the idea to introduce IONPs into water sources 
for the better adsorption of $\mathrm{CO}_{2}$ and productions of $\mathrm{H}_{2}$ and $\mathrm{O}_{2}$ were further rejected. In spite of these shortcomings, MIOIPs for photocatalytic water splitting is very promising. Generation of $\mathrm{H}_{2}$ (or $\mathrm{O}_{2}$ ) from MIOIPs for photocatalytic water splitting remains a pioneering and potential route under solar light. $\mathrm{H}_{2}$ evolution and/or $\mathrm{O}_{2}$ evolution co-catalysts (i.e. IONPs) separate the photogenerated charge carriers; create active sites for $\mathrm{H}_{2}$ or $\mathrm{O}_{2}$ evolution that enhances the production of photocatalytic $\mathrm{H}_{2}$ or $\mathrm{O}_{2}$ and stability of MIOIPs. MIOIPs improve photocatalytic $\mathrm{H}_{2}$ and $\mathrm{O}_{2}$ productions because of their some roles that are (i) MIOIPs may decrease the activation energy or over potential required for $\mathrm{H}_{2}$ or $\mathrm{O}_{2}$ evolution reactions,. (ii) They are capable to contribute in separation processes of photogenerated charge carriers (EHP) at the IONPs interface. They are also obstructing photo corrosion and improve the photocatalytic stability.

\section{References}

[1]. S. Malato, P. Fernández-Ibáñez, M. I. Maldonado, J. Blanco, W. Gernjak, Decontamination and disinfection of water by solar photocatalysis: recent overview and trends, Catal. Today, 147 (2009) 1-59.

[2]. S. Y. Lee and S. J. Park, $\mathrm{TiO}_{2}$ photocatalyst for water treatment applications, J. Ind. Eng. Chem. 19 (2013) 1761-1769.

[3]. J. Tollefson, How green is my future? UN panel foresees big growth in renewable energy, but policies will dictate just how big, Nature, 473 (2011) 134-136.

[4]. S. M. Stead, Rethinking marine resource governance for the United Nations Sustainable Development Goals, Curr. Opin. Env. Sust. 34 (2018) 54-61.

[5]. C. Stein, Global Burden of Disease (GBD) Approach and the Use of Disability-Adjusted Life Years (DALY) at the World Health Organization (WHO), Reference Module in Earth Systems and Environmental Sciences, 2018.

[6].S. Ahuja, Lessons Learned from Water Disasters of the World, Sep. Sci. Technol. 11 (2019) 417-427.

[7]. M. Rodell, I. Velicogna, J. S. Famiglietti, Satellite-based estimates of groundwater depletion in India, Nature, 460 (2009) 999. 
[8]. P. Raizada, P. Singh, A. Kumar, B. Pare, S. B. Jonnalagadda, Zero valent iron-brick grain nanocomposite for enhanced solar-Fenton removal of malachite green, Sep. Purif. Technol. 133 (2014) 429-437.

[9]. P. Shandilya, D. Mittal, A. Sudhaik, M. Soni, P. Raizada, A. K. Saini, P. Singh, GdVO 4 modified fluorine doped graphene nanosheets as dispersed photocatalyst for mitigation of phenolic compounds in aqueous environment and bacterial disinfection, Sep. Purif. Technol. 210 (2019) 804-816.

[10]. F. Montserrat, N. Belzile, Y. W. Chen, Antimony in the environment: a review focused on natural waters: I. Occurrence, Earth Sci. Rev. 57 (2002) 125-176.

[11]. D. Gedamu, I. Paulowicz, S. Kaps, O. Lupan, S. Wille, G. Haidarschin, Y. K. Mishra, R. Adelung, Rapid fabrication technique for interpenetrated $\mathrm{ZnO}$ nanotetrapod networks for fast UV sensors, Adv. Mater. 26 (2014) 1541-1550.

[12]. P. Raizada, A. Sudhaik, P. Singh, Photocatalytic water decontamination using graphene and ZnO coupled photocatalysts: A review, Mater. Sci. Energy Technol. 2 (2019) 509-525.

[13]. P. Singh, P. Raizada, D. Pathania, A. Kumar, P. Thakur, Preparation of BSA-ZnWO 4 nanocomposites with enhanced adsorptional photocatalytic activity for methylene blue degradation, Int. J. Photoenergy, 2013 (2013).

[14]. P. D. Cozzoli, R. Comparelli, E. Fanizza, M. L. Curri, A. Agostiano, Photocatalytic activity of organic-capped anatase $\mathrm{TiO}_{2}$ nanocrystals in homogeneous organic solutions, Mater. Sci. Eng. C, 23 (2003) 707-713.

[15]. P. Raizada, A. Sudhaik, P. Singh, P. Shandilya, V. K. Gupta, A. Hosseini-Bandegharaei, S. Agrawal, $\mathrm{Ag}_{3} \mathrm{PO}_{4}$ modified phosphorus and sulphur co-doped graphitic carbon nitride as a direct Z-scheme photocatalyst for 2, 4-dimethyl phenol degradation, J. Photochem. Photobiol. A. 374, (2019) 22-35.

[16]. A. J. Hoffman, E. R. Carraway, M. R. Hoffmann, Photocatalytic production of $\mathrm{H}_{2} \mathrm{O}_{2}$ and organic peroxides on quantum-sized semiconductor colloids, Environ. Sci. Technol. 28 (1994) 776-785.

[17]. P. Singh, P. Raizada, D. Pathania, G. Sharma, P. Sharma, Microwave induced KOH activation of guava peel carbon as an adsorbent for Congo red dye removal from aqueous phase, Ind. J. Chem. Technol. 20 (2013) 305-311. 
[18]. V. Dutta, S. Sharma, P. Raizada, A. Hosseini-Bandegharaei, V. K. Gupta, P. Singh, Review on augmentation in photocatalytic activity of $\mathrm{CoFe}_{2} \mathrm{O}_{4}$ via heterojunction formation for photocatalysis of organic pollutants in water, J. Saudi Chem. Soc. (2019) https://doi.org/10.1016/j.jscs.2019.07.003.

[19]. F. Schütt, S. Signetti, H. Krüger, S. Röder, D. Smazna, S. Kaps, S. N. Gorb, Y. K. Mishra, N. M. Pugno, R. Adelung, Hierarchical self-entangled carbon nanotube tube networks, Nat. Commun. 8 (2017) 1215.

[20]. P. Singh, P. Shandilya, P. Raizada, A. Sudhaik, A. R. Sani, A. H. Bandegharae, Review on various strategies for enhancing photocatalytic activity of graphene based nanocomposites for water purification, Arab. J. Chem. (2018) DOI: 10.1016/j.arabjc.2018.12.001.

[21]. M. R. Hoffmann, S. T. Martin, W. Choi, D. W. Bahnemann, Environmental applications of semiconductor photocatalysis, Chem. Rev. 95 (1995) 69-96.

[22]. J. Kou, C. Lu, J. Wang, Y. Chen, Z. Xu, R. S. Varma, Selectivity enhancement in heterogeneous photocatalytic transformations. Chem. Rev. 117 (2017) 1445-1514.

[23]. Y. K. Mishra, R. Adelung, G. Kumar, M. Elbahri, S. Mohapatra, R. Singhal, A. Tripathi, D. K. Avasthi, Formation of self-organized silver nanocup-type structures and their plasmonic absorption, Plasmonics. 8 (2013) 811-815.

[24]. R. Marschall, Semiconductor composites: strategies for enhancing charge carrier separation to improve photocatalytic activity, Adv. Funct. Mater. 24 (2014) 2421-2440.

[25]. K. Sharma, V. Dutta, S. Sharma, P. Raizada, A. Hosseini-Bandegharaei, P. Thakur, P. Singh, Recent advances in enhanced photocatalytic activity of bismuth oxyhalides for efficient photocatalysis of organic pollutants in water: A review, J. Ind. Eng. Chem. 78 (2019) 1-20.

[26]. O. Ola and M. M. Maroto-Valer, Review of material design and reactor engineering on $\mathrm{TiO}_{2}$ photocatalysis for $\mathrm{CO}_{2}$ reduction, J. Photochem. Photobiol. C, 24 (2015) 16-42.

[27]. A. L. Linsebigler, G. Lu, J. T. Yates Jr, Photocatalysis on $\mathrm{TiO}_{2}$ surfaces: principles, mechanisms, and selected results, Chem. Rev. 95 (1995) 735-758.

[28]. V. K. Gupta, D. Pathania, S. Agarwal, P. Singh, Adsorptional photocatalytic degradation of methylene blue onto pectin-CuS nanocomposite under solar light, J. Hazard. Mater. 243 (2012) 179-186. 
[29]. B. Pare, P. Singh, S. B. Jonnalgadda, Artificial light assisted photocatalytic degradation of lissamine fast yellow dye in $\mathrm{ZnO}$ suspension in a slurry batch reactor, Ind. J. Chem. A, 48 (2009) 1364-1369.

[30]. P. Raizada, A. Sudhaik, V. P. Singh, V. K. Gupta, A. Hosseini-Bandegharaei, R. Kumar, P. Singh, Solar light assisted degradation of oxytetracycline from water using $\mathrm{Bi}_{2} \mathrm{O}_{3} / \mathrm{Fe}_{3} \mathrm{O}_{4}$ supported graphitic carbon nitride photocatalyst, Desalin. Water Treat. 148 (2019) 338350.

[31]. P. Raizada, A. Sudhaik, P. Singh, A. Hosseini-Bandegharaei, P. Thakur, Converting type II $\mathrm{AgBr} / \mathrm{VO}$ into ternary $\mathrm{Z}$ scheme photocatalyst via coupling with phosphorus doped g$\mathrm{C}_{3} \mathrm{~N}_{4}$ for enhanced photocatalytic activity, Sep. Purif. Technol. 227 (2019) 115692.

[32]. A. Scheffel, M. Gruska, D. Faivre, A. Linaroudis, J. M. Plitzko, D. Schüler, An acidic protein aligns magnetosomes along a filamentous structure in magnetotactic bacteria, Nature, 440 (2006) 110.

[33]. P. Raizada, P. Singh, A. Kumar, G. Sharma, B. Pare, S. B. Jonnalagadda, P. Thakur, Solar photocatalytic activity of nano- $\mathrm{ZnO}$ supported on activated carbon or brick grain particles: role of adsorption in dye degradation, Appl. Catal. A Gen. 486 (2014)159-169.

[34]. E. Casbeer, V. K. Sharma, X. Z. Li, Synthesis and photocatalytic activity of ferrites under visible light: a review, Sep. Purif. Technol. 87 (2012) 1-14.

[35]. V. Hasija, P. Raizada, A. Sudhaik, K. Sharma, A. Kumar, P. Singh, S. B. Jonnalagaddaand, V. K. Thakur, Recent advances in noble metal free doped graphitic carbon nitride based nanohybrids for photocatalysis of organic contaminants in water: A review, Appl. Mater. Today, 15 (2019) 494-524.

[36]. Y. K. Mishra, G. Modi, V. Cretu, V. Postica, O. Lupan, T. Reimer, I. Paulowicz, V. Hrkac, W. Benecke, L. Kienle, R. Adelung, Direct growth of freestanding ZnO tetrapod networks for multifunctional applications in photocatalysis, UV photodetection, and gas sensing, ACS Appl. Mater. Interface, 7 (2015) 14303-14316.

[37]. A. Fujishima, K. Honda, Electrochemical photolysis of water at a semiconductor electrode, Nature, 238(1972) 37.

[38]. S. Jebril, H. Kuhlmann, S. Müller, C. Ronning, L. Kienle, V. Duppel, Y. K. Mishra, R. Adelung, Epitactically Interpenetrated High Quality ZnO Nanostructured Junctions on 
Microchips Grown by the Vapor- Liquid- Solid Method, Cryst. Growth Des. 10 (2010) 2842-2846.

[39]. P. Singh, B. Priya, P. Shandilya, P. Raizada, N. Singh, B. Pare, S. B. Jonnalagadda, Photocatalytic mineralization of antibiotics using $60 \% \mathrm{WO}_{3} / \mathrm{BiOCl}$ stacked to graphene sand composite and chitosan, Arab. J. Chem. (2016). https://doi.org/10.1016/j.arabjc.2016.08.005.

[40]. R. Singhal, D. C. Agarwal, S. Mohapatra, Y. K. Mishra, D. Kabiraj, F. Singh, D. K. Avasthi, A. K. Chawla, R. Chandra, G. Mattei, J. C. Pivin, Synthesis and characterizations of silver-fullerene $\mathrm{C}_{70}$ nanocomposite, Appl. Phys. Lett. 93 (2008) 103114.

[41]. P. Raizada, P. Shandilya, P. Singh, P. Thakur, Solar light-facilitated oxytetracycline removal from the aqueous phase utilizing a $\mathrm{H}_{2} \mathrm{O}_{2} / \mathrm{ZnWO}_{4} / \mathrm{CaO}$ catalytic system, J. Taibah Univ. Sci. 11 (2017) 689-699.

[42]. M. B. Gawande, P. S. Branco, R. S. Varma, Nano-magnetite $\left(\mathrm{Fe}_{3} \mathrm{O}_{4}\right)$ as a support for recyclable catalysts in the development of sustainable methodologies, Chem. Soc. Rev. 42 (2013) 3371-3393.

[43]. A. Sudhaik, P. Raizada, P. Shandilya, P. Singh, Magnetically recoverable graphitic carbon nitride and $\mathrm{NiFe}_{2} \mathrm{O}_{4}$ based magnetic photocatalyst for degradation of oxytetracycline antibiotic in simulated wastewater under solar light, J. Environ. Chem. Eng. 6 (2018) 3874-3883.

[44]. M. A. Lazar, S. Varghese, S. S. Nair, Photocatalytic water treatment by titanium dioxide: recent updates, Catalysts, 2 (2012) 572-601.

[45]. D. Jamwal, G. Kaur, P. Raizada, P. Singh, D. Pathak, P. Thakur, Twin-tail surfactant peculiarity in superficial fabrication of semiconductor quantum dots: toward structural, optical, and electrical features. J. Phys. Chem. C. 119 (2015) 5062-5073.

[46]. D. Bahnemann, Photocatalytic water treatment: solar energy applications, Sol. Energy, 77 (2004) 445-459.

[47]. W. Wu, C. Jiang, V. A. L. Roy, Recent progress in magnetic iron oxide-semiconductor composite nanomaterials as promising photocatalysts, Nanoscale, 7 (2015) 38-58. 
[48]. S. Laurent, D. Forge, M. Port, A. Roch, C. Robic, L. V. Elst, R. N. Muller, Magnetic iron oxide nanoparticles: synthesis, stabilization, vectorization, physicochemical characterizations, and biological applications, Chem. Rev. 108 (2008) 2064-2110.

[49]. S. Sharma, V. Dutta, P. Singh, P. Raizada, A. Rahmani-Sani, A. Hosseini-Bandegharaei, V. K. Thakur, Carbon quantum dot supported semiconductor photocatalysts for efficient degradation of organic pollutants in water: A review, J. Clean. Prod. 228 (2019) 755-769.

[50]. Y. Wang, Q. Wang, X. Zhan, F. Wang, M. Safdar, J. He, Visible light driven type II heterostructures and their enhanced photocatalysis properties: a review, Nanoscale, 5 (2013) 8326-8339.

[51]. W. Wu, Q. He, Changzhong Jiang, Magnetic iron oxide nanoparticles: synthesis and surface functionalization strategies, Nanoscale Res. Lett. 3 (2008) 397.

[52]. V. Hasija, A. Sudhaik, P. Raizada, A. Hosseini-Bandegharaei, P. Singh, Carbon quantum dots supported $\mathrm{AgI} / \mathrm{ZnO} /$ phosphorus doped graphitic carbon nitride as $\mathrm{Z}$-scheme photocatalyst for efficient photodegradation of 2, 4-dinitrophenol, J. Environ. Chem. Eng. 7 (2019) 103272.

[53]. S. U. Sonavane, M. B. Gawande, S. S. Deshpande, A. Venkataraman, R. V. Jayaram, Chemoselective transfer hydrogenation reactions over nanosized $\gamma-\mathrm{Fe}_{2} \mathrm{O}_{3}$ catalyst prepared by novel combustion route, Catal. Commun. 8 (2007) 1803-1806.

[54]. L. Xu, Y. Ma, Y. Zhang, Z. Jiang, W.Huang, Direct evidence for the interfacial oxidation of CO with hydroxyls catalyzed by Pt/oxide nanocatalysts, J. Am. Chem. Soc. 131 (2009) 16366-16367.

[55]. V. K. Gupta, D. Pathania, P. Singh, Pectin-cerium (IV) tungstate nanocomposite and its adsorptional activity for removal of methylene blue dye, Int. J. Environ. Sci. Technol. 11 (2014) 2015-2024.

[56]. M. Chirita, I. Grozes-cu, L. Taubert, H. Radulescu, E. Princz, É. S. Bányai, C. Caramalau, L. Bulgariu, M. Macoveanu, C. Muntean, $\mathrm{Fe}_{2} \mathrm{O}_{3}$-nanoparticles, physical properties and their photochemical and photoelectrochemical applications, Chem. Bull. 54 (2009) 1-8.

[57]. T. Palden, M. Regadío, B. Onghena, K. Binnemans, Selective metal recovery from jarosite residue by leaching with acid-equilibrated ionic liquids and precipitation-stripping, ACS Sustain. Chem. Eng. 7 (2019) 4239-4246. 
[58]. H. T. Jeng and G. Y. Guo, First-principles investigations of the electronic structure and magnetocrystalline anisotropy in strained magnetite $\mathrm{Fe}_{3} \mathrm{O}_{4}$, Phys. Rev. B. 65 (2002) 094429.

[59]. M. Mishra and D. M. Chun, $\alpha-\mathrm{Fe}_{2} \mathrm{O}_{3}$ as a photocatalytic material: A review, Appl. Catal. A -Gen. 498 (2015) 126-141.

[60]. S. Gautam, P. Shandilya, V. P. Singh, P. Raizada, P. Singh, Solar photocatalytic mineralization of antibiotics using magnetically separable $\mathrm{NiFe}_{2} \mathrm{O}_{4}$ supported onto graphene sand composite and bentonite. J. Water Process Eng. 14 (2016) 86-100.

[61]. P. L. Poizot, S. Laruelle, S. Grugeon, L. Dupont, J. M. Tarascon, Nano-sized transitionmetal oxides as negative-electrode materials for lithium-ion batteries, Nature, 407 (2000) 496.

[62]. R. M Cornell and U. Schwertmann, The iron oxides: structure, properties, reactions, occurrences and uses, John Wiley \& Sons (2003).

[63]. I. Andjelkovic, D. N. Tran, S. Kabiri, S. Azari, M. Markovic, D. Losic, Graphene aerogels decorated with $\alpha-\mathrm{FeOOH}$ nanoparticles for efficient adsorption of arsenic from contaminated waters, ACS Appl. Mater. Interface, 7 (2015) 9758-9766.

[64]. V. M. da SilvaRocha, M. de Godoi Pereira, L. R. Teles, M. O. da Guarda Souza, Effect of copper on the photocatalytic activity of semiconductor-based titanium dioxide (anatase) and hematite $\left(\alpha-\mathrm{Fe}_{2} \mathrm{O}_{3}\right)$, Mat. Sci. Eng. B 185 (2014) 13-20.

[65]. K. M. Tripathi, T. S. Tran, Y. J. Kim, T. Kim, Green fluorescent onion-like carbon nanoparticles from flaxseed oil for visible light induced photocatalytic applications and label-free detection of Al (III) ions, ACS Sustain. Chem. Eng. 5 (2017) 3982-3992.

[66]. A. Boudjemaa, A. Rebahi, B. Terfassa, R. Chebout, T. Mokrani, K. Bachari, N. J. Coville, $\mathrm{Fe}_{2} \mathrm{O}_{3} /$ carbon spheres for efficient photo-catalytic hydrogen production from water and under visible light irradiation, Sol. Energy Mater. Sol. Cells, 140 (2015) 405411.

[67]. C. Yang, J. Wu, Y. Hou, $\mathrm{Fe}_{3} \mathrm{O}_{4}$ nanostructures: synthesis, growth mechanism, properties and applications, Chem. Comm. 47 (2011) 5130-5141.

[68]. P. Raizada, J. Kumari, P. Shandilya, P. Singh, Kinetics of photocatalytic mineralization of oxytetracycline and ampicillin using activated carbon supported ZnO/ZnWO , Desalination, 79 (2017) 204-213. 
[69]. P. Raizada, J. Kumari, P. Shandilya, R. Dhiman, V. P. Singh, P. Singh, Magnetically retrievable $\mathrm{Bi}_{2} \mathrm{WO}_{6} / \mathrm{Fe}_{3} \mathrm{O}_{4}$ immobilized on graphene sand composite for investigation of photocatalytic mineralization of oxytetracycline and ampicillin, Process Saf. Environ. 106 (2017) 104-116.

[70]. A.F. Wells, Structural Inorganic Chemistry 5th edition Oxford University Press ISBN 019-855370-6 (1984).

[71]. R. C. O' Handley, Modern magnetic materials: principles and applications, Wiley (2000).

[72]. N. A. Spaldin and N. D. Mathur, Magnetic materials: fundamentals and device applications, Phys. Today, 56 (2003) 62-63.

[73]. W. Wu, Z. Wu, T. Yu, J. Changzhong, W. S. Kim, Recent progress on magnetic iron oxide nanoparticles: synthesis, surface functional strategies and biomedical applications, Sci. Technol. Adv. Mat. 16 (2015) 23501.

[74]. W. Wu, X. H. Xiao, F. Ren, S. F. Zhang, C. Z. Jiang, A comparative study of the magnetic behavior of single and tubular clustered magnetite nanoparticles, J. Low. Temp. Phys. 168 (2012) 306-313.

[75]. J. Choi, J. Cha, J. K. Lee, Synthesis of various magnetite nanoparticles through simple phase transformation and their shape-dependent magnetic properties, RSC Adv. 3 (2013) 8365-8371.

[76]. W. Wu, X. Xiao, S. Zhang, H. Li, X. Zhou, C. Jiang, One-pot reaction and subsequent annealing to synthesis hollow spherical magnetite and maghemite nanocages, Nanoscale Res. Lett. 4 (2009) 926.

[77]. M. Yamaura, R. L. Camilo, L. C. Sampaio, M. A. Macedo, M. Nakamura, H. E. Toma, Preparation and characterization of (3-aminopropyl) triethoxysilane-coated magnetite nanoparticles, J. Magn. Magn. Mater. 279 (2004) 210-217.

[78]. I. M. L. Billas, A. Chatelain, W. A. de Heer, Magnetism from the atom to the bulk in iron, cobalt, and nickel clusters, Science, 265 (1994) 1682-1684.

[79]. G. F. Goya, T. S. Berquo, F. C. Fonseca, M. P. Morales, Static and dynamic magnetic properties of spherical magnetite nanoparticles, J. Appl. Phys. 94 (2003) 3520-3528.

[80]. J. Domenech and A. Prieto, Stability of zinc oxide particles in aqueous suspensions under UV illumination, J. Phy. Chem. 90 (1986) 1123-1126. 
[81]. S. Gautam, P. Shandilya, B. Priya, V. P. Singh, P. Raizada, R. Rai, M. A. Valente, P. Singh, Superparamagnetic $\mathrm{MnFe}_{2} \mathrm{O}_{4}$ dispersed over graphitic carbon sand composite and bentonite as magnetically recoverable photocatalyst for antibiotic mineralization, Sep. Purif. Technol. 172 (2017) 498-511.

[82]. S. M. Hussain, K. L. Hess, J. M. Gearhart, K. T. Geiss, J. J. Schlager, In vitro toxicity of nanoparticles in BRL 3A rat liver cells, Toxicol. In Vitro 19 (2005) 975-983.

[83]. H. H. Yiu, M. R. Pickard, C. I. Olariu, S. R. Williams, D. M. Chari, M. J. Rosseinsky, $\mathrm{Fe}_{3} \mathrm{O}_{4}$-PEI-RITC magnetic nanoparticles with imaging and gene transfer capability: development of a tool for neural cell transplantation therapies, Pharm. Res. 29 (2012) 1328-1343.

[84]. V. Valdiglesias, N. Fernandez-Bertolez, G. Kiliç, C. Costa, S. Costa, S. Fraga, M. J. Bessa, E. Pasaro, J. P. Teixeira, B. Laffon, Are iron oxide nanoparticles safe? Current knowledge and future perspectives, J. Trace Elem. Med. Biol. 38 (2016) 53-63.

[85]. V. Polshettiwar, R. S. Varma, Microwave-assisted organic synthesis and transformations using benign reaction media, Accounts Chem. Res. 41 (2008) 629-639.

[86]. M. R. Gholipour, C.T. Dinh, F. Béland, T. O. Do, Nanocomposite heterojunctions as sunlight-driven photocatalysts for hydrogen production from water splitting, Nanoscale, 7 (2015) 8187-8208.

[87]. P. Shandilya, D. Mittal, M. Soni, P. Raizada, J. H. Lim, D. Y. Jeong, R. P. Dewedi, A. K. Saini, P. Singh, Islanding of $\mathrm{EuVO}_{4}$ on high-dispersed fluorine doped few layered graphene sheets for efficient photocatalytic mineralization of phenolic compounds and bacterial disinfection, J. Taiwan Inst. Chem. E. 93 (2018) 528-542.

[88]. P. Sharma, P. Kumar, D. Deva, R. Shrivastav, S. Dass, V. R. Satsangi, Nanostructured $\mathrm{Zn}-\mathrm{Fe}_{2} \mathrm{O}_{3}$ thin film modified by $\mathrm{Fe}-\mathrm{TiO}_{2}$ for photoelectrochemical generation of hydrogen, Int. J. Hydrogen Energy, 35 (2010) 10883-10889.

[89]. P. Raizada, A. Sudhaik, P. Singh, P. Shandilya, P. Thakur, H. Jung, Visible light assisted photodegradation of 2, 4-dinitrophenol using $\mathrm{Ag}_{2} \mathrm{CO}_{3}$ loaded phosphorus and sulphur codoped graphitic carbon nitride nanosheets in simulated wastewater, Arab. J. Chem. (2018). https://doi.org/10.1016/j.arabjc.2018.10.004. 
[90]. P. Singh, P. Raizada, A. Sudhaik, P. Shandilya, P. Thakur, S. Agarwal, V. K. Gupta, Enhanced photocatalytic activity and stability of $\mathrm{AgBr} / \mathrm{BiOBr} / g r a p h e n e$ heterojunction for phenol degradation under visible light, J. Saudi Chem. Soc. (2018).

[91]. O. Carp, C. L. Huisman, A. Reller, Photoinduced reactivity of titanium dioxide, Prog. Solid State Chem. 32 (2004) 33-177.

[92]. A. Testino, I. R. Bellobono, V. Buscaglia, C. Canevali, M. D'Arienzo, S. Polizzi, R. Scotti, F. Morazzoni, Optimizing the photocatalytic properties of hydrothermal $\mathrm{TiO}_{2}$ by the control of phase composition and particle morphology. A systematic approach, J. Am. Chem. Soc. 129 (2007) 3564-3575.

[93]. B. Pare, S. B. Jonnalagadda, H. Tomar, P. Singh, V. W. Bhagwat, ZnO assisted photocatalytic degradation of acridine orange in aqueous solution using visible irradiation. Desalination, 232 (2008) 80-90.

[94]. B. Pare, S. B. Jonnalagadda, H. S. Tomar, P. Singh, V. W. Bhagwat, Photodegradation of Safranine-O dye using visible irradiation and aqueous suspension of $\mathrm{ZnO}$ in a slurry batch reactor, J. Indian Chem. Soc. 87 (2010) 1359-1367.

[95]. J. Ryu and W. Choi, Substrate-specific photocatalytic activities of $\mathrm{TiO}_{2}$ and multiactivity test for water treatment application, Environ. Sci. Technol. 42 (2007) 294-300.

[96]. P. Raizada, A. Sudhaik, P. Shandilya, A. Saini, V. Gupta, P. Singh, Fabrication of $\mathrm{Ag}_{3} \mathrm{VO}_{4}$ decorated phosphorus and sulphur co-doped graphitic carbon nitride as highdispersed photocatalyst for phenol mineralization and E.Coli disinfection, Sep. Purif. Technol. 212 (2019) 887-900.

[97]. P. Shandilya, D. Mittal, M. Kumar, P. Raizada, A. Hosseini-Bandegharaee, A.K. Saini, P. Singh, Fabrication of fluorine doped graphene and $\mathrm{SmVO}_{4}$ based dispersed and adsorptive photocatalyst for abatement of phenolic compounds from water and bacterial disinfection, J. Clean. Prod. 203 (2018) 386-399.

[98]. A. Sudhaik, P. Raizada, P. Shandilya, D.Y. Jeong, J.H. Lim, P. Singh, Review on fabrication of graphitic carbon nitride based efficient nanocomposites for photodegradation of aqueous phase organic pollutants, J. Ind. Eng. Chem. 67 (2018) 28-51.

[99]. X. Hou, X. Wang, W. Mi, Progress in $\mathrm{Fe}_{3} \mathrm{O}_{4}$-based multiferroic heterostructures, J. Alloys Compd. 765 (2018) 1127-1138. 
[100]. P. Falcaro, R. Ricco, A. Yazdi, I. Imaz, S. Furukawa, D. Maspoch, R. Ameloot, J. D. Evans, C. J. Doonan, Application of metal and metal oxide nanoparticles@ MOFs, Coord. Chem. Rev. 307 (2016) 237-254.

[101]. S. Odenbach and S. Thurm, Magnetoviscous effects in ferrofluids, In Ferrofluids, Springer, Berlin, Heidelberg, 594 (2002) 185-201.

[102]. L. Babes, B. Denizot, G.Tanguy, J. J. L. Jeune, P. Jallet, Synthesis of iron oxide nanoparticles used as MRI contrast agents: a parametric study, J. Colloid Interf. Sci. 212 (1999) 474-482.

[103]. A. C. Nunes and Z. C. Yu, Fractionation of a water-based ferrofluid, J. Magn. Magn. Mater. 65 (1987) 265-268.

[104]. C. E. Sjogren, H. Johansson, A. Nevestad, P. C. Sontum, K. Brilley-Saebo, A. K. Fahlvik, Crystal size and properties of Superparamagnetic iron oxide (SPIO) particles, Magn. Reson. Imaging, 15 (1997) 55-67.

[105]. G. Salazar-Alvarez, M. Muhammed, A. A. Zagorodni, Novel flow injection synthesis of iron oxide nanoparticles with narrow size distribution, Chem. Eng. Sci. 61 (2006) 46254633.

[106]. E. H. Kim, Y. Ahn, H. S. Lee, Biomedical applications of Superparamagnetic iron oxide nanoparticles encapsulated within chitosan, J. Alloys Compd. 434 (2007) 633-636.

[107]. J. Wan, X. Chen, Z. Wang, X. Yang, Y. Qian, A soft-template-assisted hydrothermal approach to singlecrystal $\mathrm{Fe}_{3} \mathrm{O}_{4}$ nanorods, J. Cryst. Growth, 276 (2005) 571-576.

[108]. S. Basak, D. R. Chen, P. Biswas, Electrospray of ionic precursor solutions to synthesize iron oxide nanoparticles: modified scaling law, Chem. Eng. Sci. 62 (2007) 1263-1268.

[109]. C. Albornoz and S. E. Jacobo, Preparation of a biocompatible magnetic film from an aqueous ferrofluid, J. Magn. Magn. Mater. 305 (2006) 12-15.

[110]. A. B. Chin and I. I. Yaacob, Synthesis and characterization of magnetic iron oxide nanoparticles via w/o microemulsion and Massart's procedure, J. Mater. Process. Technol. 191 (2007) 235-237.

[111]. T. Douglas and M. Young, Host-guest encapsulation of materials by assembled virus protein cages, Nature, 393 (1998)152-155.

[112]. T. Douglas and V. T. Stark, Nanophase cobalt oxy hydroxide mineral synthesized within the protein cage of ferritin, Inorg. Chem. 39 (2000) 1828-1830. 
[113]. T. Douglas, E. Strable, D. Willits, A. Aitouchen, M. Libera, M. Young, Protein engineering of a viral cage for constrained nanomaterials synthesis, Adv. Mater.14 (2002) 415-418.

[114]. L. Levy, J. Hochepied, M. Pileni, Control of the size and composition of three dimensionally diluted magnetic semiconductor clusters, J. Phys. Chem. 100 (1996) 1832218326.

[115]. L. Levy, D. Ingert, N. Feltin, V. Briois, M. P. Pileni, Solid solution of Cd1-yMny S nanocrystals, Langmuir, 18 (2002)1490-1493.

[116]. M. A. Malik, N. Revaprasadu, P. O'Brien, Air-stable single-source precursors for the synthesis of chalcogenide semiconductor nanoparticles, Chem. Mater. 13 (2001) 913-920.

[117]. V. Ladizhansky, G. Hodes, S. Vega, Surface properties of precipitated CdS nanoparticles studied by NMR, J. Phys. Chem. B, 102 (1998) 8505-8509.

[118]. G. Counio, T. Gacoin, J. Boilot, Synthesis and photoluminescence of $\mathrm{Cd}_{1}{ }_{\mathrm{x}} \mathrm{Mn} \mathrm{n}_{\mathrm{x}} \mathrm{S}(\mathrm{x}<5)$ nanocrystals, J. Phys. Chem. B, 102 (1998) 5257-5260.

[119]. W. Shenton, T. Douglas, M. Young, G. Stubbs, S. Mann, Inorganic-organic nanotube composites from template mineralization of tobacco mosaic virus, Adv. Mater. 11 (1999) $253-256$.

[120]. S. A. Anderson, R. K. Rader, W. F. Westlin, C. Null, D. Jackson, G. M. Lanza, S. A. Wickline, J. J. Kotyk, Magnetic resonance contrast enhancement of neovasculature with avß3- targeted nanoparticles, Magn. Reson. Med. 44 (2000) 433-439.

[121]. M. Mahmoudi, A. Simchi, A. S. Milani, P. Stroeve, Cell toxicity of superparamagnetic iron oxide nanoparticles, J. Colloid Interf. Sci. 336 (2009)510-518.

[122]. H. Lee, E. Lee, D. K. Kim, N. K. Jang, Y. Y. Jeong, S. Jon, Antibiofouling polymercoated superparamagnetic iron oxide nanoparticles as potential magnetic resonance contrast agents for in vivo cancer imaging, J. Am. Chem. Soc.128 (2006)7383-7389.

[123]. K. K. Kefeni, T. A. M. Msagati, B. B. Mamba, Ferrite nanoparticles: Synthesis, charaterisation and applications in electronic devices, Mater Sci. Eng. B. 215 (2017) 3755.

[124]. L. Tan, Q. Liu, X. Jing, J. Liu, D. Song, S. Hu, L. Liu, J. Wang, Removal of uranium(VI) ions from aqueous solution by magnetic cobalt ferrite/multiwalled carbon nanotubes composites, Chem. Eng. J. 273 (2015) 307-315. 
[125]. U. Wongpratat, S. Maensiri, E. Swatsitang, EXAFS study of cations distribution dependence of magnetic properties in $\mathrm{Co} 1-\mathrm{xZnxFe}_{2} \mathrm{O}_{4}$ nanoparticles prepared by hydrothermal method, Microelectron. Eng. 146 (2015) 68- 75.

[126]. R. Chen, W. Wang, X. Zhao, Y. Zhang, S. Wu, F. Li, Rapid hydrothermal synthesis of magnetic $\mathrm{Co}_{\mathrm{x}} \mathrm{Ni}_{1-\mathrm{x}} \mathrm{Fe}_{2} \mathrm{O}_{4}$ nanoparticles and their application on removal of Congo red, Chem. Eng. J. 242 (2014) 226-233.

[127]. F. L. Deepak, M. Bañobre-López, E. Carbó-Argibay, M. F. Cerqueira, Y. PiñeiroRedondo, J. Rivas, C. M. Thompson, S. Kamali, C. Rodríguez-Abreu, K. Kovnir, Y. V. Kolen'ko, A Systematic Study of the Structural and Magnetic Properties of Mn-, Co, and Ni-Doped Colloidal Magnetite Nanoparticles, J. Phys. Chem. C 119 (2015) 1194711957.

[128]. V. Georgiadou, V. Tangoulis, I. Arvanitidis, O. Kalogirou, C. Dendrinou-Samara, Unveiling the Physicochemical Features of $\mathrm{CoFe}_{2} \mathrm{O}_{4}$ Nanoparticles Synthesized via a Variant Hydrothermal Method: NMR Relaxometric Properties, J. Phys. Chem. C 119 (2015) 8336-8348.

[129]. J. H. Peng, M. Hojamberdiev, Y. H. Xu, B. W. Cao, J. Wang, H. Wu, Hydrothermal synthesis and magnetic properties of gadolinium-doped $\mathrm{CoFe}_{2} \mathrm{O}_{4}$ nanoparticles, J. Magn. Magn. Mater. 323 (2011) 133-138.

[130]. F. Wang, X. F. Qin, Y. F. Meng, Z. L. Guo, L. X. Yang, Y. F. Ming, Hydrothermal synthesis and characterization of $\alpha-\mathrm{Fe}_{2} \mathrm{O}_{3}$ nanoparticles, Mat. Sci. Semicond. Process. 16 (2013) 802-806.

[131]. M. Tadic, S. Kralj, M. Jagodic, D. Hanzel, D. Makovec, Magnetic properties of novel superparamagnetic iron oxide nanoclusters and their peculiarity under annealing treatment, Appl. Surf. Sci. 322 (2014) 255-264.

[132]. H. Zhang, G.Zhu, One-step hydrothermal synthesis of magnetic $\mathrm{Fe}_{3} \mathrm{O}_{4}$ nanoparticles immobilized on polyamide fabric, Appl. Surf. Sci. 258 (2012) 4952-4959.

[133]. J. Zhang, J. M. Song, H. L. Niu, C. J. Mao, S. Y. Zhang, Y. H. Shen, $\mathrm{ZnFe}_{2} \mathrm{O}_{4}$ nanoparticles: Synthesis, characterization, and enhanced gas sensing property for acetone, Sens. Actuators B-Chem. 221 (2015) 55-62. 
[134]. S. Pauline and A. P. Amaliya, Synthesis and characterization of highly monodispersive $\mathrm{CoFe}_{2} \mathrm{O}_{4}$ magnetic nanoparticles by hydrothermal chemical rout, Arch. Appl. Sci. Res. 3 (2011) 213-223.

[135]. T. Taniguchi, K. Nakagawa, T. Watanabe, N. Matsushita, M. Yoshimura, Hydrothermal growth of fatty acid stabilized iron oxide nanocrystals, J. Phys. Chem. C. 113(2008) 839843.

[136]. R. Rahimi, A. Maleki, S. Maleki, A. Morsali, M. J. Rahimi, Synthesis and characterization of magnetic dichromate hybrid nanomaterials with triphenylphosphine surface modified iron oxide nanoparticles $\left(\mathrm{Fe}_{3} \mathrm{O}_{4} @ \mathrm{SiO}_{2} @ \mathrm{PPh}_{3} @ \mathrm{Cr}_{2} \mathrm{O}_{7}{ }^{2-}\right)$, Solid State Sci. 28 (2014) 9-13.

[137]. H. E. Ghandoor, H. M. Zidan, M. M. H. Khalil, M. I. M. Ismai, Synthesis and Some Physical Properties of Magnetite $\left(\mathrm{Fe}_{3} \mathrm{O}_{4}\right)$ Nanoparticles, Int. J. Electrochem. Sci. 7 (2012) 5734-5745.

[138]. Y. Xing, Y. Y. Jin, J. C. Si, M. L. Peng, X. F. Wang, C. Chen, Y. L. Cui, Controllable synthesis and characterization of $\mathrm{Fe}_{3} \mathrm{O}_{4} / \mathrm{Au}$ composite nanoparticles, J. Magn. Magn. Mater. 380 (2015) 150-156.

[139]. S. Thakur, R. Rai, S. Sharma, Structural, characterization and magnetic study of $\mathrm{NiFe}_{\mathrm{x}} \mathrm{O}_{4}$ synthesized by Co-precipitation method, Mater. Lett. 139 (2015) 368-372.

[140]. F. L. Zabotto, A. J. Gualdi, J. A. Eiras, A. J. A. d Oliveira, D. Garcia, Influence of the sintering temperature on the magnetic and electric properties of $\mathrm{NiFe}_{2} \mathrm{O}_{4}$ ferrites, Mater. Res. 2012 (15) 428- 433.

[141]. D. Romimoghadam, S. Bagheri, S. B. A. Hamid, Progress in electrochemical synthesis of magnetic iron oxide nanoparticles, J. Magn. Magn. Mater. 368 (2014) 207-229.

[142]. N. J. Tang, W. Zhong, H. Y. Jiang, X. L. Wu, W. Liu, Y. W. Du, Nanostructured magnetite $\left(\mathrm{Fe}_{3} \mathrm{O}_{4}\right)$ thin films prepared by sol-gel method, J. Magn. Magn. Mater. 282 (2004) 92-95.

[143]. S. Ramesh, B. C. Sekhar, P. S. V. S. Rao, B. P. Rao, Microstructural and magnetic behavior of mixed Ni-Zn-Co and Ni-Zn-Mn ferrites, Ceram. Int. 40 (2014) 8729-8735.

[144]. T. Maron, Y. Rosenberg, Y. Lereah, G. Markovich, Synthesis and assembly of highquality coabalt ferrite nanocrysrtals prepared by a modified sol gel method, J. Magn. Magn. Mater. 292 (2005)11-16. 
[145]. S. Sun, H. Zeng, D. B. Robinson, S. Raoux, P. M. Rice, S. X. Wang, G. Li, Monodisperse $\mathrm{MFe}_{2} \mathrm{O}_{4}(\mathrm{M}=\mathrm{Fe}, \mathrm{Co}, \mathrm{Mn})$ nanoparticles, J. Am. Chem. Soc. 126 (2004) 273-279.

[146]. M. Byun, J. Wang, Z. Lin, Massively ordered microstructures composed of magnetic nanoparticles, J. Phys. Condens. Matter, 21 (2009) 264014.

[147]. H. Dong, S. R. Du, X. Y. Zheng, G. M. Lyu, L. D. Sun, L. D. Li, P. Z. Zhang, C. Zhang, C. H. Yan, Lanthanide nanoparticles: from design toward bioimaging and therapy, Chem. Rev. 115 (2015) 10725-10815.

[148]. P. Singh, S. Gautam, P. Shandilya, B. Priya, V. P. Singh, P. Raizada, Graphene bentonite supported $\mathrm{ZnFe}_{2} \mathrm{O}_{4}$ as superparamagnetic photocatalyst for antibiotic degradation, Adv. Mater. Lett. 8 (2017) 229-238.

[149]. E. Darezereshki, F. Bakhtiari, M. Alizadeh, A. Behrad vakylabad, M. Ranjbar, Direct thermal decomposition synthesis and characterization of hematite $\left(\alpha-\mathrm{Fe}_{2} \mathrm{O}_{3}\right)$ nanoparticles, Mat. Sci. Semicond. Process. 15 (2012) 91-97.

[150]. Y. Tian, B. Yu, X. Li, K. Li, Facile solvothermal synthesis of monodisperse $\mathrm{Fe}_{3} \mathrm{O}_{4}$ nanocrystals with precise size control of one nanometre as potential MRI contrast agents, J. Mater. Chem. 21 (2011) 2476-2481.

[151]. Q. Yuanchun, Z. Yanbao, W. Zhishen, Preparation of cobalt oxide nanoparticles and cobalt powders by solvothermal process and their characterization, Mater. Chem. Phys. 110 (2008) 457-462.

[152]. H. Wu, G. Liu, X. Wang, J. Zhang, Y. Chen, J. Shi, H. Yang, H. Hu, S. Yang, Solvothermal synthesis of cobalt ferrite nanoparticles loaded on multiwalled carbon nanotubes for magnetic resonance imaging and drug delivery, Acta Biomater. 7 (2011) 3496-3504.

[153]. S. Ameer, I. H. Gul, M. Mujahid, Ultra low permittivity loss $\mathrm{CoFe}_{2} \mathrm{O}_{4}$ and $\mathrm{CoFe}_{2} \mathrm{O}_{4}{ }^{-\mathrm{rGO}}$ nanohybrids by novel 1-hexagonal assisted solvothermal process, J. Alloys Compd. 642 (2015) 78-82.

[154]. K. V. P. M. Shafi, A. Ulman, A. Dyal, X. Yan, N. Yang, C. Estournes, L. Fournes, A. Wattiaux, H. White, M. Rafailovich, Magnetic Enhancement of $\gamma-\mathrm{Fe}_{2} \mathrm{O}_{3}$ Nanoparticles by Sonochemical Coating, Chem. Mater. 14 (2002) 1778-1787. 
[155]. H. Xu, B. W. Zeiger, K. S. Suslick, Sonochemical synthesis of nanomaterials, Chem. Soc. Rev. 42 (2013) 2555-2567.

[156]. P. Tartaj, M. D. P. Morales, S. Veintemillas-Verdaguer, T. González-Carreño, C. J. Serna, The preparation of magnetic nanoparticles for applications in biomedicine, J. Phys. D Appl. Phys. 36 (2003) R182.

[157]. A. L. Morel, S. I. Nikitenko, K. Gionnet, A. Wattiaux, J. Lai-Kee-Him, B. C. Labrugere, Chevalier, G. Deleris, C. Petibois, A. Brisson, M. Simonoff, Sonochemical approach to the synthesis of $\mathrm{Fe}_{3} \mathrm{O}_{4} @ \mathrm{SiO}_{2}$ core-shell nanoparticles with tunable properties, ACS Nano, 2 (2008) 847-856.

[158]. W. Z. Lv, B. Liu, Z. K. Luo, X. Z. Ren, P. X. Zhang, XRD studies on the nanosized copper ferrite powders synthesized by sonochemical method, J. Alloys Compd. 46(2008) 261-264.

[159]. R. A. Mukh-Qasem and A. Gedanken, Sonochemical synthesis of stable hydrosol of $\mathrm{Fe}_{3} \mathrm{O}_{4}$ nanoparticles, J. Colloid Interface Sci. 284 (2005) 489-494.

[160]. J. H. Bang and K.S. Suslick. Applications of ultrasound to the synthesis of nanostructured materials, Adv. Mater. 22 (2010) 1039-59.

[161]. A. Hassanjani-Roshan, M. R. Vaezi, A. Shokuhfar, Z. Rajabali, Synthesis of iron oxide nanoparticles via sonochemical method and their characterization, Particuology, 9 (2011) 95-99.

[162]. R. K. Patel, S. Mandal, T. Padhi, M. K. Sahu, Synthesis of Magnetic Iron-oxide Nanoparticle through Micro emulsion for Environmental Application, (2013).

[163]. A. Di Paola, E. García-López, G. Marcì, L. Palmisano, A survey of photocatalytic materials for environmental remediation, J. Hazard. Mater. 211(2012) 3-29.

[164]. L. Shi, Y. He, X. Wang, Y. Hu, Recyclable photo-thermal conversion and purification systems via $\mathrm{Fe}_{3} \mathrm{O}_{4} @ \mathrm{TiO}_{2}$ nanoparticles, Energy Convers. Manage. 171 (2018) 272-278.

[165]. Y. Li, H. Yi, X. Tang, X. Liu, Y. Wang, B. Cui, S. Zhao, Study on the performance of simultaneous desulfurization and denitrification of $\mathrm{Fe}_{3} \mathrm{O}_{4}-\mathrm{TiO}_{2}$ composites, Chem. Eng. J. 304 (2016) 89-97.

[166]. Q. Sun, Y. Hong, Q. Liu, L. Dong, Synergistic operation of photocatalytic degradation and Fenton process by magnetic $\mathrm{Fe}_{3} \mathrm{O}_{4}$ loaded $\mathrm{TiO}_{2}$, Appl. Surf. Sci. 430 (2018) 399-406. 
[167]. Z. Guanghong, D. Hongyan, Z. Yufu, L. Yuebin, L. Peng, High visible-light photocatalytic activity of $\gamma-\mathrm{Fe}_{2} \mathrm{O}_{3} / \mathrm{TiO}_{2}$ nanotube heterojunction arrays, Rare Met. Mater. Eng. 45 (2016) 1117-1121.

[168]. T. C. Cheng, K. S. Yao, N. Yeh, C. I. Chang, H. C. Hsu, Y. T. Chien, C. Y. Chang. Visible light activated bactericidal effect of $\mathrm{TiO}_{2} / \mathrm{Fe}_{3} \mathrm{O}_{4}$ magnetic particles on fish pathogens, Surf. Coat. Technol. 204 (2009) 1141-1144.

[169]. M. A. Zazouli, F. Ghanbari, M.Yousefi, S. Madihi-Bidgoli, Photocatalytic degradation of food dye by $\mathrm{Fe}_{3} \mathrm{O}_{4}-\mathrm{TiO}_{2}$ nanoparticles in presence of peroxymonosulfate: The effect of UV sources, J. Environ. Chem. Eng. 5(2017) 2459-2468.

[170]. J. Jing, J. Li, J. Feng, W. Li, W. Y. William, Photodegradation of quinoline in water over magnetically separable $\mathrm{Fe}_{3} \mathrm{O}_{4} / \mathrm{TiO}_{2}$ composite photocatalysts, Chem. Eng. J. 219 (2013) 355-360.

[171]. S. Dehghan, B. Kakavandi, R. R. Kalantary, Heterogeneous sonocatalytic degradation of amoxicillin using $\mathrm{ZnO} @ \mathrm{Fe}_{3} \mathrm{O}_{4}$ magnetic nanocomposite: Influential factors, reusability and mechanisms, J. Mol. Liq. 264 (2018) 98-109.

[172]. P. Goyal, S. Chakraborty, S. K. Misra, Multifunctional $\mathrm{Fe}_{3} \mathrm{O}_{4}-\mathrm{ZnO}$ nanocomposites for environmental remediation applications, Environ. Nanotechnol. Monit. Manage. 10 (2018) 28-35.

[173]. M. Xu, Q. Li, H. Fan, Monodisperse nanostructured $\mathrm{Fe}_{3} \mathrm{O}_{4} / \mathrm{ZnO}$ microrods using for waste water treatment, Adv. Powder Technol. 25 (2014)1715-1720.

[174]. J. Xia, A. Wang, X. Liu, Z. Su, Preparation and characterization of bifunctional, $\mathrm{Fe}_{3} \mathrm{O}_{4} / \mathrm{ZnO}$ nanocomposites and their use as photocatalysts, Appl. Surf. Sci. 257 (2011) 9724-9732.

[175]. J. C. Sin, S. Q. Tan, J. A. Quek, S. M. Lam, A. R. Mohamed, Facile fabrication of hierarchical porous $\mathrm{ZnO} / \mathrm{Fe}_{3} \mathrm{O}_{4}$ composites with enhanced magnetic, photocatalytic and antibacterial properties, Mater. Lett. 228 (2018) 207-211.

[176]. N. Li, Y. Tian, J. Zhao, W. Zhan, J. Du, L. Kong, J. Zhang, W. Zuo, Ultrafast selective capture of phosphorus from sewage by $3 \mathrm{D} \mathrm{Fe}_{3} \mathrm{O}_{4} @ \mathrm{ZnO}$ via weak magnetic field enhanced adsorption, Chem. Eng. J. 341(2018) 289-297.

[177]. C. Karunakaran, S. SakthiRaadha, P. Gomathisankar, P. Vinayagamoorthy, $\mathrm{Fe}_{3} \mathrm{O}_{4} / \mathrm{SnO}_{2}$ nanocomposite: Hydrothermal and sonochemical synthesis, characterization, 
and visible-light photocatalytic and bactericidal activities, Powder Technol. 246 (2013) 635-642.

[178]. Z. Dong, Q. Zhang, B. Y. Chen, J. Hong, Oxidation of Bisphenol A by persulfate via $\mathrm{Fe}_{3} \mathrm{O}_{4}-\alpha-\mathrm{MnO}_{2}$ nanoflower-like catalyst: Mechanism and efficiency, Chem. Eng. J. 357 (2019) 337-347.

[179]. J. Zhang, Z. Guo, Y. Li, S. Pan, X. Chen, J. Xu, Effect of environmental conditions on the sorption of uranium on $\mathrm{Fe}_{3} \mathrm{O}_{4} @ \mathrm{MnO}_{2}$ hollow spheres, J. Mol. Liq. 223 (2016) 534540.

[180]. J. Zhao, J. Liu, N. Li, W. Wang, J. Nan, Z. Zhao, F. Cui, Highly efficient removal of bivalent heavy metals from aqueous systems by magnetic porous $\mathrm{Fe}_{3} \mathrm{O}_{4}-\mathrm{MnO}_{2}$ : adsorption behavior and process study, Chem. Eng. J. 304 (2016) 737-746.

[181]. Q. Yang, H. Song, Y. Li, Z. Pan, M. Dong, F. Chen, Z. Chen, Flower-like core-shell $\mathrm{Fe}_{3} \mathrm{O}_{4} @ \mathrm{MnO}_{2}$ microspheres: Synthesis and selective removal of Congo red dye from aqueous solution, J. Mol. Liq. 234 (2017)18-23.

[182]. Z. D. Fang, K. Zhang, J. Liu, J. Y. Fan, Z. W. Zhao, Fenton-like oxidation of azo dye in aqueous solution using magnetic $\mathrm{Fe}_{3} \mathrm{O}_{4}-\mathrm{MnO}_{2}$ nanocomposites as catalysts, Water Sci. Eng. 10 (2017) 326-333.

[183]. Z. Yingzhe, H. Yuxing, Q. Qingdong, W. Fuchun, W. Wankun, L. Yongmei, The synthesis of $\mathrm{Cu} / \mathrm{Fe} / \mathrm{Fe}_{3} \mathrm{O}_{4}$ catalyst through the aqueous solution ball milling method assisted by high-frequency electromagnetic field, Superlattices Microstruct. 118 (2018) 123-129.

[184]. X. Hou, Y. Tian, X. Zhang, S. Dou, L. Pan, W. Wang, Y. Li, J. Zhao, Preparation and characterization of $\mathrm{Fe}_{3} \mathrm{O}_{4} / \mathrm{SiO}_{2} / \mathrm{Bi}_{2} \mathrm{MoO}_{6}$ composite as magnetically separable photocatalyst, J. Alloys Compd. 638 (2015) 214-220.

[185]. M. S. Gohari and A. H. Yangjeh, Ultrasonic-assisted preparation of novel ternary $\mathrm{ZnO} / \mathrm{AgI} / \mathrm{Fe}_{3} \mathrm{O}_{4}$ nanocomposites as magnetically separable visible-light-driven photocatalysts with excellent activity, J. Colloid. Interf. Sci. 461 (2016) 144-153.

[186]. A. R. Vartooni, A. M. Saadatmand, M. Mahdavi, Catalytic reduction of organic pollutants using biosynthesized $\mathrm{Ag} / \mathrm{C} / \mathrm{Fe}_{3} \mathrm{O}_{4}$ nanocomposite by red water and Caesalpinia gilliesii flower extract, Mater. Chem. Phys. 219 (2018) 328-339. 
[187]. L. F. Tian, Y. Z. Hu, Y. R. Guo, Q. J. Pan, Dual effect of lignin amine on fabrication of magnetic $\mathrm{Fe}_{3} \mathrm{O}_{4} / \mathrm{C} / \mathrm{ZnO}$ nanocomposite in situ and photocatalytic property, Ceram. Int. 44 (2018) 14480-14486.

[188]. L. Cheng, S. Zhang, Y. Wang, G. Ding, Z. Jiao, Ternary P25-graphene- $-\mathrm{Fe}_{3} \mathrm{O}_{4}$ nanocomposite as a magnetically recyclable hybrid for photodegradation of dyes, Mater. Res. Bull. 73 (2016) 77-83.

[189]. S. Banerjee, P. Benjwal, M. Singh, K. K. Kar, Graphene oxide (rGO)-metal oxide $\left(\mathrm{TiO}_{2} / \mathrm{Fe}_{3} \mathrm{O}_{4}\right)$ based nanocomposites for the removal of methylene blue, Appl. Surf. Sci. 439 (2018) 560-568.

[190]. M. Mousavi, A. Habibi-Yangjeh, D. Seifzadeh, Novel ternary g- $\mathrm{C}_{3} \mathrm{~N}_{4} / \mathrm{Fe}_{3} \mathrm{O}_{4} / \mathrm{MnWO}_{4}$ nanocomposites: Synthesis, characterization, and visible-light photocatalytic performance for environmental purposes, J. Mater. Sci. Technol. 34(2018)1638-1651.

[191]. A. Habibi-Yangje and A. Akhundi, Novel ternary g- $\mathrm{C}_{3} \mathrm{~N}_{4} / \mathrm{Fe}_{3} \mathrm{O}_{4} / \mathrm{Ag}_{2} \mathrm{CrO}_{4}$ nanocomposites: magnetically separable and visible-light-driven photocatalysts for degradation of water pollutants, J. Mol. Catal. A-Chem. 415 (2016) 122-130.

[192]. M. Mousavi and A. Habibi-Yangjeh, Magnetically separable ternary g$\mathrm{C}_{3} \mathrm{~N}_{4} / \mathrm{Fe}_{3} \mathrm{O}_{4} / \mathrm{BiOI}$ nanocomposites: novel visible-light-driven photocatalysts based on graphitic carbon nitride, J. Colloid Interf. Sci. 465 (2016) 83-92.

[193]. A. Habibi-Yangjeh and M. Shekofteh-Gohari, $\mathrm{Fe}_{3} \mathrm{O}_{4} / \mathrm{ZnO} / \mathrm{Ag}_{3} \mathrm{VO}_{4} / \mathrm{AgI}$ nanocomposites: Quaternary magnetic photocatalysts with excellent activity in degradation of water pollutants under visible light, Sep. Purif. Technol. 166 (2016) 63-72.

[194]. A. Kumar, A. Kumar, G. Sharma, H. Ala'a, M. Naushad, A. A. Ghfar, F. J. Stadler, Quaternary magnetic $\mathrm{BiOCl} / \mathrm{g}-\mathrm{C}_{3} \mathrm{~N}_{4} / \mathrm{Cu}_{2} \mathrm{O} / \mathrm{Fe}_{3} \mathrm{O}_{4}$ nano-junction for visible light and solar powered degradation of sulfamethoxazole from aqueous environment, Chem. Eng. J. 334 (2018) 462-478. 


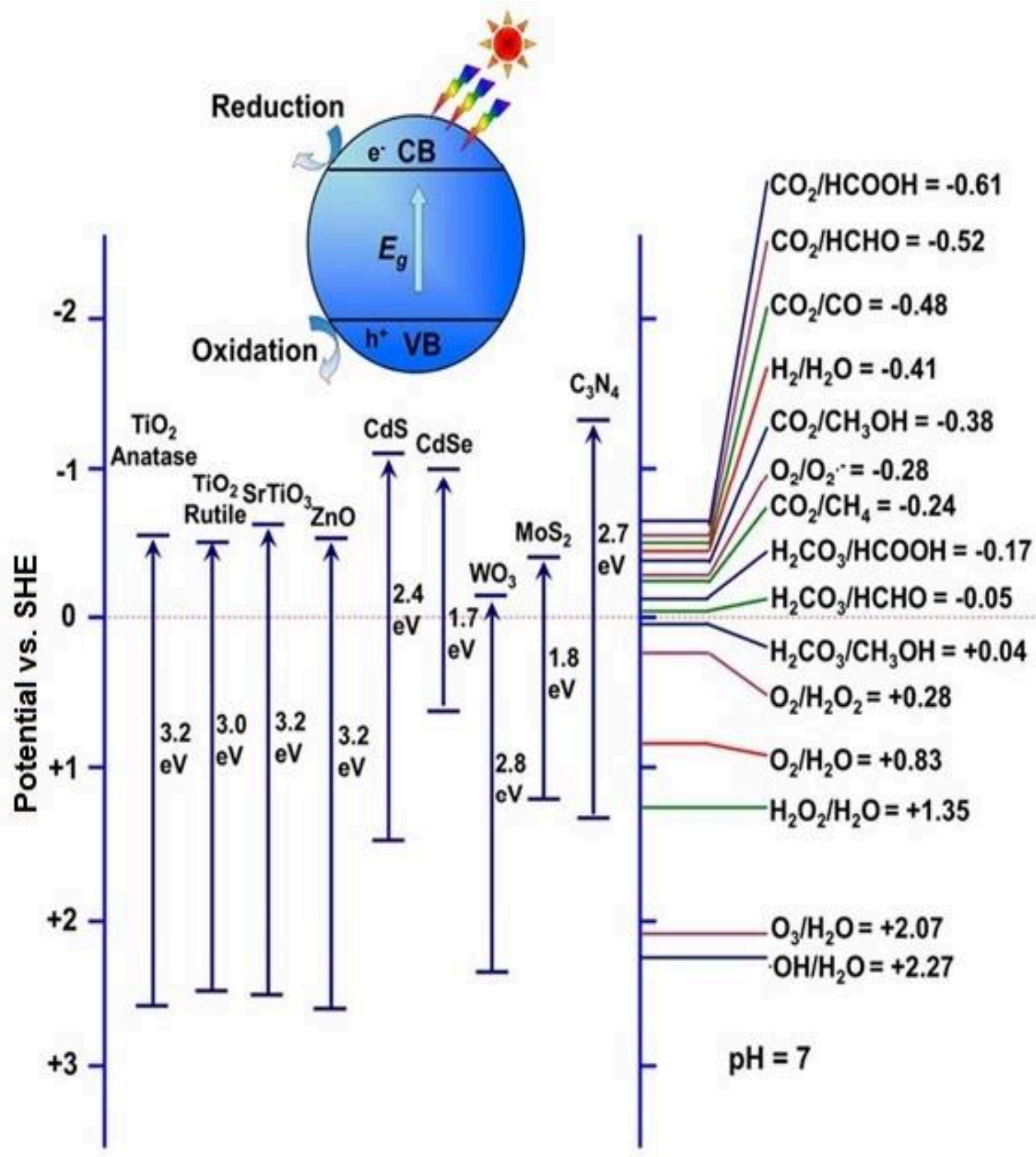

Fig. 1. Potential for various redox couples in water $(\mathrm{pH} 7)$ and the band-edge positions of semiconductor photoctalysts [22]. 


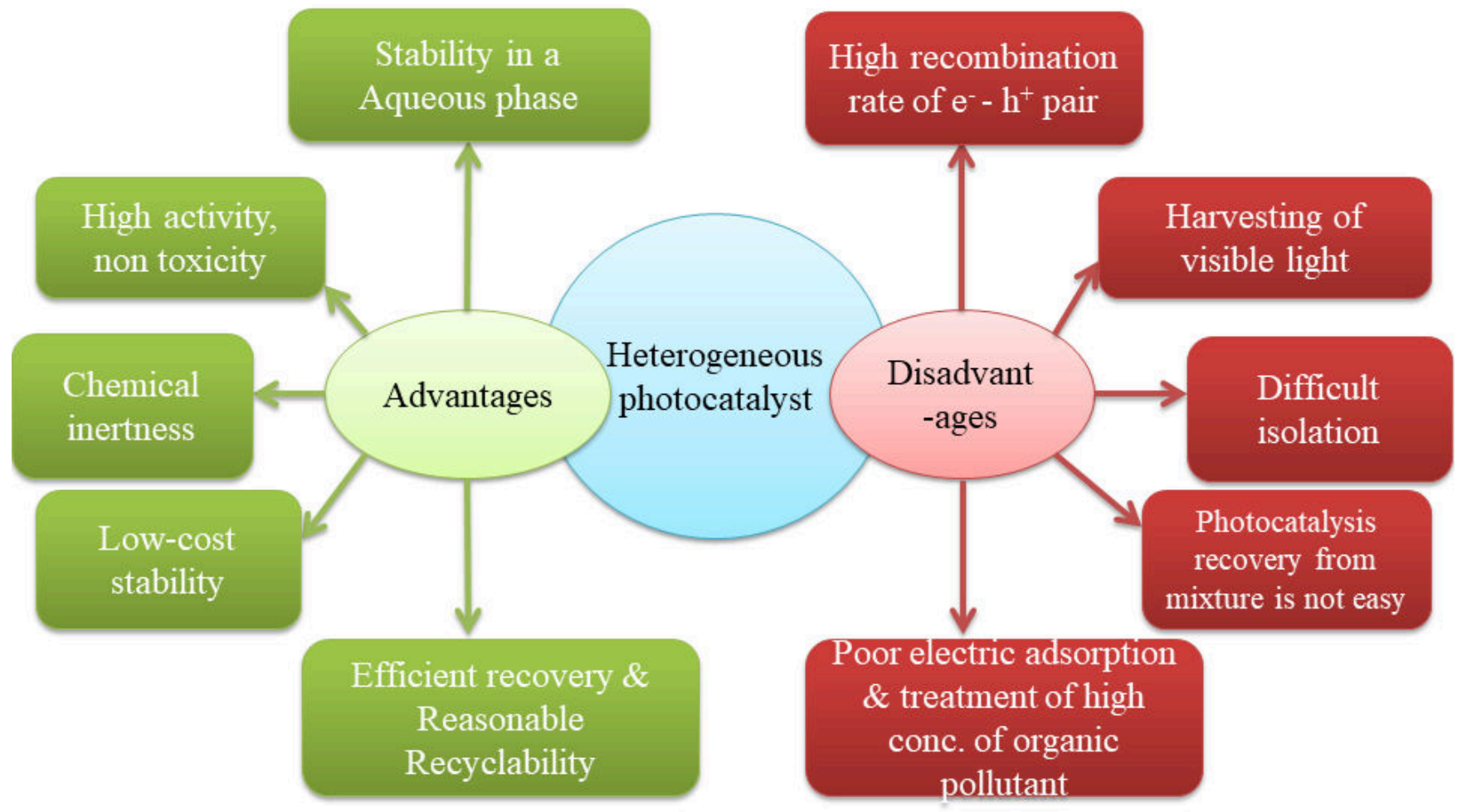

Fig. 2. Advantages and disadvantages of heterogeneous photocatalyst. 


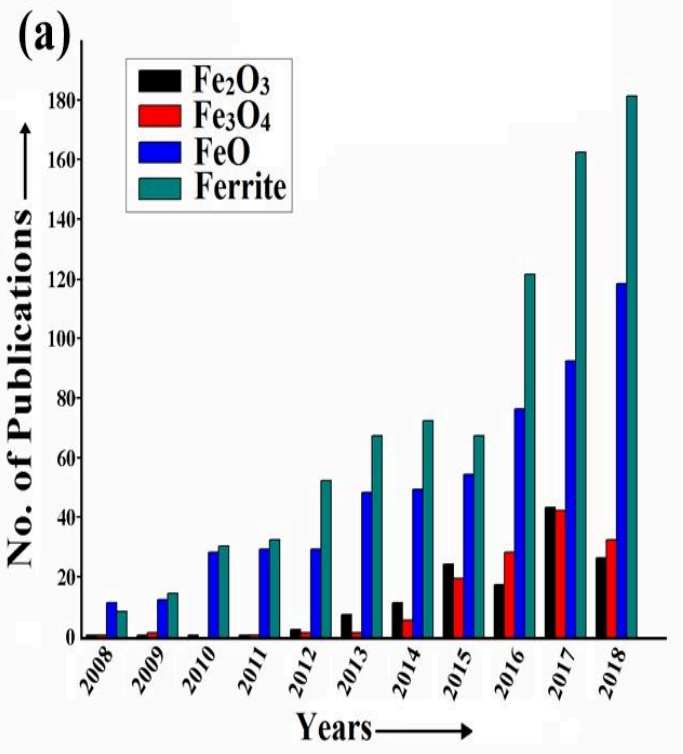

(b)

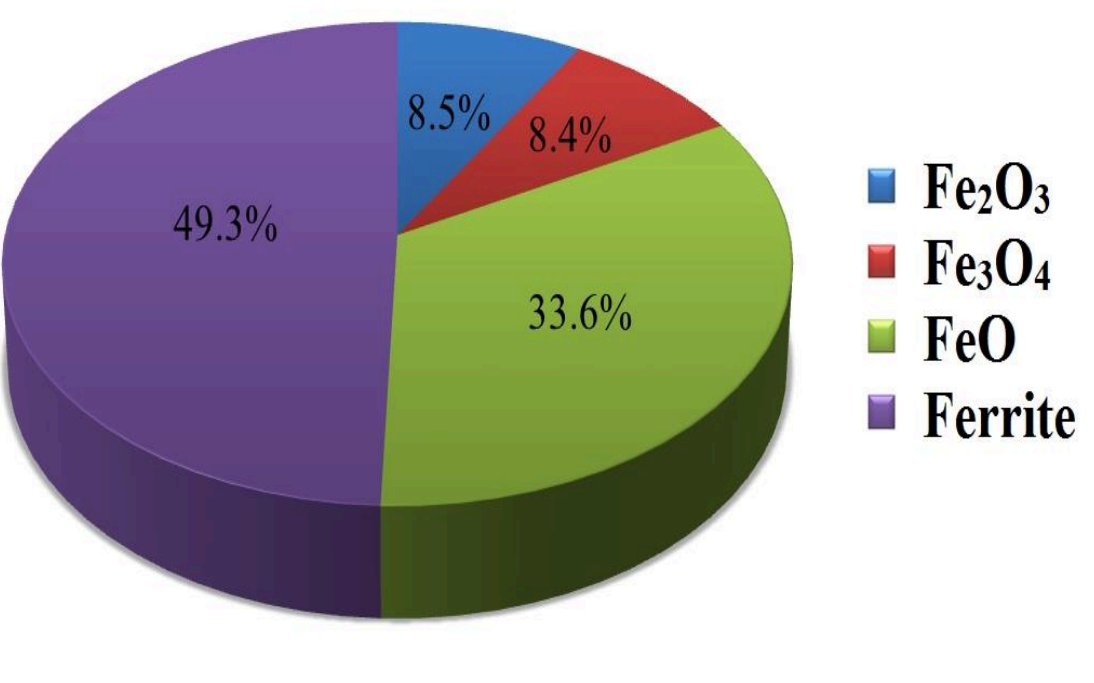

Fig. 3. (a) Survey of Publications of last ten years from 2008 to 2018. (b) Percentage of publications of different Iron oxide of previous ten years from 2008-2018. 
(a)

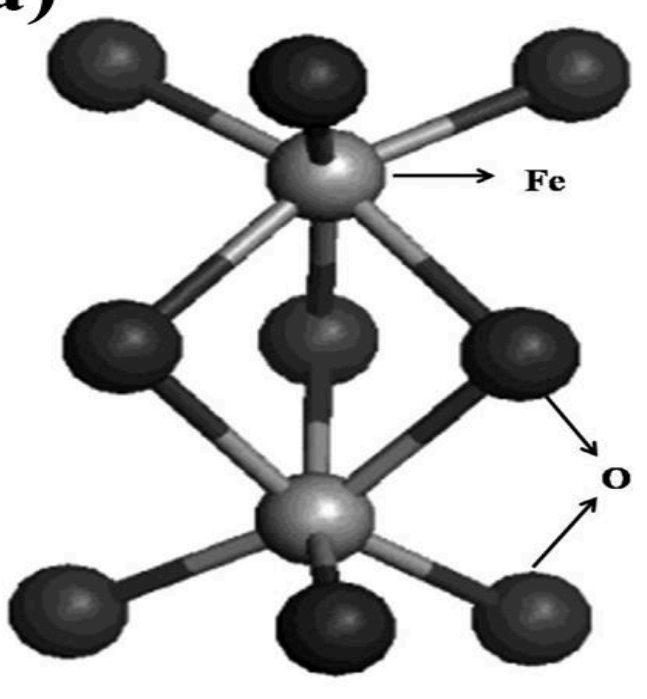

(c)

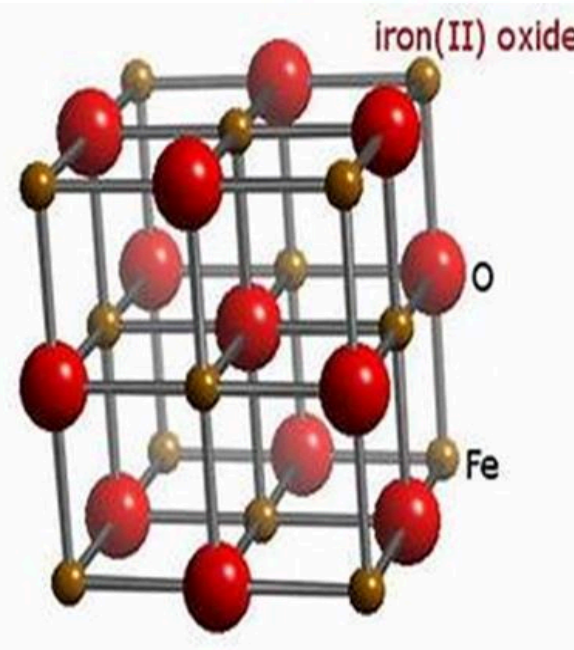

(b)

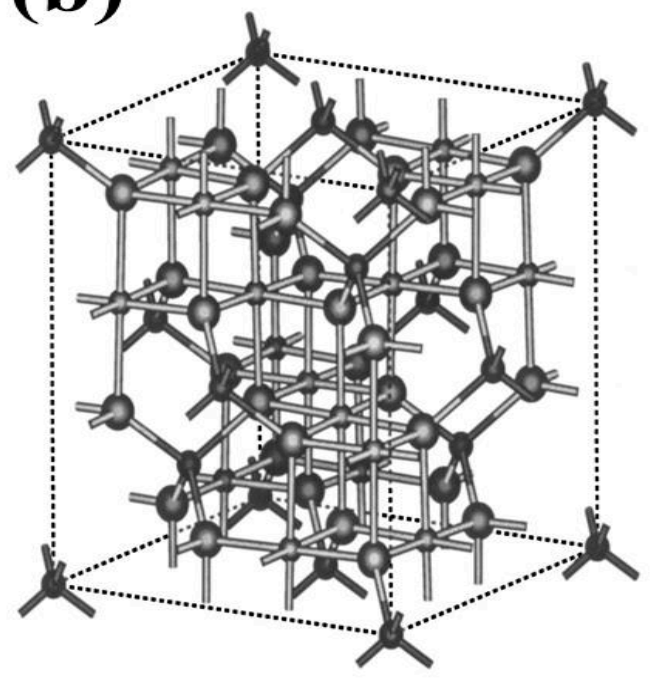

(d)

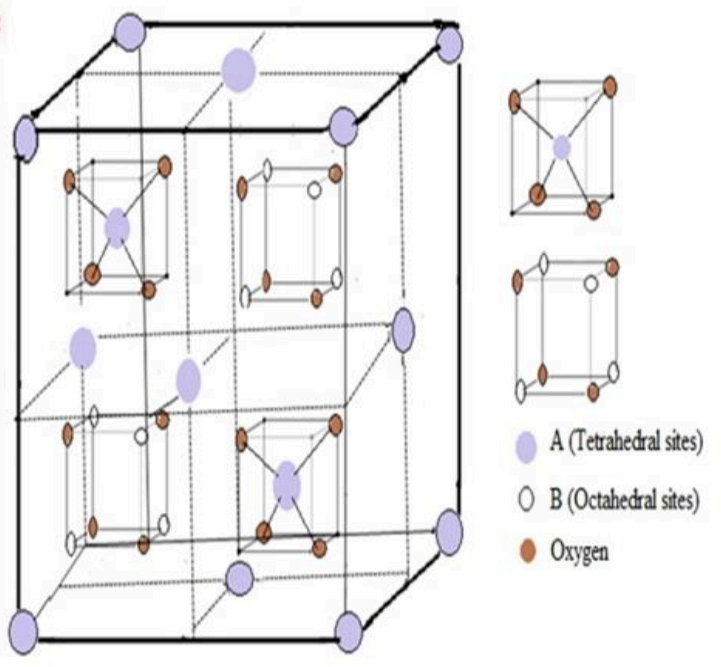

Fig. 4. (a) Crystal structure of $\alpha-\mathrm{Fe}_{2} \mathrm{O}_{3}$. (b) Crystal Structure of $\mathrm{Fe}_{3} \mathrm{O}_{4}$. (c) Structure of $\mathrm{FeO} \&$ (d) structure of Spinel ferrite showing tetrahedral and octahedral sites [58, 59]. 


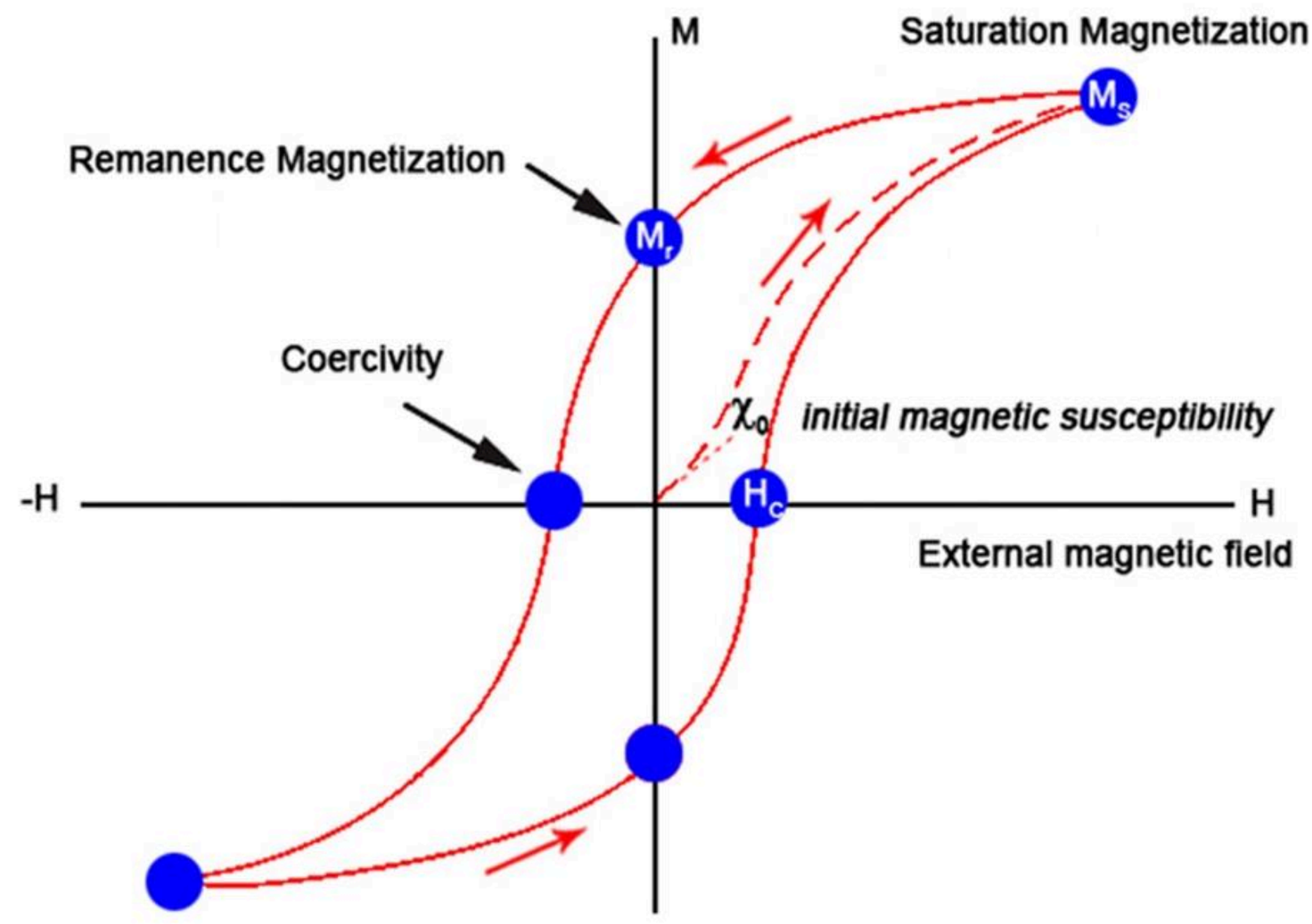

Fig. 5. Schematic presentation of the typical hysteresis loops of IONPs [73]. 
(a)

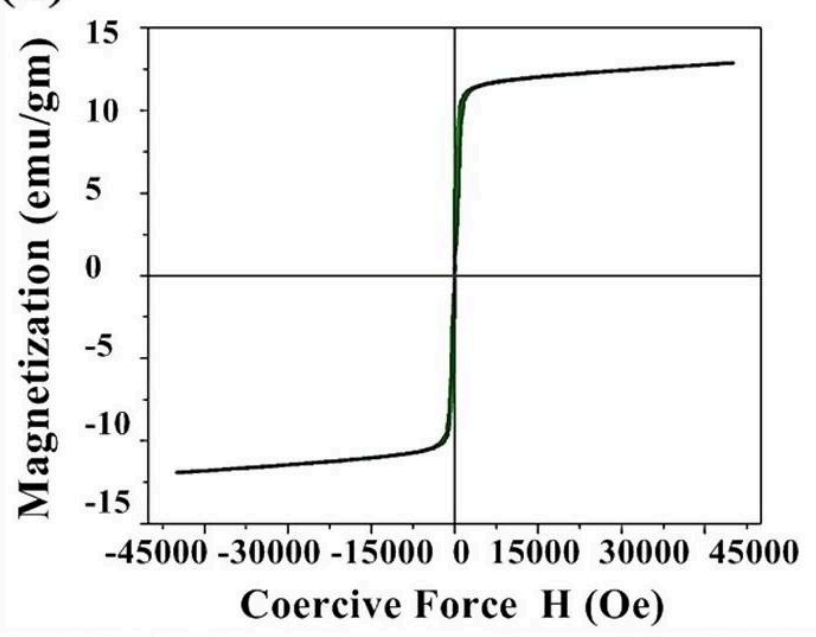

(c)

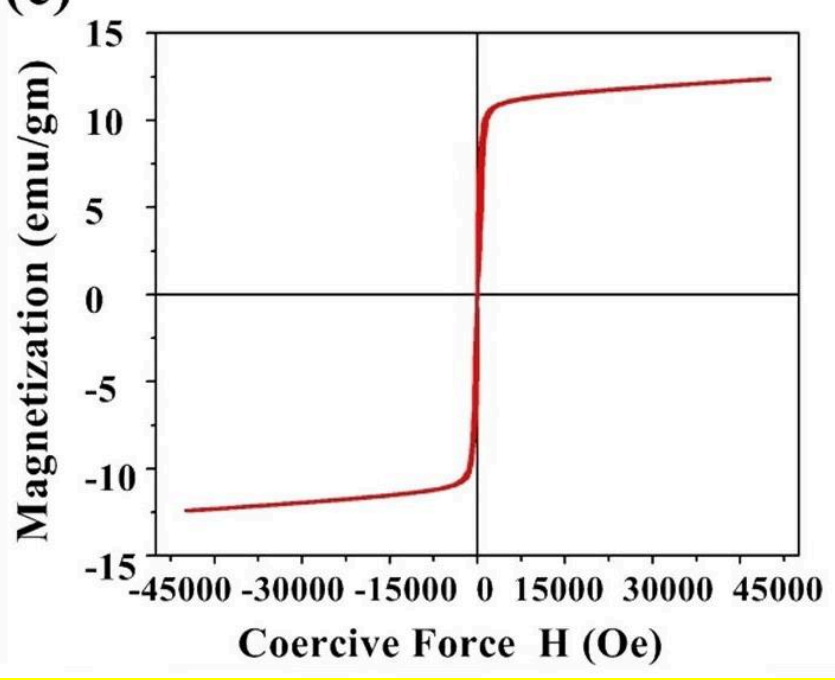

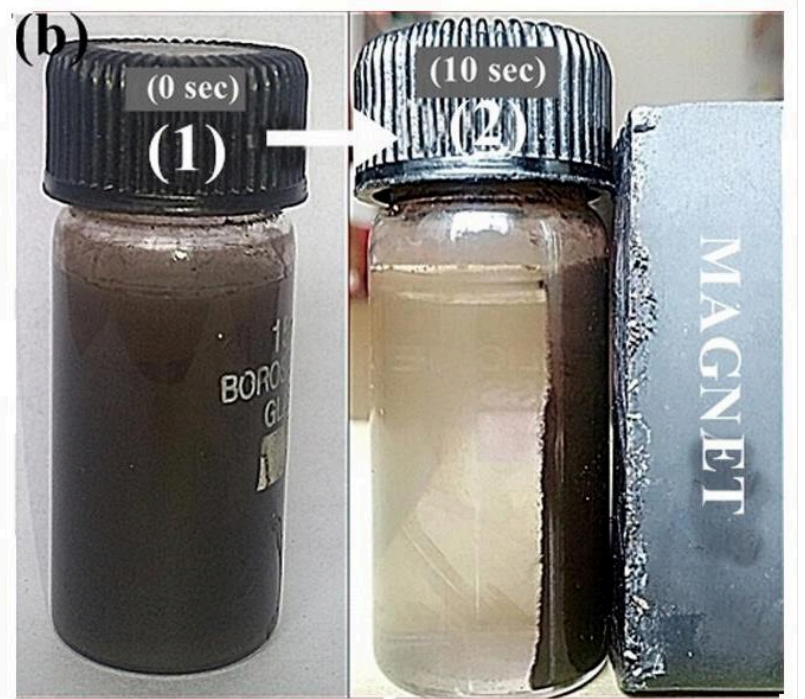

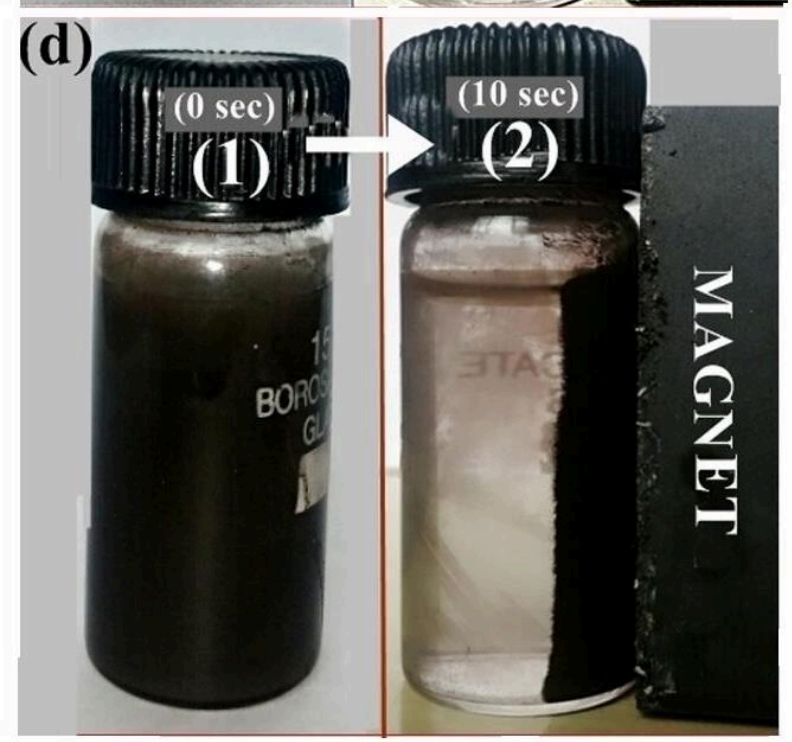

Fig. 6. (a-d) The magnetization hysteresis loop and magnetic separation of $\mathrm{MnFe}_{2} \mathrm{O}_{4} / \mathrm{BT}$ and $\mathrm{MnFe}_{2} \mathrm{O}_{4} / \mathrm{GSC}$. (a) Hysteresis loop of $\mathrm{MnFe}_{2} \mathrm{O}_{4} / \mathrm{BT}$, (b) magnetic separation of $\mathrm{MnFe}_{2} \mathrm{O}_{4} / \mathrm{BT}$. (c) Hysteresis loop of $\mathrm{MnFe}_{2} \mathrm{O}_{4} / \mathrm{GSC}$ and (d) magnetic separation of $\mathrm{MnFe}_{2} \mathrm{O}_{4} / \mathrm{GSC}$ (1) in the absence of magnetic field (2) under external magnetic field.(Permission taken from Elesvier, License Number:4482471388715) [81]. 
(a)

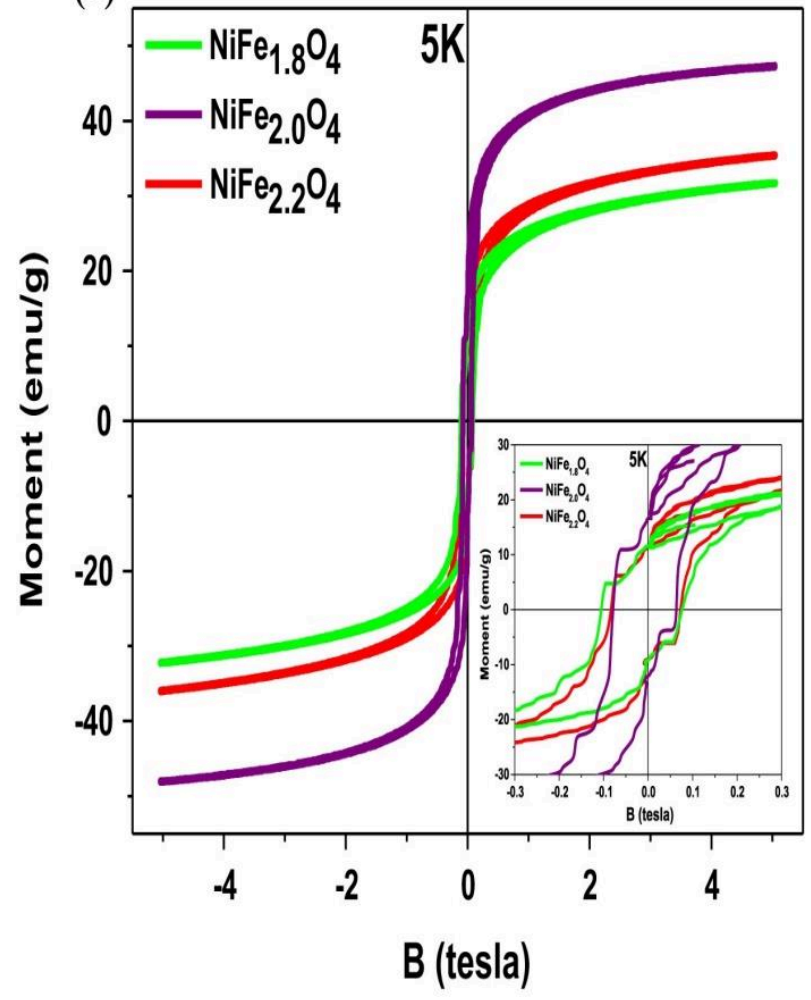

(b)

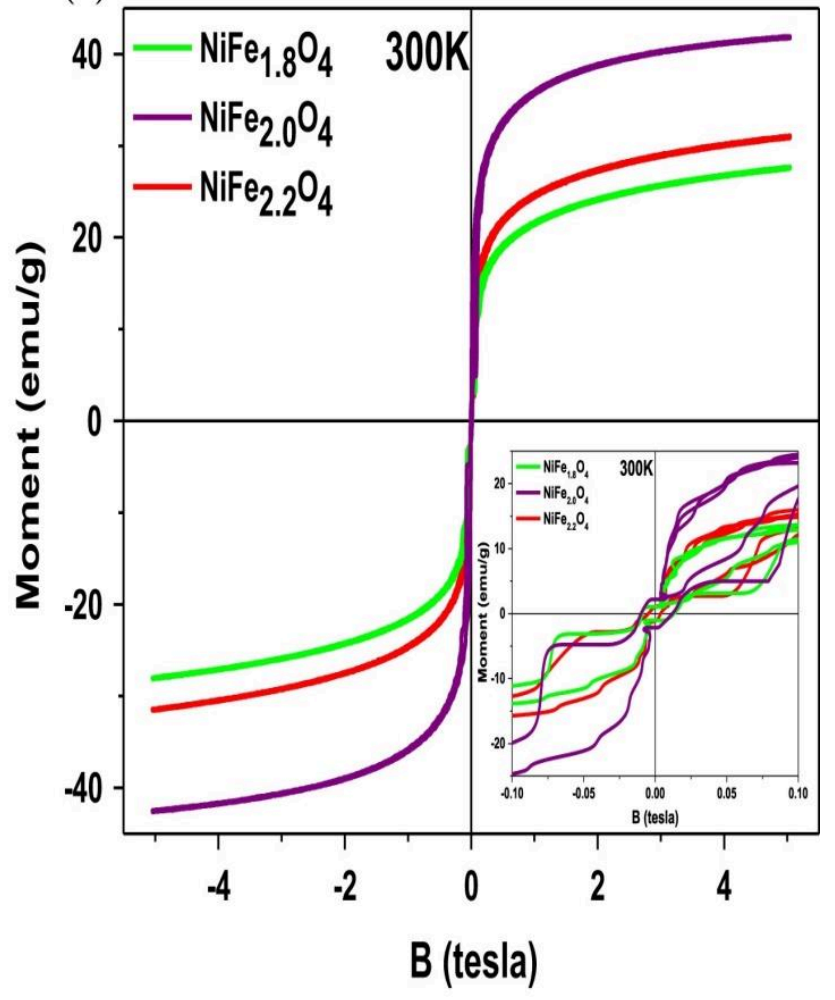

Fig. 7. $\mathrm{M}-\mathrm{H}$ loops of $\mathrm{NiFe}_{\mathrm{x}} \mathrm{O}_{4}$ where $\mathrm{x}=1.8,2.0,2.2$ ) ceramics at (a) $5 \mathrm{~K}$ and (b) $300 \mathrm{~K}$. (Permission taken from Elesvier, License Number: 4473480461906) [139]. 

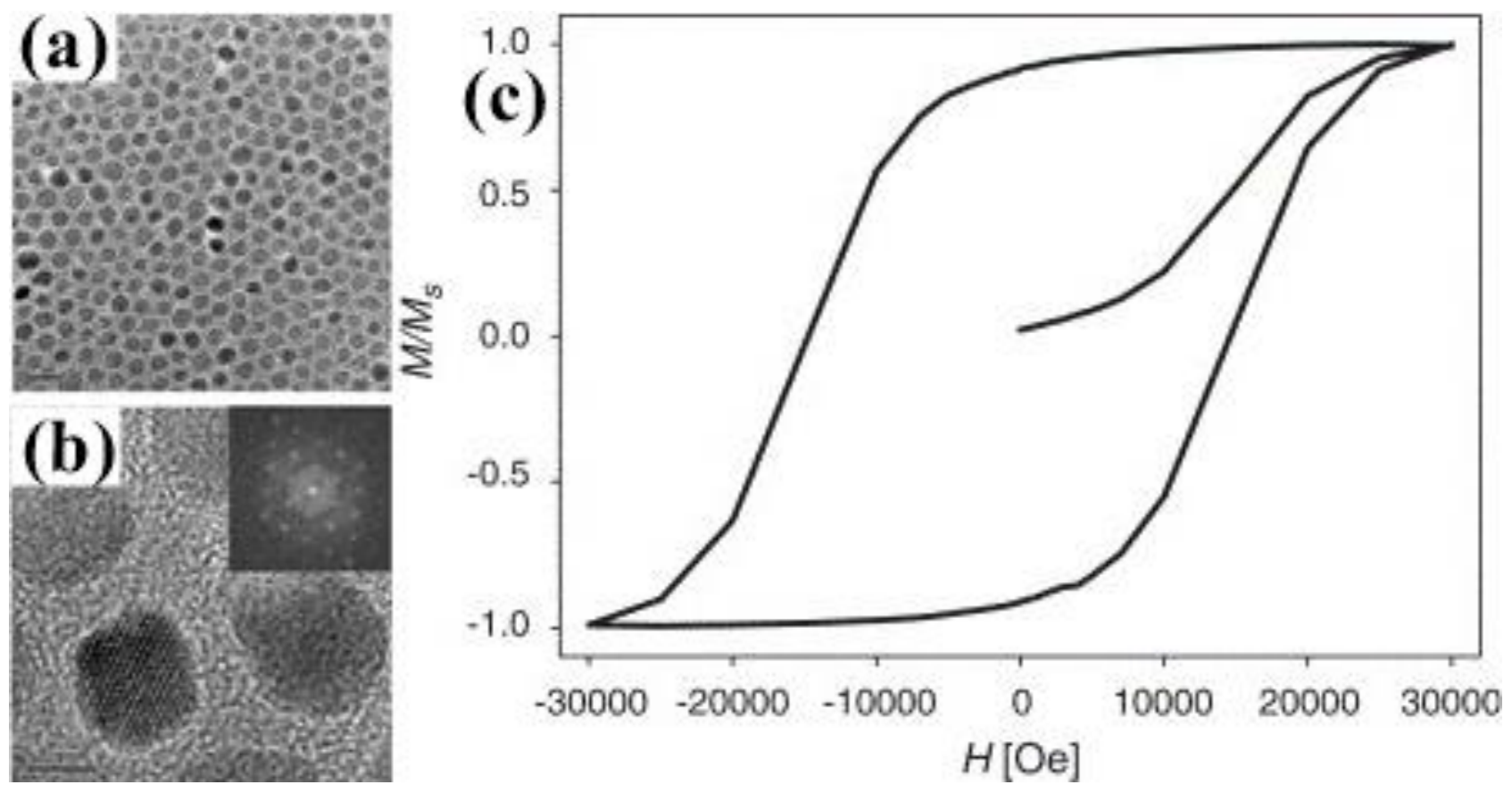

Fig. 8. (a) TEM images of a Langmuir-Blodgett film of the cobalt ferrite nanocrystals (b) High resolution of TEM image of several nanocrystals showing their single crystal structure (c) Reduced hysteresis curve of the isolated particles sample measured at $10 \mathrm{~K}$ with a maximal field of 30KOe.(Permission taken from Elesvier, License Number: 4473480877037) [144]. 

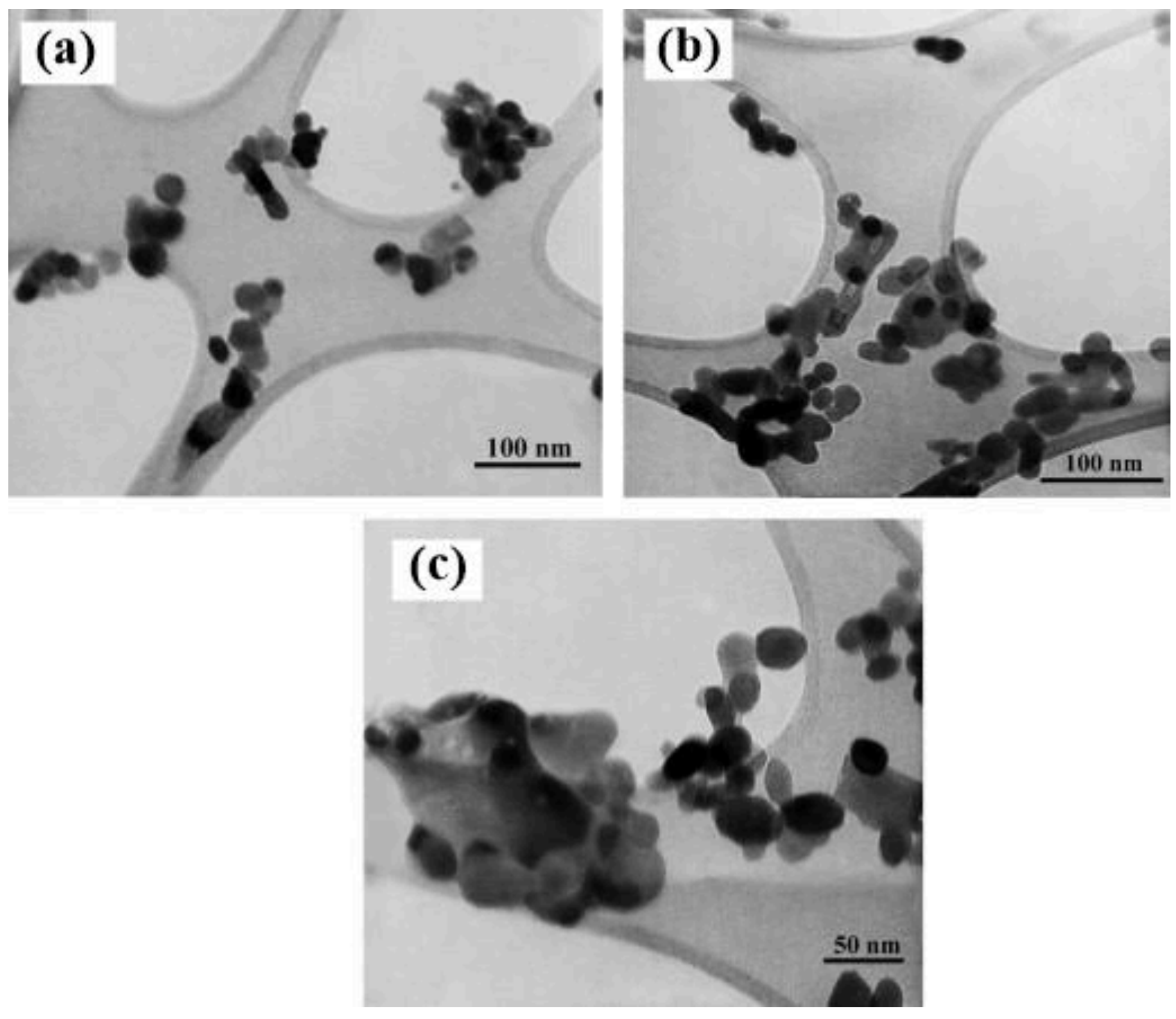

Fig. 9. TEM images of the $\alpha-\mathrm{Fe}_{2} \mathrm{O}_{3}$ nanoparticles synthesized by direct thermal decomposition of $\mathrm{y}-\mathrm{Fe}_{2} \mathrm{O}_{3}$ at $500{ }^{\circ} \mathrm{C}$ for $2 \mathrm{~h}$ (a) $120,000 \mathrm{x}$, (b) 160,000x and (c) 200,000x magnification. (Permission taken from Elesvier, License Number: 4473481196967) [149]. 


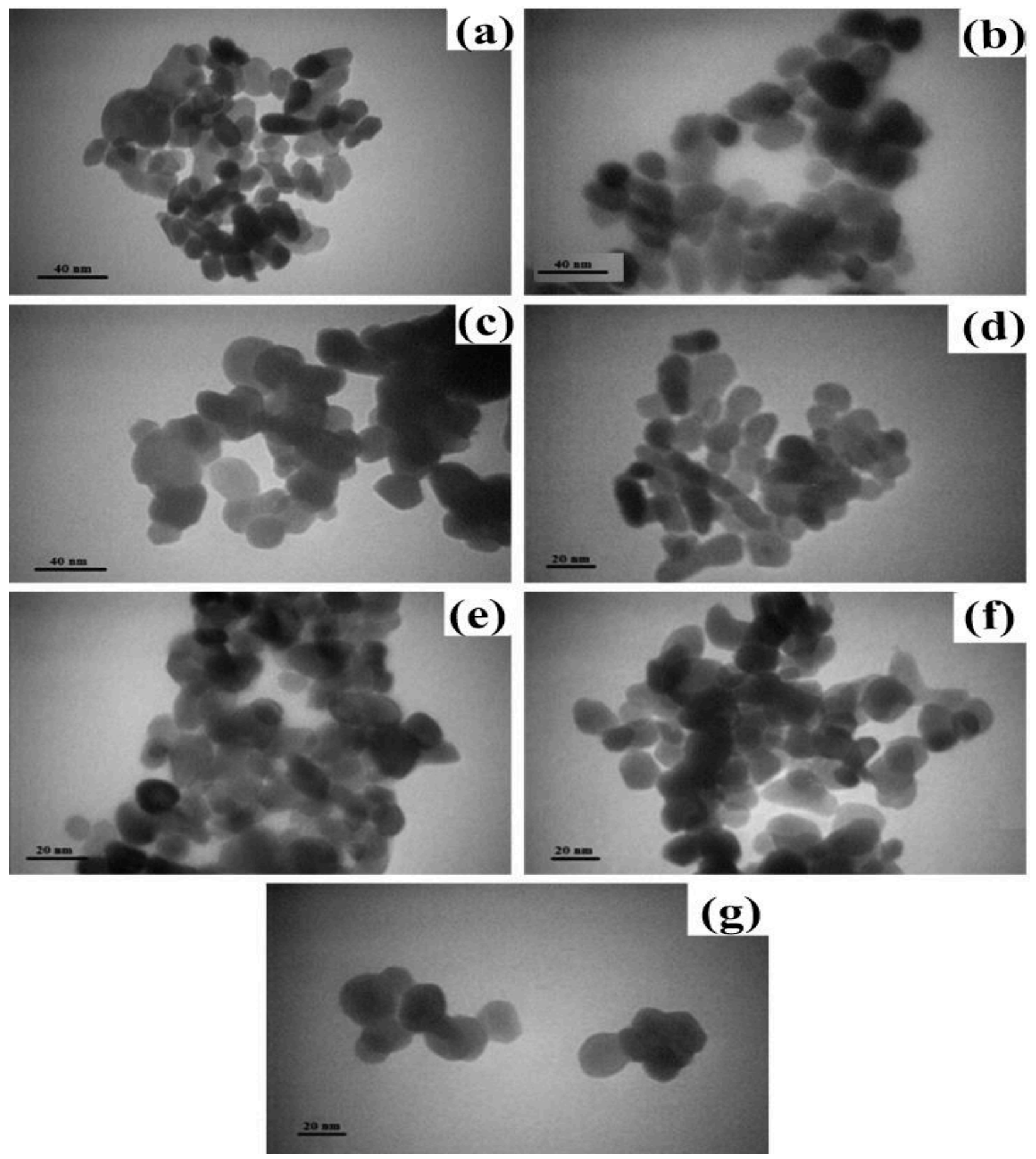

Fig. 10. TEM images of Iron oxide nanoparticles prepared via sonochemical method. (Permission taken from Elesvier, License Number: 4473481407697) [161]. 


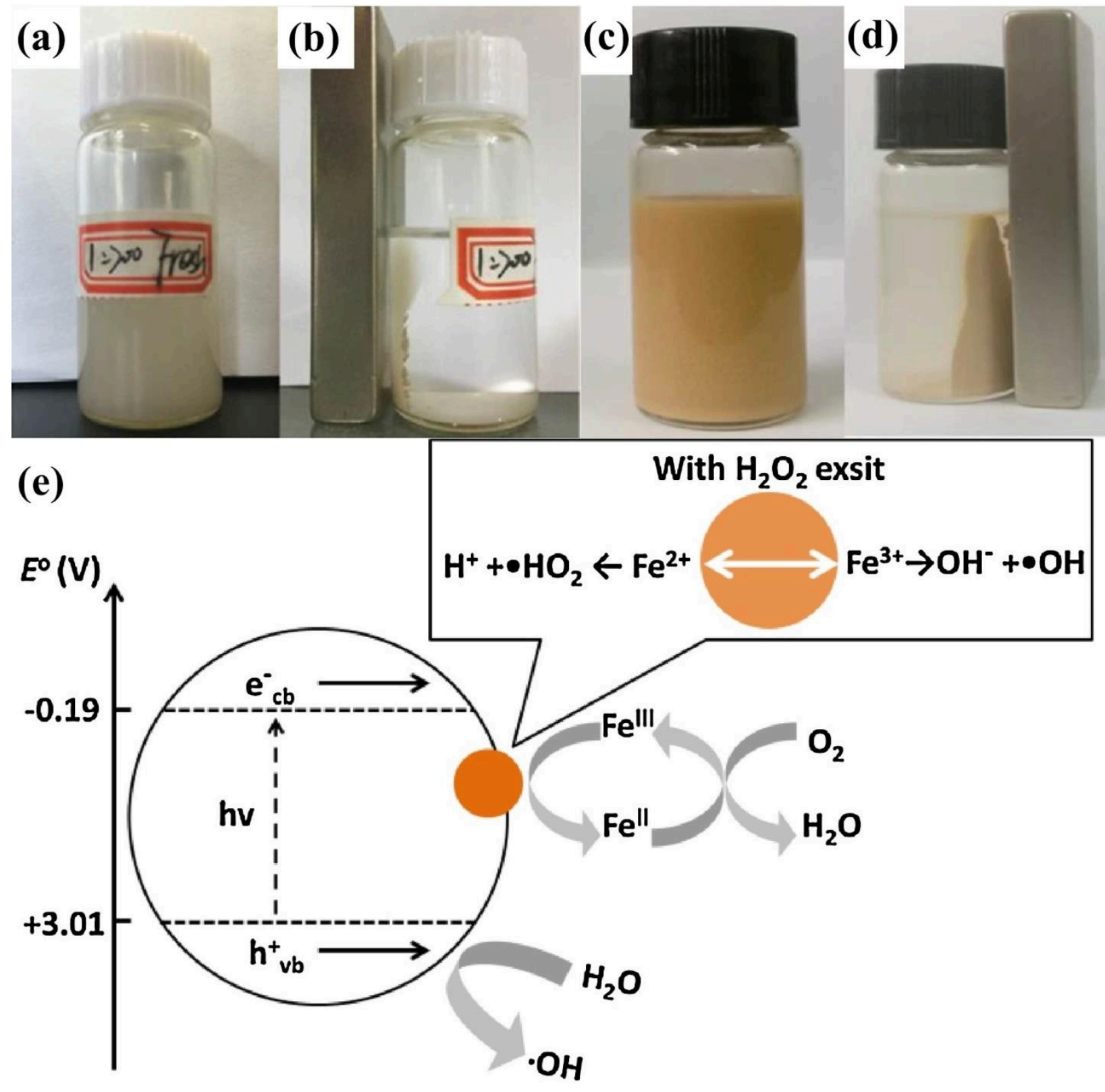

Fig. 11. The $\mathrm{Fe}-\mathrm{TiO}_{2}$ 1:200 (a, b) and 1:5 (c, d) suspensions before (a, c) and after (b, d) the magnetic attraction \& (e) The plausible mechanism of synergistic operation with $\mathrm{Fe}-\mathrm{TiO}_{2}$. (Permission taken from Elesvier, License Number: 4473490205987) [166]. 


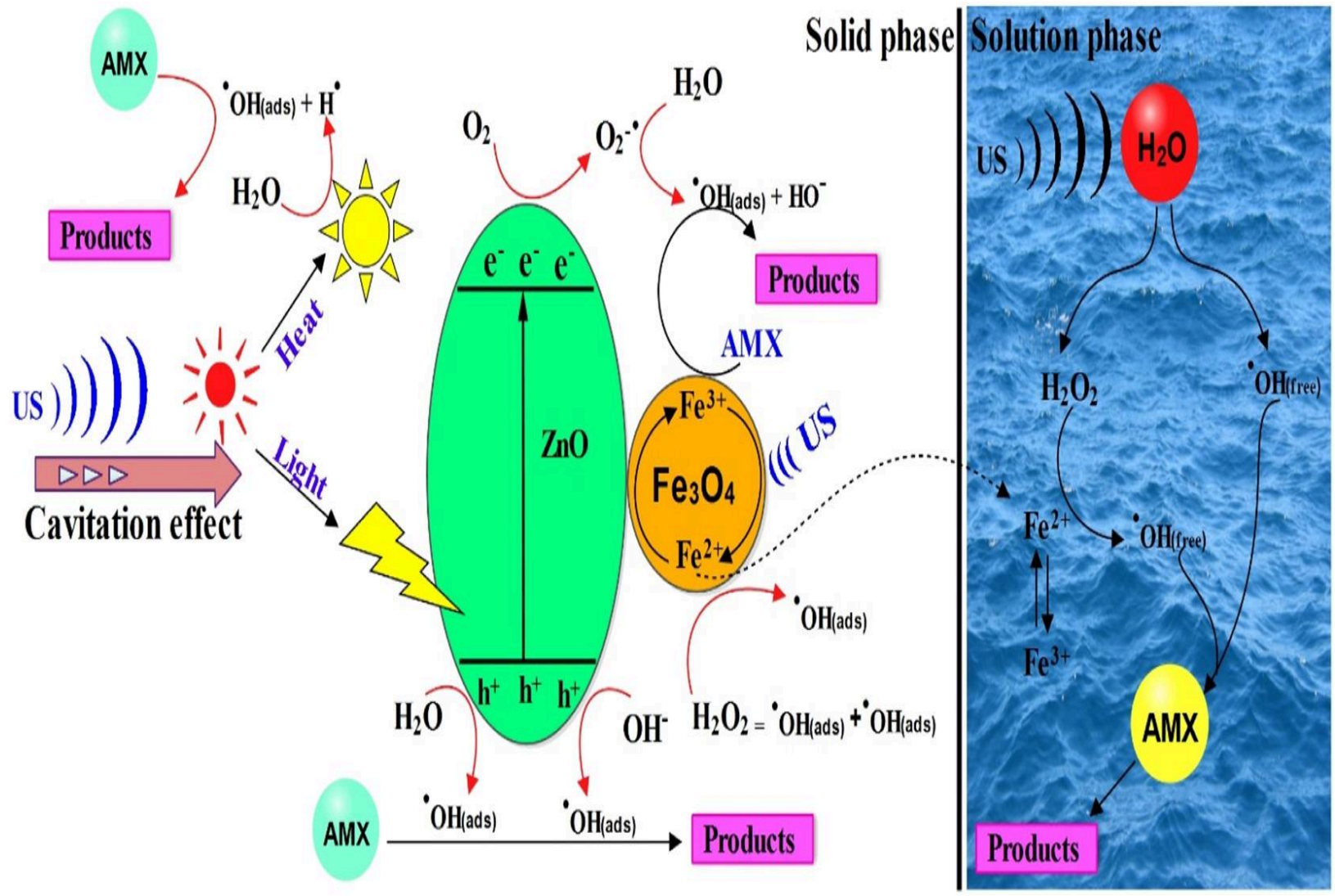

Fig. 12. Possible catalytic mechanism of $\mathrm{ZnO} @ \mathrm{Fe}_{3} \mathrm{O}_{4} / \mathrm{US}$ system in $\mathrm{AMX}$ degradation. (Permission taken from Elesvier, License Number: 4473490484542) [171]. 


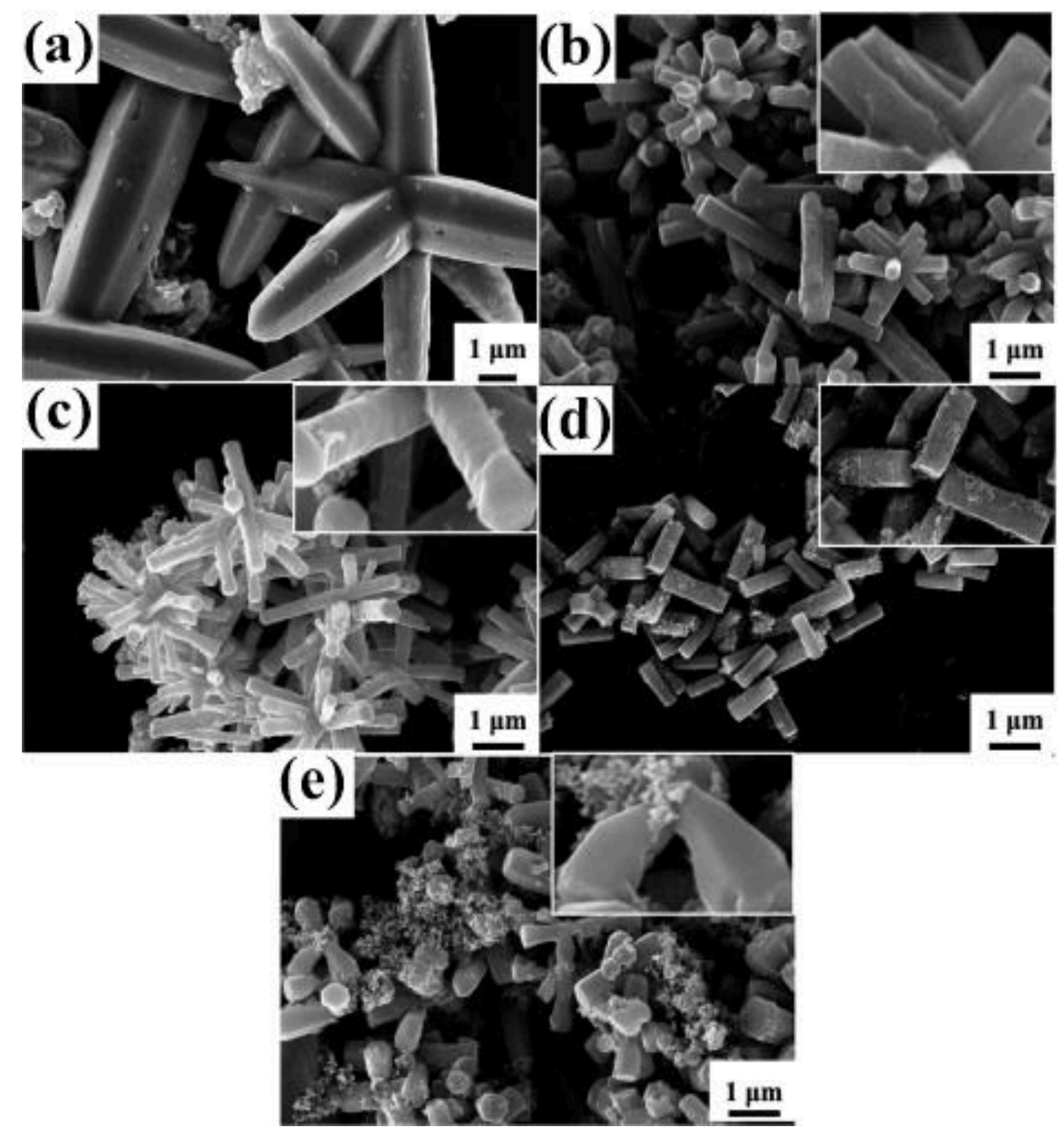

Fig. 13. (a-e) Shows the images of $\mathrm{ZF1}, \mathrm{ZF} 2, \mathrm{ZF} 3, \mathrm{ZF} 4$, and $\mathrm{ZF5}$. The insets are the higher magnification of SEM images. (Permission taken from Elesvier, License Number: 4473490773949) [173]. 

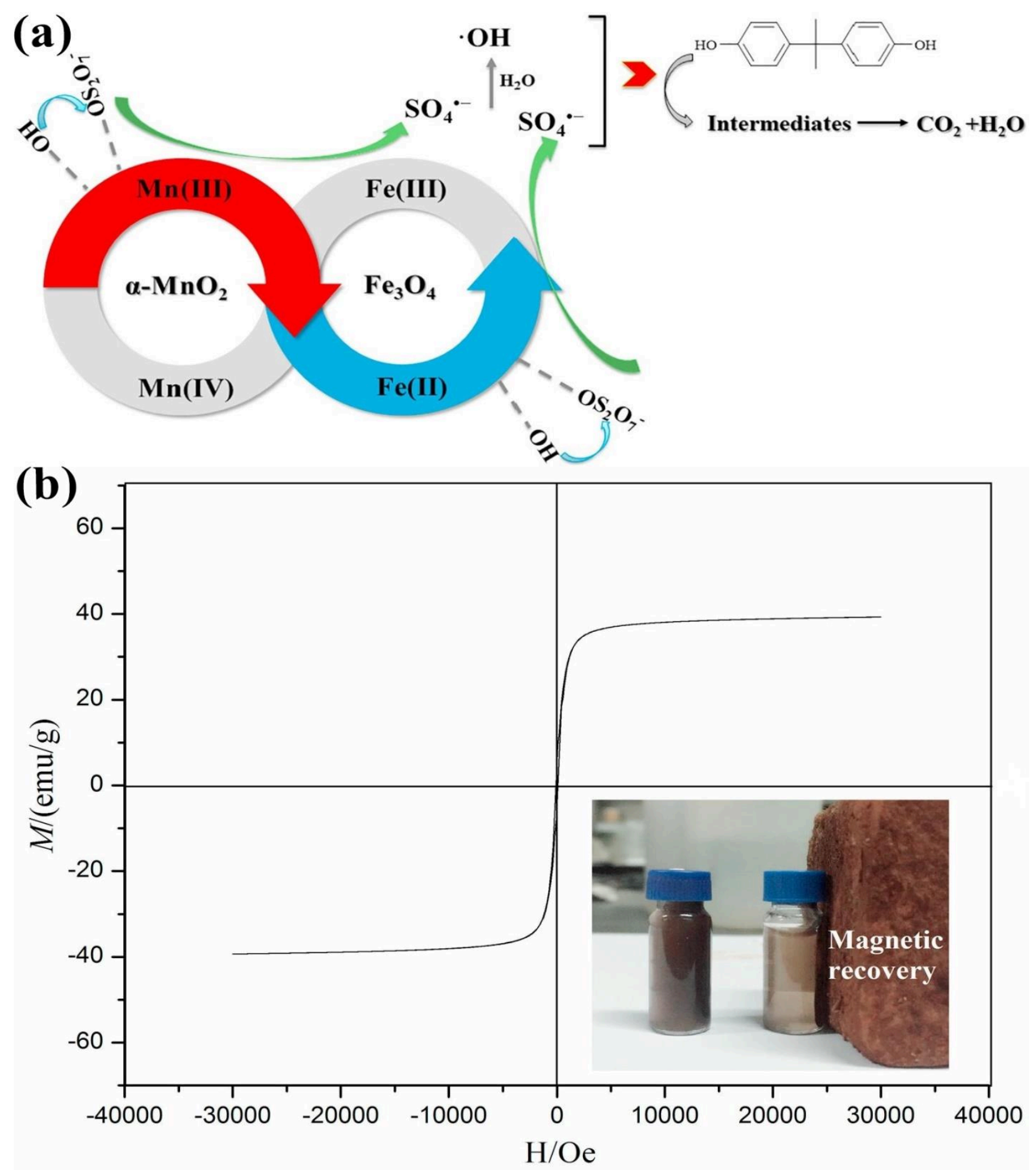

Fig. 14. (a) Proposed mechanism of BPA degradation under $\mathrm{Fe}_{3} \mathrm{O}_{4}-\alpha-\mathrm{MnO}_{2}$. (b) The magnetic hysteresis loop of $\mathrm{Fe}_{3} \mathrm{O}_{4}-\alpha-\mathrm{MnO}_{2}$ catalyst. (Permission taken from Elesvier, License Number: 4473491364906) [178]. 


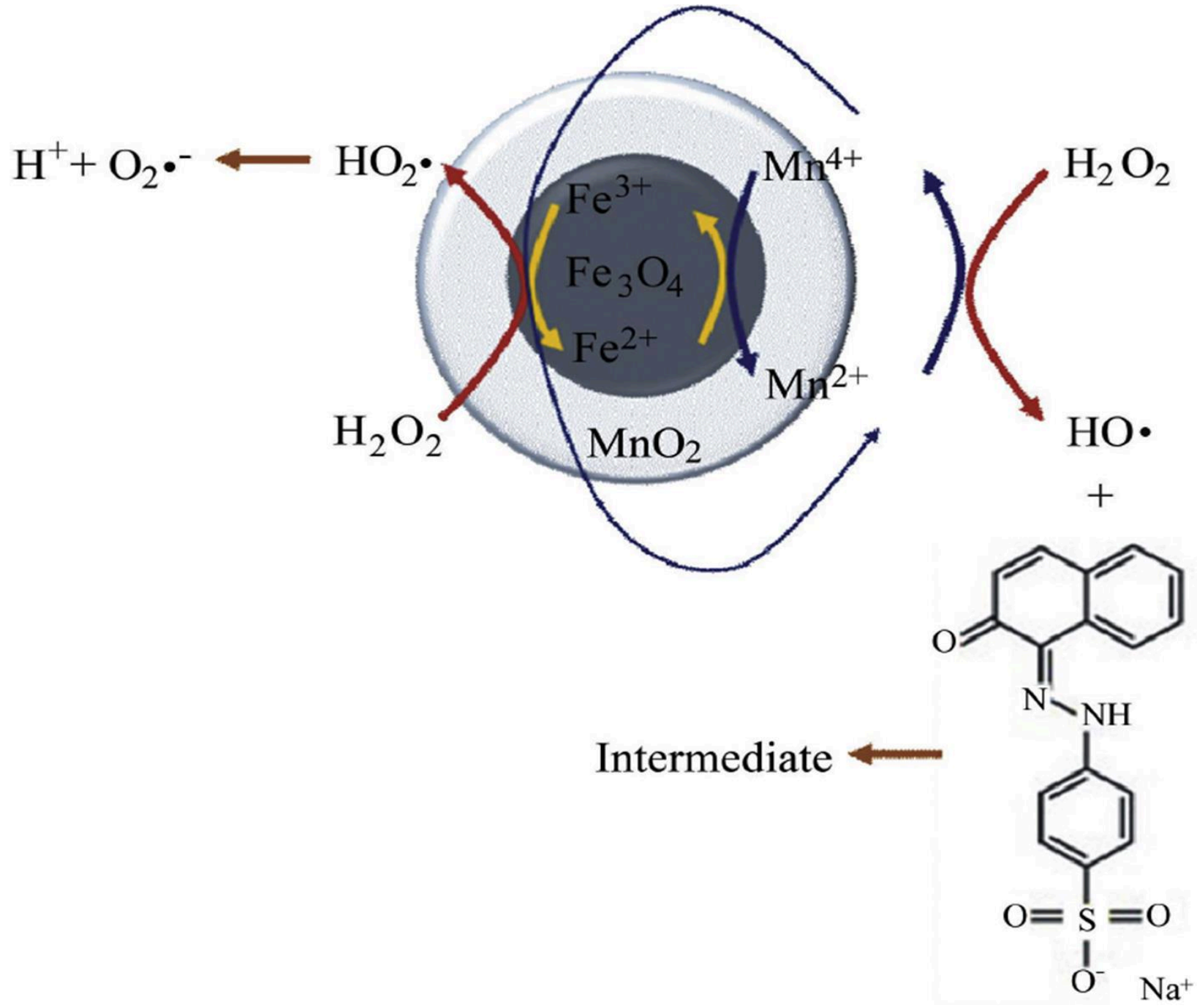

Fig. 15. Proposed mechanism for generation of $\mathrm{HO} \cdot$ and degradation of $\mathrm{AO} 7$ in $\mathrm{Fe}_{3} \mathrm{O}_{4} @ \mathrm{MnO}_{2} / \mathrm{H}_{2} \mathrm{O}_{2}$ system [182]. 


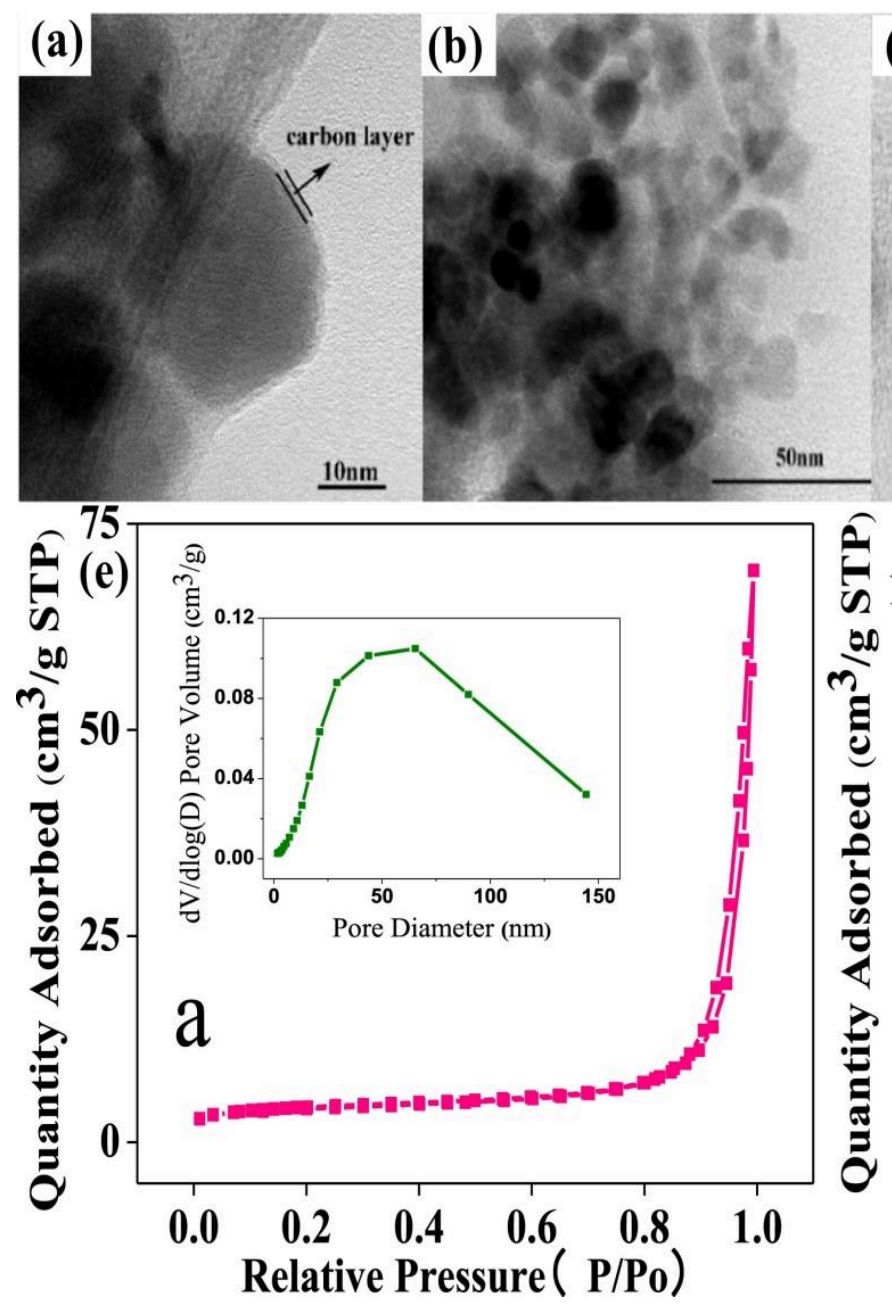

(c)

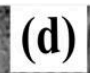

$5 \mathrm{~nm}$

$\mathrm{ZnO}(110)$

$0.16 \mathrm{~nm}$
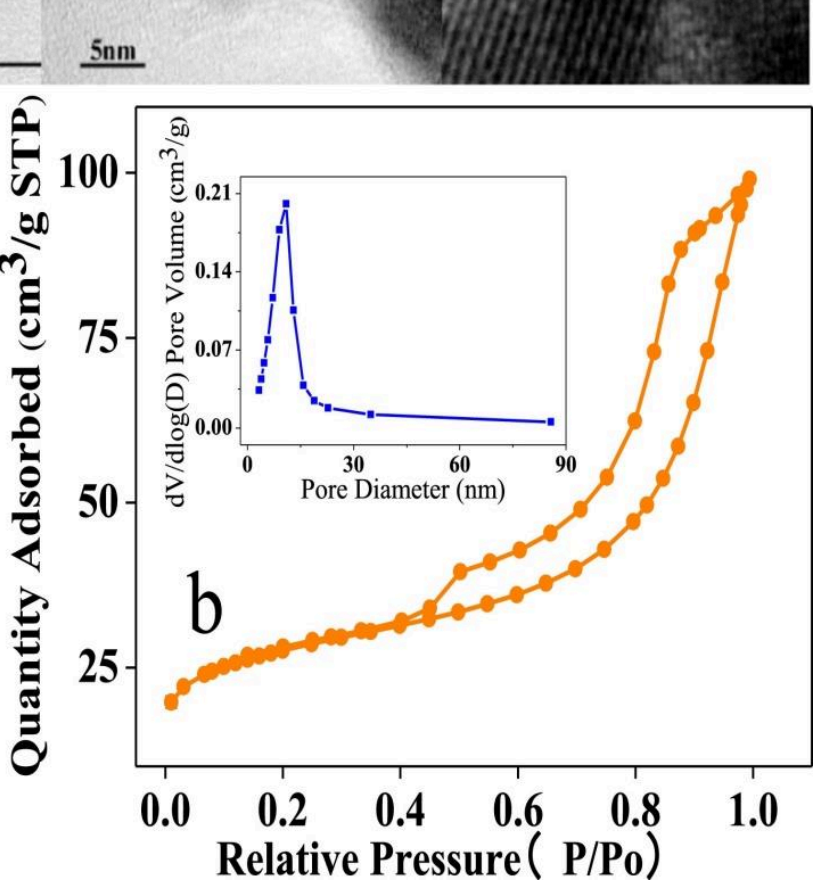

Fig. 16. TEM images of $\mathrm{Fe}_{3} \mathrm{O}_{4} / \mathrm{C}$ (a), and $\mathrm{Fe}_{3} \mathrm{O}_{4} / \mathrm{C} / \mathrm{ZnO}-0.5$ (b, c and d). (e) The adsorption/desorption isothermal curves of $\mathrm{Fe}_{3} \mathrm{O}_{4} / \mathrm{ZnO}$ and $\mathrm{Fe}_{3} \mathrm{O}_{4} / \mathrm{C} / \mathrm{ZnO}(0.5)$ and pore side distribution plots (display in inserted figures). (Permission taken from Elesvier, License Number: 4473530103260) [187]. 

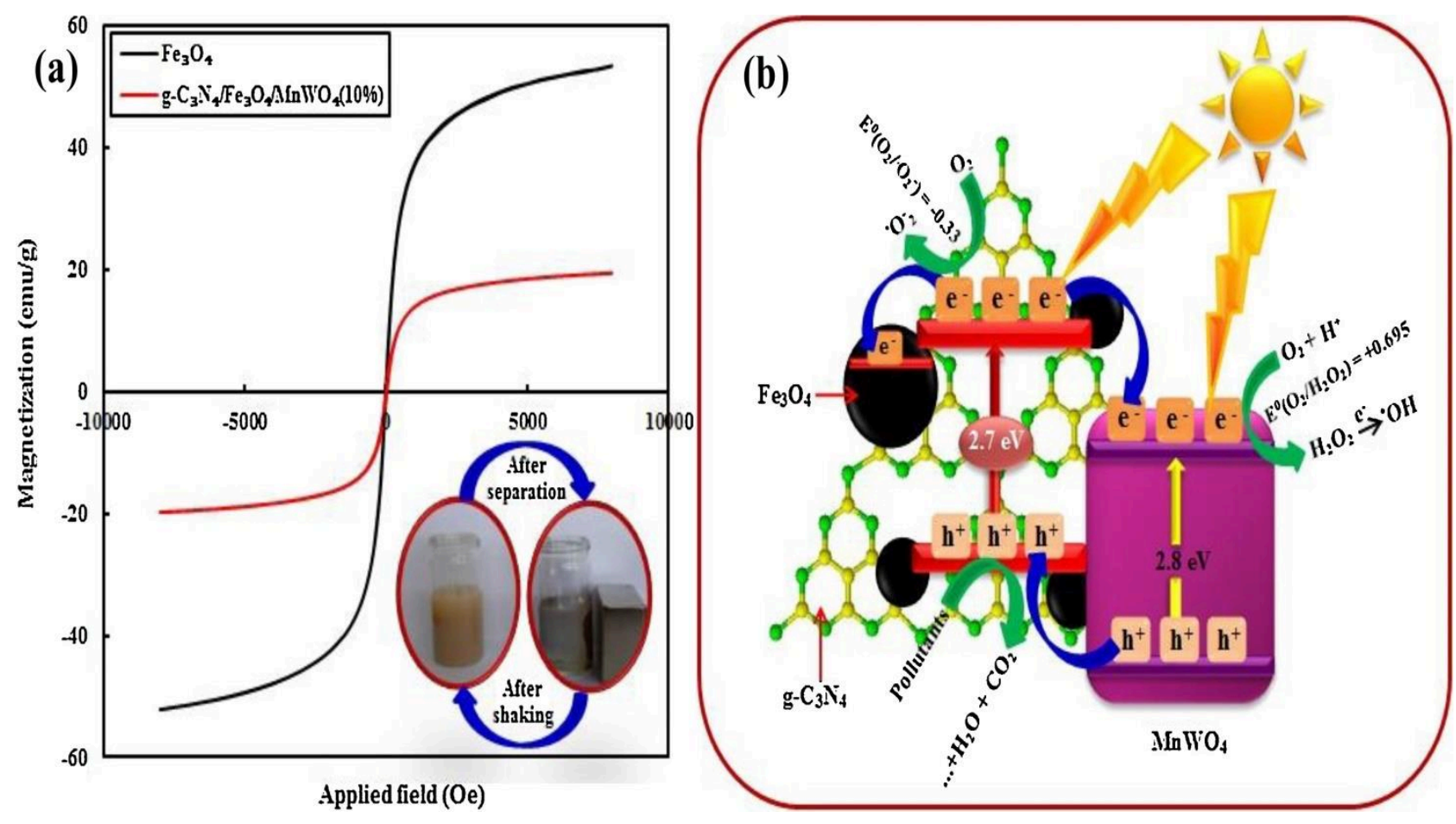

Fig. 17. (a) VSM curves for the $\mathrm{Fe}_{3} \mathrm{O}_{4}$ and $\mathrm{g}-\mathrm{C}_{3} \mathrm{~N}_{4} / \mathrm{Fe}_{3} \mathrm{O}_{4} / \mathrm{MnWO}_{4}(10 \%)$ samples. (b) A plausible mechanism for the separation of electron-hole pairs in $\mathrm{g}-\mathrm{C}_{3} \mathrm{~N}_{4} / \mathrm{Fe}_{3} \mathrm{O}_{4} / \mathrm{MnWO}_{4}$ nanocomposites. (Permission taken from Elesvier, License Number: 4473530375943) [190]. 

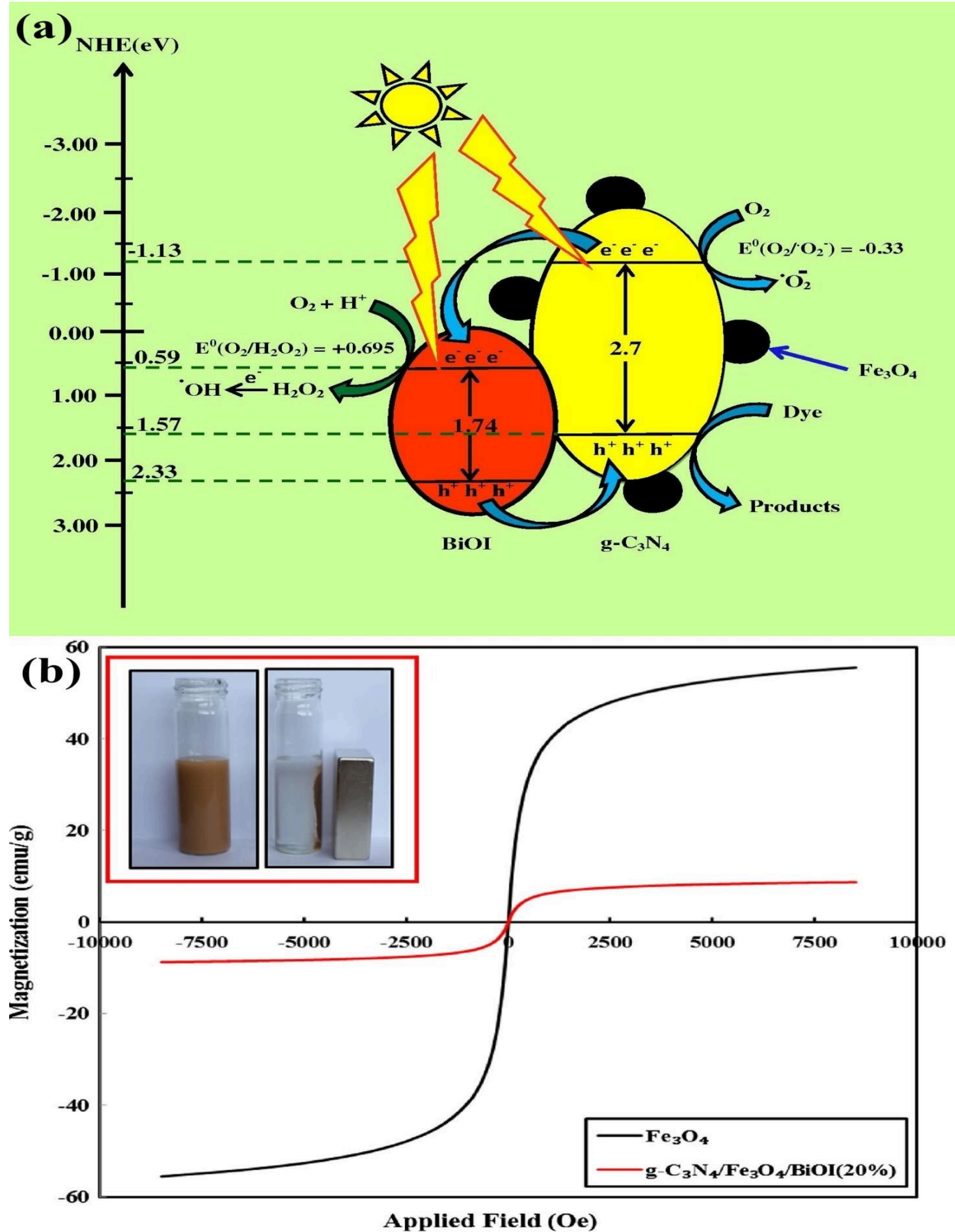
Fig. 18. (a) The possible degradation mechanism of $\mathrm{RhB}$ over the $\mathrm{g}_{-} \mathrm{C}_{3} \mathrm{~N}_{4} / \mathrm{Fe}_{3} \mathrm{O}_{4} / \mathrm{BiOI}$ nanocomposites. (b) Magnetization curves for the $\mathrm{Fe}_{3} \mathrm{O}_{4}$ nanoparticles and $\mathrm{g}_{-} \mathrm{C}_{3} \mathrm{~N}_{4} / \mathrm{Fe}_{3} \mathrm{O}_{4} / \mathrm{BiOI}$ (20\%) nanocomposite. Inset of the figure display the separation of nanocomposite from the treated solution using an external magnetic field. (Permission taken from Elesvier, License Number: 4473530902459) [192]. 

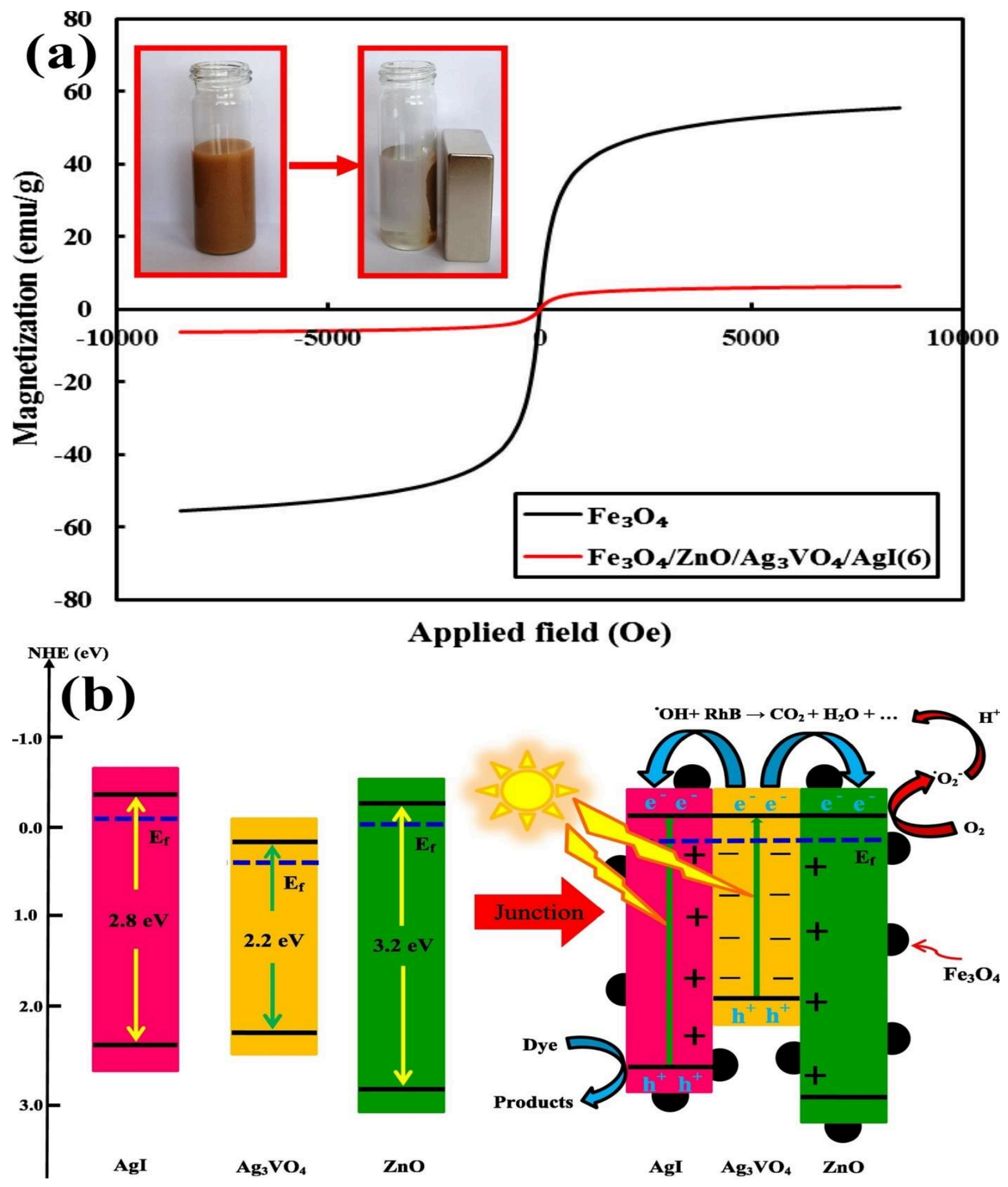

Fig. 19. (a) Magnetisation curve for the $\mathrm{Fe}_{3} \mathrm{O}_{4}$ nanoparticles and $\mathrm{Fe}_{3} \mathrm{O}_{4} / \mathrm{ZnO} / \mathrm{Ag}_{3} \mathrm{VO}_{4} / \mathrm{AgI}$ nanocomposite. Inset of the figure shows the separation processes by using a magnet. (b) Proposed 
mechanism of enhanced photocatalyst activity of the $\mathrm{Fe}_{3} \mathrm{O}_{4} / \mathrm{ZnO} / \mathrm{Ag}_{3} \mathrm{VO}_{4} / \mathrm{AgI}$ nanocomposites in degradation of RhB. (Permission taken from Elesvier, License Number: 4473540062295) [193]. 
2019-09-20

Systematic review on applicability of magnetic iron-oxides integrated photocatalysts for degradation of organic pollutants in water

\author{
Singh, Pardeep
}

Elsevier

Singh P. Sharma K, Hasija V, et al., (2019) Systematic review on applicability of magnetic iron-oxides integrated photocatalysts for degradation of organic pollutants in water. Materials Today Chemistry, Volume 14, December 2019, Article number 100186

https://doi.org/10.1016/j.mtchem.2019.08.005

Downloaded from Cranfield Library Services E-Repository 